\title{
Na Suklit: Benicio Sokkong and the Bamboo Musical Instruments of the Kalinga
}

\author{
By \\ Aaron Prior
}

A thesis submitted for the Victoria University of Wellington in fulfilment of the requirements for the degree of Master of Musicology

2011

New Zealand School of Music

Wellington

New Zealand 


\section{Table of Contents}

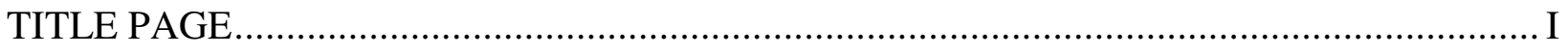

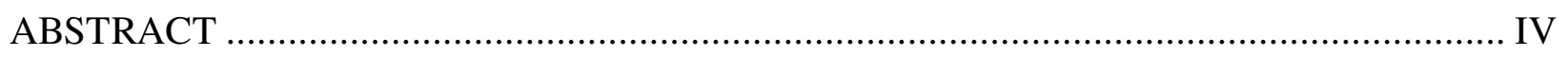

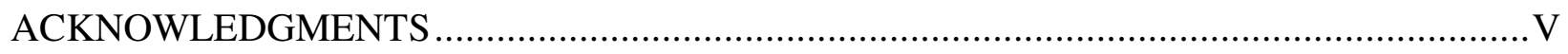

LIST OF FIGURES .............................................................................................. VII

LIST OF MUSICAL EXAMPLES ........................................................................ VIII

LIST OF TABLES .......................................................................................... VIII

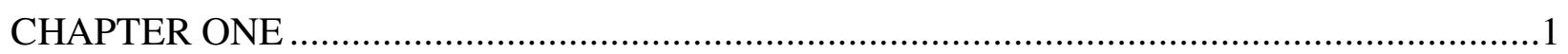

The Ethnographic Setting ....................................................................................

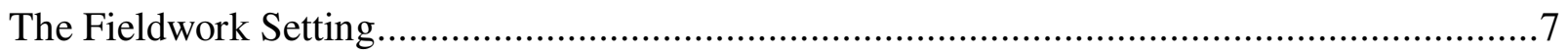

The Interpretive Setting................................................................................... 15

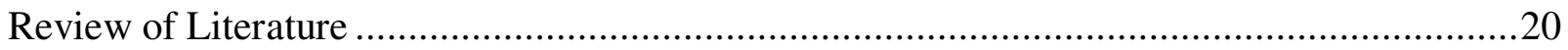

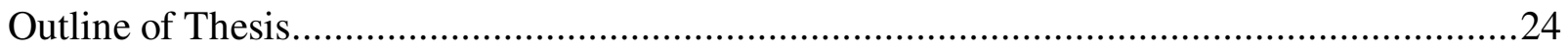

CHAPTER TWO: BENICIO SOKKONG AND HIS MUSICAL COMMUNITIES .................25

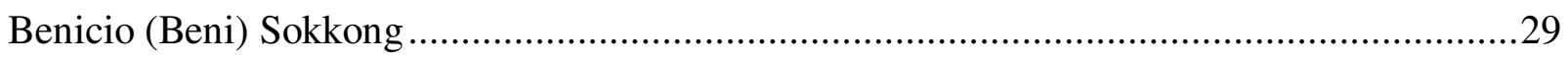

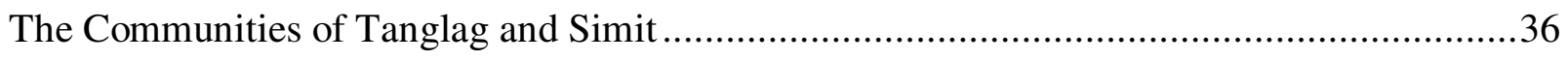

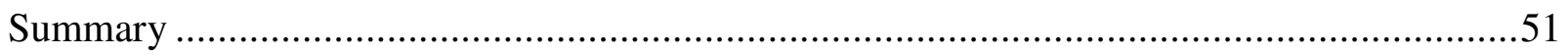

CHAPTER THREE: THE BAMBOO MUSICAL INSTRUMENTS ....................................54

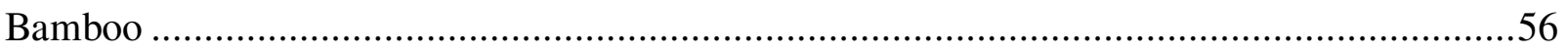

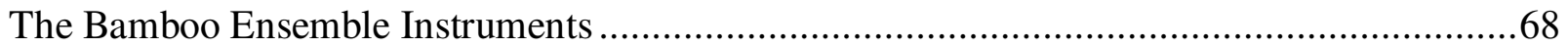

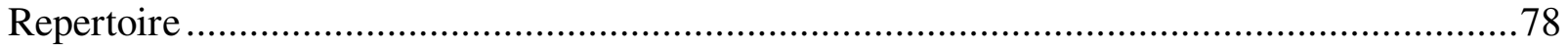

The Bamboo Solo Instruments ..........................................................................90

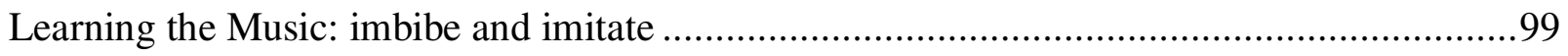

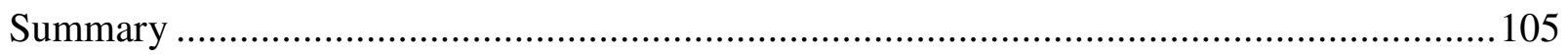

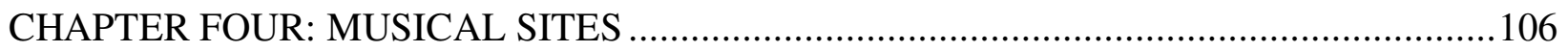

Musical Activities During Relaxation....................................................................... 108

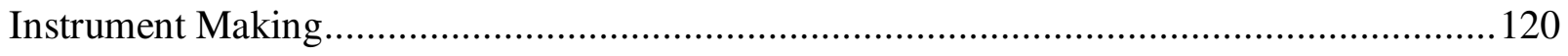

Lewliwa: an impromptu performance in Sukiap, Kalinga ............................................. 128 


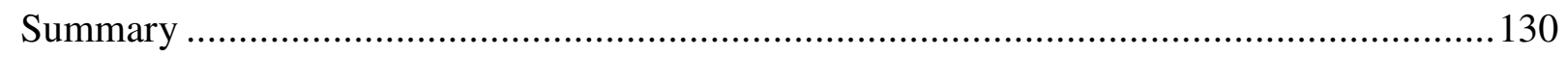

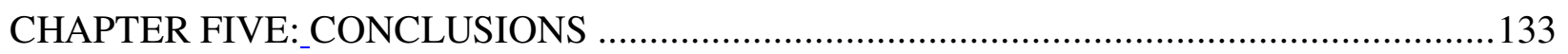

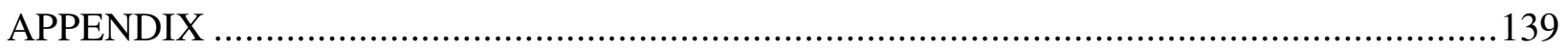

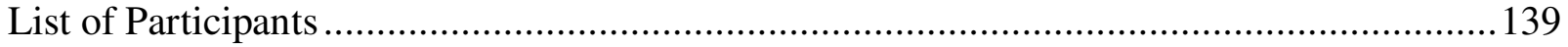

Compact Disc Contents .................................................................................... 140

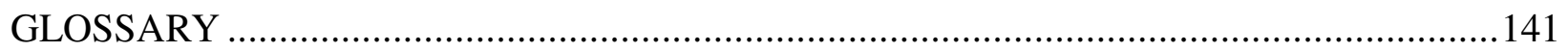

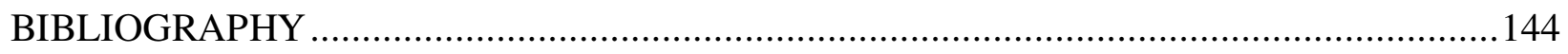

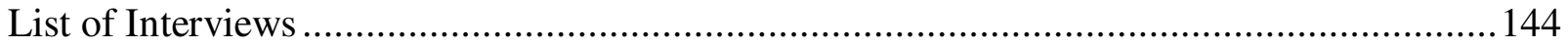

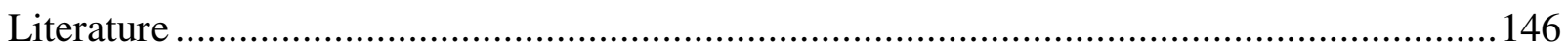




\begin{abstract}
This ethnomusicology study explores the contexts of the bamboo musical instruments of the Kalinga people of the Philippines in two distinct contemporary locations: the urban setting of Lucnab, Baguio City, and the rural setting of Sukiap, Kalinga. Through the study of the instruments, the music, and the individuals who participate in the music, I will examine the fluid and reflexive contextualisation of the music of the bamboo instruments, and how traditional musics undergo redefinition, reformation and a re-investing with new cultural significance. At the centre of this thesis lies an individual, Benicio Sokkong, a teacher, researcher, instrument maker and performer, who is key to the revival of the bamboo musical instruments not only in Kalinga but also internationally. The two communities focused on in this thesis have direct connections to Beni: the community of Lucnab, Baguio City, is his current home, and Sukiap village in Kalinga which is the birth place of his parents and his ancestral home. This study investigates the contexts of the bamboo instruments in these locations, and the effect of an individual reviving, recreating, and maintaining musical traditions.
\end{abstract}

I have employed a contemporary and eclectic approach in presenting the research in this dissertation, drawing on concepts of ethnic and self- identity (Rice 2007, Stokes 1994, Giddens 1991), revival (Livingston 1999), and the individual (Rice 1994, Stock 1996, Vander 1988). I argue that although the contexts of music shift from ritual and ceremony to secular gatherings, and also move geographically throughout local and national locations, the music remains an expression of community and communal identity. I also posit that the shape and form of the contexts are created by individuals who participate in the process of revival and maintenance. 


\section{Acknowledgments}

I would not have conceived, carried out or completed this study without the help of many individuals from both the Philippines and New Zealand to whom I am extremely grateful. Above all, I would like to thank Benicio Sokkong for not only providing me the opportunity to experience his music but also providing guidance in the research and sharing his knowledge. Without Beni's extraordinary passion for the music and culture of Kalinga and the Cordillera, the incredible sounds of the bamboo instruments would no longer be heard, and this thesis would have no subject.

I am extremely grateful to all the people of Sukiap, especially the family of Ermenio Donga-as (Gallming), my host, and Lorenzo Damagon (Bagtang) for his all his assistance. In Baguio, I would like thank the members of Simit, Ariel, Jayson, Rowell, Edward, Dexter and Shane, who were always ready to share their music, thoughts and good times with me.

Also, I would like to thank the members of Pasiking and the CMTRC whose musical expertise, translations, and enthusiasm for the subject contributed greatly to this thesis: Fidel Tayawa, Benedict Damagon, Delfin Sallidao, Manny Gayao and Arvin Villalon.

Thanks to Rosalinda Jacinto and family in Manila, and Humby, Jhoone, Xena, Yaira and BJ in Baguio; you always make me feel at home and part of the family when I am in the Philippines. In New Zealand, thanks to Constancia and Imelda Sokkong for your correspondence and friendship.

This thesis would not have been conceived if it were not for the inspiration and encouragement of Dr. Allan Thomas, whose enthusiasm and curiosity for all things musical was contagious, hugely inspiring, and life changing. I am also extremely grateful to Brian Diettrich for his 
support and guidance, helping to make sense an overwhelming collection of experiences from the field to create this thesis.

I would like to thank The Freemasons of New Zealand and Asia New Zealand Foundation who contributed financially to the research in the Philippines.

Lastly, I thank Emma for everything else: editing, counselling, support, patience, and ensuring I finished. 


\section{List of Figures}

Figure 1: View of Lucnab, Baguio City from Beni's home. (Photo by author, May 2010)...........4

Figure 2: The rice terraces of Sukiap, Kalinga. (Photo by author, May 2010) .........................6

Figure 3: Beni Sokkong in traditional dress playing the kolitong (tube zither), (Image Services,

Victoria University of Wellington, 1998) ...........................................................30

Figure 4: Fidel Tayawa with a collection of completed instruments. (Photo by author, July 2007)

Figure 5: The village of Sukiap nestled amongst the coconut palms and rice paddies (note the plume of bvulo (thin walled bamboo) in the lower centre right of the photo.) (Photo by

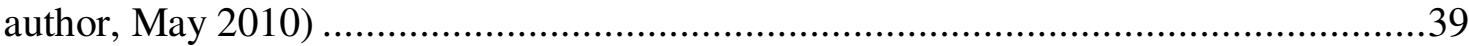

Figure 6: Simit playing gangsa: Ariel is dancing, leading Jayson, Edward, Dexter and Rowell playing the gangsa (flat gongs). (Photo by author, June 2007)...............................45

Figure 7: Bvulo culms (Photo by author, June 2007) .......................................................60

Figure 8: Stacks of bvulo cut to approximate length. (Photo by author, June 2007).................61

Figure 9: Feathery bvuyog culms, reaching up to eight metres in height. (Photo by Author, June

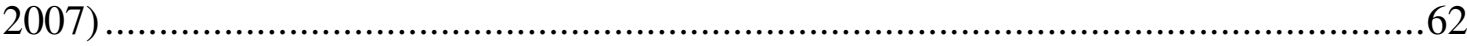

Figure 10: The base of the bvuyog where Beni has harvested culms for instruments. (Photo by

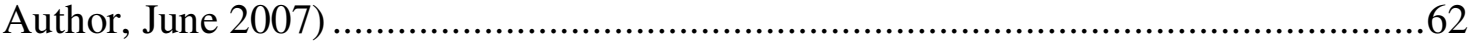

Figure 11: Gangsa (flat bronze gong). (Photo by author, July 2007) ..................................64

Figure 12: A gangsa ensemble performing Tuppayya. Beni is playing balbal of the second set.

(Photo by author, June 2007) ..................................................................67

Figure 13: Pattatag or gallupak (bamboo xylophone blades). (Photo by author, August 2011) ..70

Figure 14: Pattanggok (quill shaped bamboo percussion tube). (Photo by author, August 2011)71

Figure 15: A single ballingbing. (Photo by author, August 2011) ......................................72

Figure 16: Set of saggeypo (note Beni's labels - the letter B refers to the set). (Photo by author,

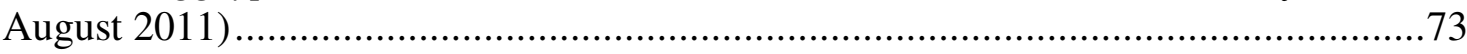

Figure 17: Tambi (two string zither). (Photo by author, August 2011) .................................74

Figure 18: Paldong (lip valley flute). (Photo by author, August 2011)...............................91

Figure 19: A tongali (bamboo nose flute) made by Fidel Tayawa (the weaved rattan rings are decorative). The back side is shown with the thumb hole visible. (Photo by author, August 2011).

Figure 20: Paldong hole spacing using finger widths as a guide. (Photo by author, August 2011)

Figure 21: Kolitong or kolibit (six string bamboo tube zither). (Photo by author, August 2011).96

Figure 22: Kulibaw outer face (left), and inner face showing construction (right). (Photo by author, August 2011).

Figure 23: Bagtang's decorated tongali. The picture represents the traditional function of the instrument, used to serenade a prospective wife from outside her house. (Photo by

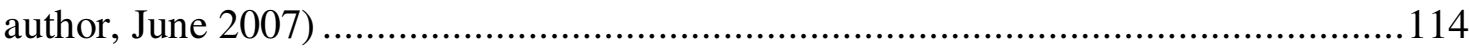

Figure 24: Ben (left) and Lumayog (right) playing a kolitong duet. (Photo by author, June 2007)

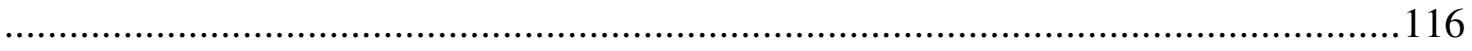

Figure 25: Children of Sukiap on Bagtang's veranda (Photo by author, June 2007) ...............118

Figure 26: Beni constructing ballingbing, while members of Simit sand bamboo tubes in preparation of instruments. (Photo by author, June 2007). 
Figure 27: Ben and the boys trying out the newly made tongatong. (Photo by author, June 2007)

Figure 28: The group trying out Ben's ballingbing. (Photo by author, June 2007)..... 126

\section{List of Musical Examples}

Musical Example 1: Transcription of Ginallupak (Alternation) ........................................8

Musical Example 2: Fundamental pattern of the Tuppayya and Pattang ...............................82

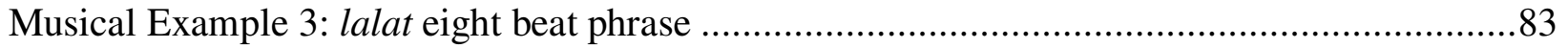

Musical Example 4: Transcription of Binutbut pattern......................................................8 83

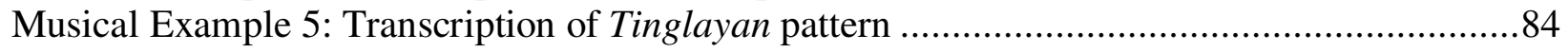

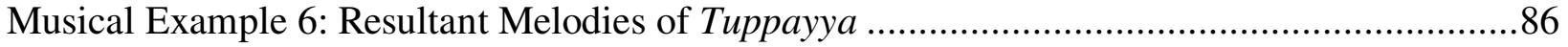

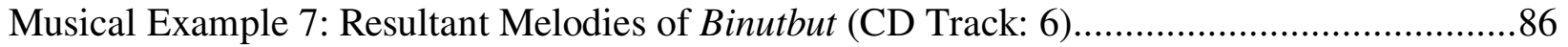

Musical Example 8: Resultant Melodies of Tinglayan (CD Track: 1) .................................86

Musical Example 9: Example of paldong tuning made by Beni (CD Track: 7)......................93

\section{List of Tables}

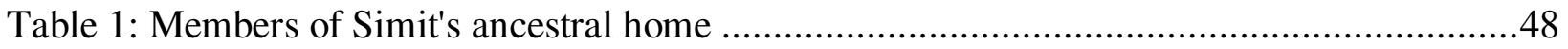

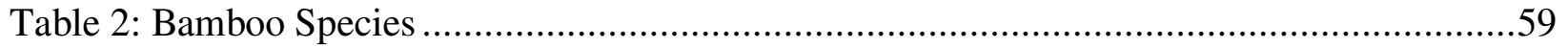

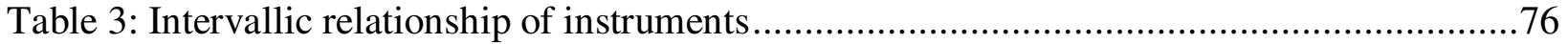

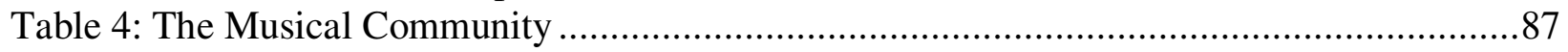




\section{CHAPTER ONE}

\section{The Ethnographic Setting}

\section{The Cordillera Region}

The fieldwork for this study was concentrated in two distinct geographical locations in the Cordillera Administrative Region of the Philippines: the barangay of Lucnab in the densely populated urban centre of Baguio City, and the isolated rural community of the Tanglag people in the village of Sukiap, Kalinga. Although the fieldwork included interviews, recordings and research from other locations, such as the Philippines capital Manila, and the municipalities of Sagada and Paracelis also in the Cordillera Administrative Region, the majority of the research material is from Lucnab and Sukiap.

The Cordillera Administrative Region covers the mountainous central northern region of Luzon, the largest island in the Philippines archipelago. The Cordillera Mountain Range runs northsouth; stretching from to the coastal province of Cagayan in the north to the Central Luzon plains to the south. The landscape of the Cordilleras is defined by the river valleys of the Chico and Pasil River and the steep ridges leading to mountain peaks of up to $2922 \mathrm{~m}$ (www.pinoymountaineer.com 2008). The Cordillera Administrative Region is divided into seven provinces derived from indigenous ethnolinguistic groups of the area. These are: Benguet, Mountain Province, Ifugao, Abra, Apayao, Kalinga and Baguio City (National Mapping and Resource Information Authority 1997). The provinces share similarities in music styles and instrumentation such as: the use of the gangsa (flat gongs), sung vocal epics such as the gasumbi 
and ullalim of the Kalinga (Prundente 1984; Benicio Sokkong, February 2007, correspondence), and the $h u^{\prime} d h u d$ of the Ifugao, and the use of bamboo musical instruments ${ }^{1}$ (Maceda 1998).

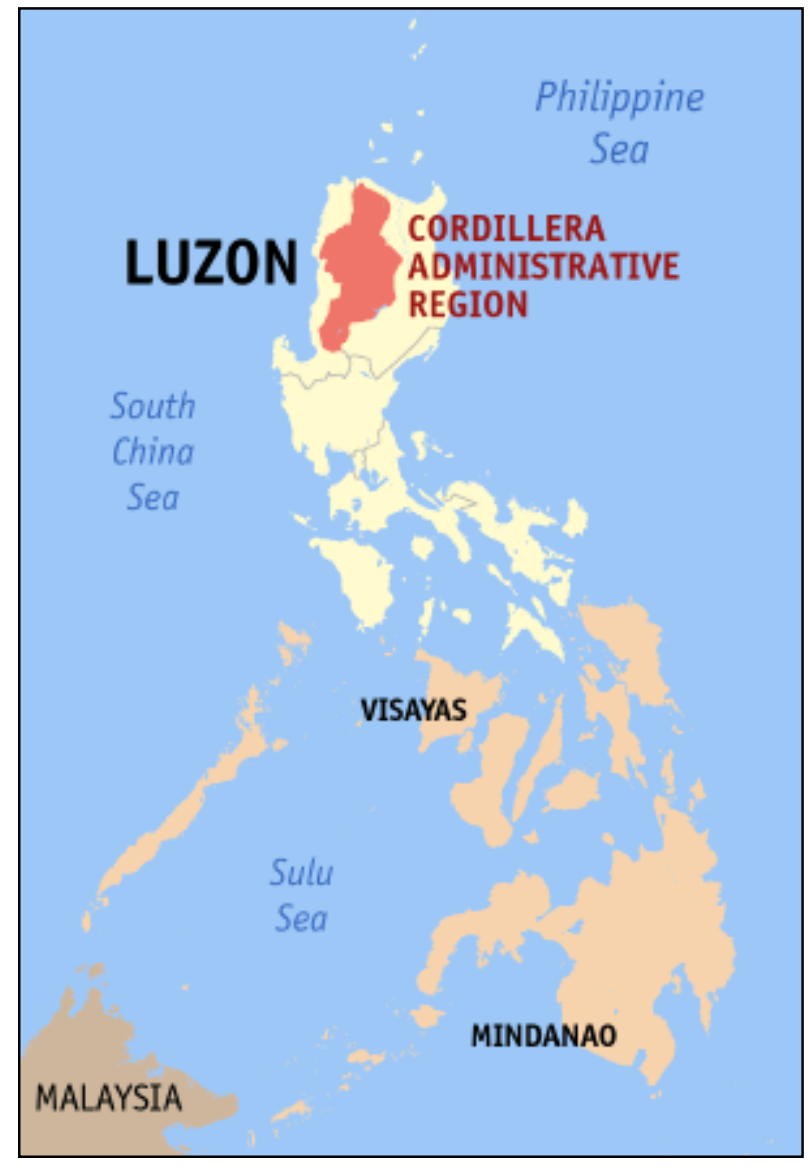

Map 1: Cordillera Administrative Region, the Philippines (Wikipedia.org 2003)

\footnotetext{
${ }^{1}$ See José Maceda's book Gongs and Bamboo: A panorama of Philippines Music Instruments for an excellent overview of the instruments of the Cordillera (1998).
} 


\section{The Barangay of Lucnab, Baguio City}

Baguio City is the political and financial capital of the Cordillera Administrative Region, and is located within the province of Benguet in the south of the mountain range. The city, founded by the American administration in 1903 as a retreat to escape the intense heat of Manila, sits upon an alpine plateau $1400 \mathrm{~m}$ above sea level and was originally the location of a village of the local indigenous group, Ibaloi (Karnow 1990:215, Russell 1989:255). The city was built as an American town; the first buildings being a country club complete with golf course and the military recreation facility Camp John Hay. Over the last 100 years, the city has attracted people from all over the Philippines, although predominately from throughout the Cordillera and the nearby lowlands of central Luzon (Russell 1989:251). Today, the city covers around 57 square kilometres with a population of 301,926 (gobaguio.com 2011, census.gov.ph 2007). Sixty-five percent of the population is under the age of thirty due to the significant number of tertiary institutions attracting students from throughout the Philippines (baguio.islandsphilippines.com 2010).

Contemporary Baguio City retains the feel of a hill station retreat. The city still appears lush with belts of pine forest throughout the city and many residential vegetable gardens. Narrow roads wind around the rugged terrain where hollow block houses cling to the side of steep inclines. Overlooking the city, one can see the giant SM Mall, the largest shopping mall in the region, dominating the skyline, and also the steeples of the numerous Catholic churches scattered around the city. 


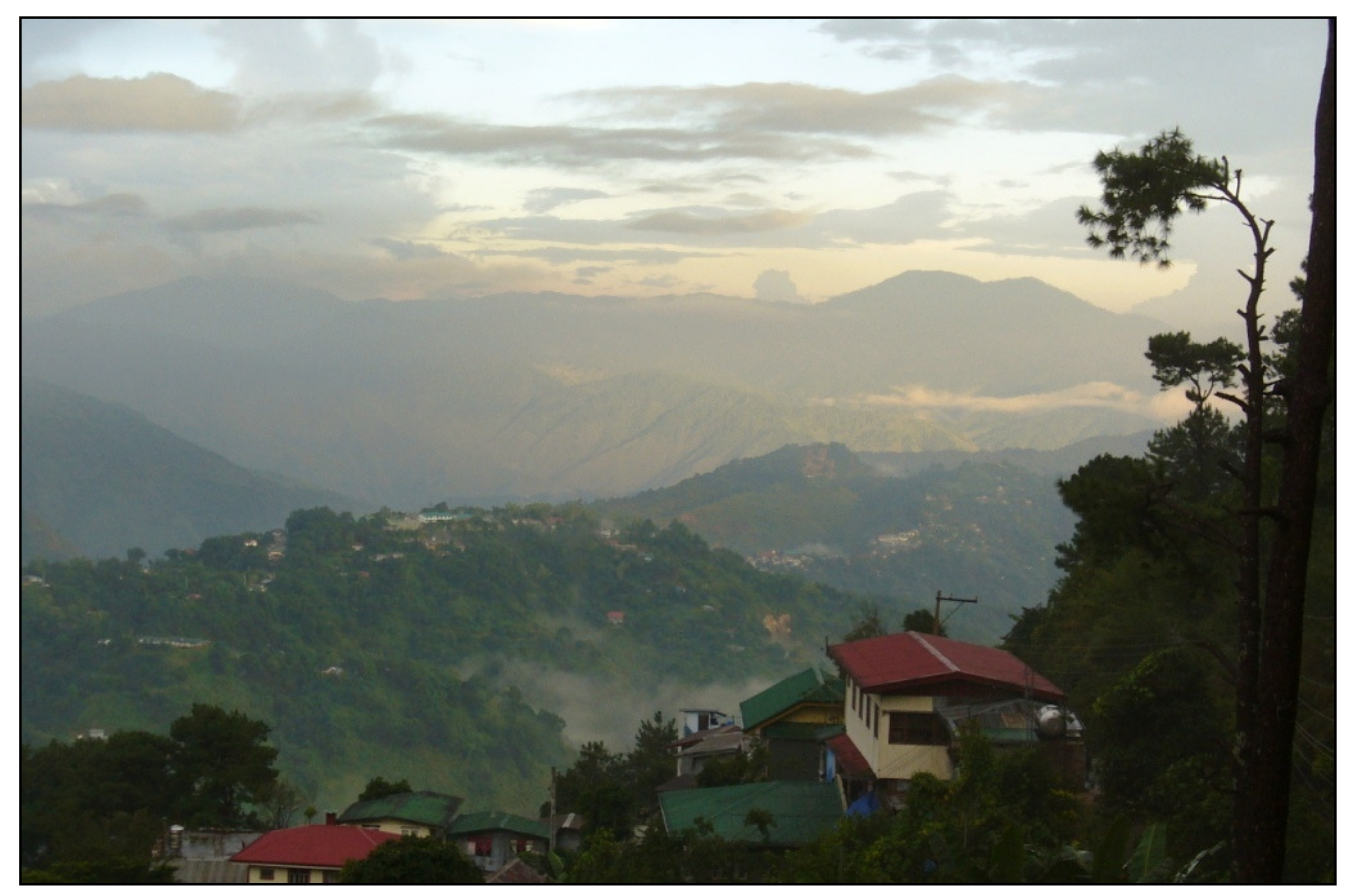

Figure 1: View of Lucnab, Baguio City from Beni's home. (Photo by author, May 2010)

The Baguio City fieldwork was centred in the barangay (village or suburb ${ }^{2}$ ) of Lucnab, positioned on the eastern edge of the plateau on which Baguio City is built. Lucnab covers an area of steep ridges and valleys. The Mary Hurst Seminary, the largest building in the barangay, and Beni's home, is located on a one-way road that descends from central Baguio City into the valley below. The barangay still maintains a semi-rural setting; bamboo groves, large pine trees and fertile gardens cover more land than the housing. In the cool mornings, thick clouds cling to the mountainous city, which is over $1500 \mathrm{~m}$ above sea level (www.gobaguio.com 2009). The population of Lucnab is approximately 1,349 (www.census.gov.ph 2007) and is comprised mostly of migrants from the provinces of the Cordillera Administrative Region, many of which

\footnotetext{
${ }^{2}$ The word barangay is the name given to a unit of administration in Philippine society (www.merriamwebster.com).
} 
have lived in Lucnab for over two generations, but still retain close ties to their ancestral homes, often returning for occasions such as weddings and fiestas.

Although the population of Baguio City contains a collection of ethno-linguistic groups, Ilocano is the predominant language (www.gobaguio.com 2009). The Ilocano language has been adopted by the people of Baguio City because of the high number immigrants from the low-land, Ilocos regions, and is now the first language of many residents, although most are also fluent in the language of their parents' home province.

\section{The Communities of Tanglag, Kalinga}

The village of Sukiap is located in the province of Kalinga, approximately 120km north of Baguio City. The name Tanglag denotes a community of approximately 681 residents of two villages: Sukiap and Liglig (www.census.gov.ph 2007). The two villages share common ancestry and remain closely linked through kinship ties. Sukiap and Liglig are located on opposite banks of the Chico River in the Municipality of Lubuagan, approximately $30 \mathrm{~km}$ from Tabuk, the capital of the Kalinga Province. The residents practice terraced, wet rice farming and swidden agriculture, using methods that have change little over the past few generations ${ }^{3}$. Through various government programmes and self initiated efforts, basic services are now available, such as running water, indoor plumbing and cell phone coverage. However, electricity and a road, connecting the village to the main Bontoc to Tabuk road, were still to be completed in 2007. The permanent population of Sukiap is predominately adults and young children under 12; the young adults spend the majority of the year living with relatives in the larger urban centres for high

\footnotetext{
${ }^{3}$ See: Barton (1949) Dozier (1967) and Sugguiyao (1990)
} 
school and tertiary education. The students return during the summer holidays when weddings and other festivals are held. Kalinga is the first language for all those born in Sukiap and Liglig, although Ilocano, Filipino (Tagalog), and English is taught within the school system (Benicio Sokkong, June 2007, correspondence).

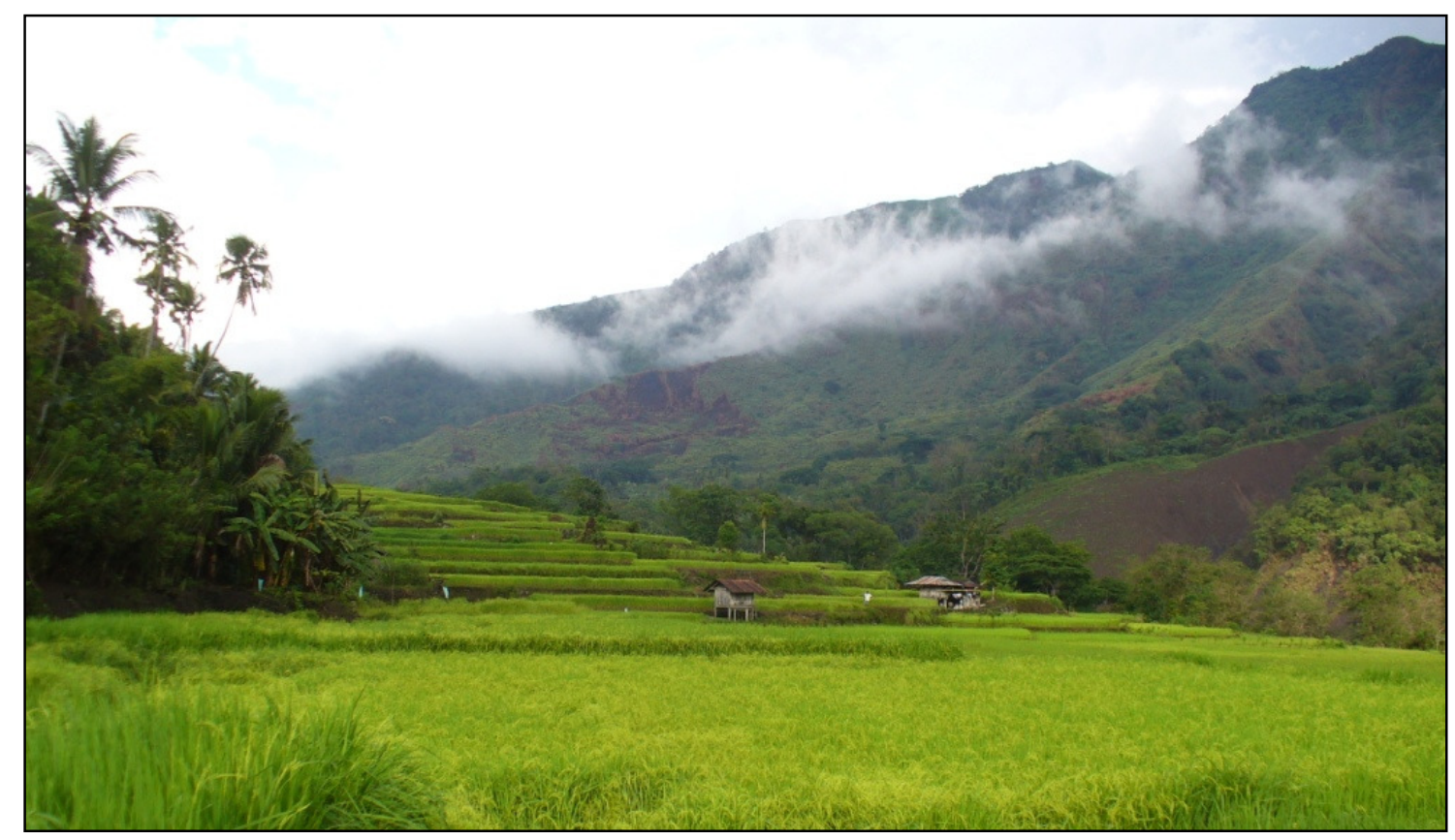

Figure 2: The rice terraces of Sukiap, Kalinga. (Photo by author, May 2010) 


\section{The Fieldwork Setting}

The fieldwork for the thesis was completed over a three year period, and included three visits to the Philippines and working with Beni Sokkong in Wellington, New Zealand. The initial research was carried out during Beni's visit to Wellington in 2007 for the Asia New Zealand Festival, which coincides with the Asian Composers League Conference. His participation in the festival involved performances, workshops, and a two month artist in residence position at Victoria University of Wellington Music School. During this period I was Beni's host, teaching assistant and tour guide. This enabled me to begin preliminary interviews about his music and life as a musician. It was throughout those months that I was to develop the beginning of a relationship which would extend beyond the research leading to this thesis, and to relationships with his family and friends, and further visits to the Philippines.

\section{In Wellington, New Zealand}

In 2001, Beni had also held an artist in residence position for three months at Victoria University Music School. At this time I was a student of composition and ethnomusicology in the last year of my undergraduate degree. Beni conducted workshops for classes of both subjects which included vocal and instrumental music, and dance. This provided me with two significant experiences which were the impetus for this thesis: (1) composing and playing music with Beni in an art music context, and (2) through the learning of a traditional wedding dance and music, awareness and insight into the function of the music in the traditional contexts.

I had the opportunity to investigate the music and music culture of the Kalinga further when Beni returned to Wellington for the Asian Composers Conference and Asia Pacific Festival in 
February 2007. The festival programme included a performance of Jonas Baes' composition Dulay I-V (2007), arranged for two performers playing traditional bamboo instruments and the audience. As I was already familiar with the instruments and the music, I joined Beni in the performance. Interestingly, my first performance playing the traditional bamboo musical instruments of the Kalinga was in a thoroughly contemporary context, playing a post-modern composition which explores ideas of cultural and social identity (Baes 2011).

Throughout the next two months Beni presented further workshops to both composition and ethnomusicology students. As Beni's teaching assistant, these workshops provided me with the opportunity to absorb a significant amount of introductory information on the instruments and music. Outside of the university environment Beni and I spent time talking about his experiences in music, both in formal interviews and in casual conversation.

This period of my research outside of the Philippines enabled me to observe Beni's methods of transferring knowledge to an audience vastly different than those I would later experience in the Philippines. For example, in the Philippines the music is primarily taught through imitation, whereas at Victoria University Beni used graphical representations and audible counting to teach the music of the bamboo instruments. Beni has developed means of explaining the materials of the music - the desired timbre and aesthetic - using methods and tools that are accessible and familiar to students within the post-modern university environment. 


\section{In the Philippines}

To continue my research I travelled to the Philippines in 2007, three months after Beni left New Zealand. During his stay in Wellington we had discussed possible fieldwork opportunities and locations where I could carry out further research. Using Beni's extensive connections with musicians and institutions, we outlined an itinerary for a two month stay. My first introduction to the Philippines was Manila where I was hosted by Beni's sister Linda and her family, allowing me the opportunity to talk at length about Kalinga, which they consider their place of origin, and the Kalinga music traditions. While in Manila I was also able to conduct archival research at the University of the Philippines Center for Ethnomusicology ${ }^{4}$.

The first significant period of field research was in the barangay of Lucnab, Baguio City, where Beni hosted me at his home. This was my base for the majority of my stay in the Philippines and where I met the many people that are part of Beni's musical communities, including the young performance group Simit, colleagues from the Cordillera Music Tutorial and Research Centre, and his extended family. As I spent time both as a researcher and as a visitor experiencing exceptional Filipino hospitality, the subject of the present study began to formulate and evolve. Perhaps because of age or outlook, I became close to the members of Simit, a group of six young male adults around the age of twenty, which Beni had brought together. What was extraordinary to me was their pride and passion for their cultural heritage, and the empowerment and solidarity they created through relearning the music of their ancestors.

\footnotetext{
44 The University of the Philippines Center for Ethnomusicology was founded by José Maceda in 1997.
} 
The other significant period of field research was spent in Sukiap, Kalinga, the birthplace of Beni's father, and where many members of his extended family live. This is also the where the bamboo musical instruments originate; where Beni grew up listening to the instruments, and where he learnt to make and play them - this is where his musical experience began.

\section{Methodology}

The three primary phases of research, with Beni in Wellington, in Baguio City, and in Kalinga, enabled me to practise the pre-prescribed methods of fieldwork (interviews, observation and participation), and also discover how I would learn to negotiate and navigate the complex environment of relationships and knowledge. As the fieldwork period progressed, my approach and the methods employed shifted organically to suit the situation of my position as a researcher, and this is reflected in the present study.

Participant observation was the primary method employed during the field research. This tried and true method has evolved dramatically since its conception in the early twentieth century by anthropologists such as Bronislaw Malinowski (1922). Two relatively recent developments in the practise of participant observation had a particular on influence on my research. Firstly, the trend toward reflexive ethnography, beginning with the writing of John Miller Chernoff in 1979, and including Michael Jackson $(1982,1995)$ and Timothy Rice (1994); and secondly, the acknowledgment of the identities we construct in the field and the role we play as researches (Kisliuk 1998). These two aspects of contemporary ethnomusicology are intimately linked; a reflection on experience leads to questioning the role within that experience. Within the larger umbrella term of participant observation are a number of methods which all feed into the 
experience of being a participating observer, such as the development of relationships. These are all ways we realise our dual function in the field: collecting information and being and becoming a member of a community.

My participation as a player of the bamboo instruments was integral to my research. During the first phase of the fieldwork in Wellington, I used my skills as a player of the bamboo instruments in a contemporary art music performance. This experience of playing the instruments was vastly different from the experience I would have in the Philippines. In Wellington I performed on a stage in an organised concert event with a sit-down audience, and played a well rehearsed contemporary composition containing complex political and social reference. In the Philippines I would play within a close community of players with no audience apart from the players, and the music played would have connections to nostalgia, solidarity and joy. Playing a part on a bamboo instrument within an ensemble is absolutely key to the understanding the music and how the music captures the spirit of the community.

The participation in the construction of the bamboo musical instruments was another musical activity which is highly relevant to both the community and the music itself. As I discuss later in this thesis, the construction of the instruments is an integral part of the music making process, and reflects many aspects of the actual music and the community. Instrument making also forms an important part of Beni's role within the revival and transmission of the traditions of the bamboo musical instruments, and is key to this thesis.

Beni was the primary source of information for this thesis, gathered through both formal and informal interviews. During the initial investigations in Wellington in February 2007, I conducted interviews with Beni with pre-prepared questions. These interviews covered much of 
the introductory information and, in many cases, led to more questions. As my relationship with Beni developed and began to gain an independence from the research, the interviews took on a less formal shape and, more often than not, grew out of casual conversation. Both formal and informal interviews were also conducted in the Philippines with the musical communities which form the subject of this thesis.

In the tradition of Anthony Seeger (1989), I sought to capture specific performance events experienced in the field. Investigating a specific event which not only includes the actual musical performance but the organisation beforehand and the reactions afterward, can lead to a greater understanding of the contexts of that music and the construction of identity and place (Stallsmith 2007, Wallach 2008). Influenced by Jeremy Wallach's recent study of popular music in Indonesia (2007), I also focused on particular locations where people would gather regularly with musical activities, and collected video and audio recordings while in the field.

The practical convenience of digital video recording is almost mandatory in today's fieldwork environment, and can not only provide an unparalleled means of empirically capturing what is happening but also isolate a researcher to a restricted view from only behind the lens. The video footage was, however, integral during the process of interpreting the performance events, enabling repetitive viewing and therefore reflection, and, together with field notes, providing multiple angles from which the event can be analyzed.

My initial entry point into the music of the Kalinga and bamboo instruments was through sound - with the ears of a composer. It is this music and these sounds that drew me to the individuals and the communities which I eventually became intimately involved in. The process of my transition from a composer treating the music as sound object, to an ethnomusicologist 
concerned with the human impetus of the sounds, underlies this thesis. Audio recordings that accompany this thesis attempt to not only capture the musical performances, but also the social and sonic environment in which the performances happened. The sounds of the cicadas, pompous charged fighting cocks, and the complex musical sounds of bamboo produced in Beni's instrument workshop provided a sonic backdrop to my research. Inspired by Steven Feld's concept of acoustemology: ‘...one's sonic way of knowing and being in the world' (2004), the recordings seek to provide insight into the sound world of the bamboo musical instruments of the Kalinga.

\section{Reflections of Participant Observation}

As researchers in the field we are confronted by a number of challenges which can be academic, financial, linguistic, and logistic. Although fieldwork involves a number of methods to acquire information, the fundamental means, I believe, are through the relationships we develop and maintain. Without these relationships, which exist because of the identity we create and project in the field, the information gathered would reveal little more than photographs and recording. Howver, these relationships could be said to be artificial - the environment is consciously constructed, and the researcher has specific motivation for creating the relationship (Kisliuk, $2008: 185)^{5}$

It was these issues which I found most challenging, not only while in the field, but in reviewing notes and video material, reflecting on the larger experience of ethnographic research, and the

\footnotetext{
${ }^{5}$ This is not to say that other relationships in our lives are not created consciously, but are formed with a mutual understanding.
} 
process of writing this dissertation itself. As my relationship with Beni grew and I began to learn more about not only his music and traditions but also his personal history and ideas, my approach to my research evolved.

Although I had developed a friendship with Beni outside of my research, how was I viewed by his peers and family? Was I Beni's apprentice or simply an outsider conducting academic research? In the Philippines, I found that I would introduce myself as a student of Beni's, learning about the traditional music of the Kalinga. This provided a suitable explanation for my presence and also placed Beni in the key role as my principle informant/ teacher/ subject, which I was comfortable with and thought appropriate. This concept was tangible to other participants as it is well known throughout the communities that Beni has travelled extensively teaching and performing Kalinga music.

I was, however, introduced to a number of people while in the field as an academic researcher; a term which carries connotations of social status, wealth and education, and privilege, and in many situations, I did not want these pre-conceptions to bias the relationship I was aiming to create. I found the title of 'music researcher' to be distancing in many situations, isolating me from a more direct, relaxed involvement in the community activities. I hoped, as a participant observer, to blend into the communities, to change my role from a researcher to member of the community and absorb knowledge, or as Beni would say, imbibe, through natural processes ${ }^{6}$.

${ }^{6}$ As a participating observer I drew not only on my training as an ethnomusicologist and a musician, but on my ability to become an active member of a community. I found that the position of a participating observer can be overwhelmingly self-conscious and I had to let my character, my person, run its course, and let the relationships create themselves. In retrospect, the challenge of accepting this position, or transposition, is the experience we long for in the field. The actual progression from academic outsider to an active participator in the community reveals much about music and its people. 


\section{The Interpretive Setting}

This study investigates three aspects of the bamboo musical instruments of the Kalinga: (1) the musical experiences and influence of Benicio Sokkong (Beni), (2) the musical experiences of two contrasting musical communities directly connected to Beni, one in the urban centre of Baguio, and the other in the rural location of Sukiap, Kalinga, and (3) the musical instruments themselves, their physical, ecological and musical attributes. I build on current approaches in ethnomusicology, which I believe are successful and appropriate to the subject and research gathered. Through investigating these aspects and the connections between them, I aim to provide a picture of a music tradition in the processes of revival and re-contextualisation.

\section{The Individual}

Recent ethnomusicology studies have shown that focusing on an individual can reveal how music is experienced and what shapes that experience (Rice 1994, Stock 1996, Vander 1988). In the book May it Fill Your Soul, author Timothy Rice placed two individuals at the centre of his study of Bulgarian music, and showed how these musicians 'act musically' to create socially meaningful experiences, and how music is historically constructed and maintained. Jonathan Stock also employs this approach in his study of the Chinese musician, Blind Abing, and explores how social and historical context structure individual musical experience. Following these approaches, the present study focuses on an individual musician, teacher, researcher, and instrument maker, Benicio Sokkong (Beni). Beni's multifaceted role in Kalinga music, and his connections to rural Kalinga communities, urban youth music groups, and academic institutions, provide a unique example of how an individual experiences music, and can shape how others 
experience music. I include biographical information to place Beni’s actions within historical and social context in an effort to understand and show how Beni came to be an agent of his traditions.

\section{Rural and Urban Musical Communities}

In the 1970 s and 1980s the subjects of ethnomusicology were often located in isolated rural communities, where music traditions are practiced and maintained, dislocated from modern technology, media and politics (Zemp 1978, Seeger 1989, Feld 1990). More recently, studies have investigated the inexhaustible array of traditional and contemporary urban genres, such as jazz, rap, and popular musics (Berliner 1994, Keyes 1996, Turino 2000, Wallach 2007). These latter studies explore the effect of migration, mass production and globalization on music (Turino 1993, Appadurai 1996). In this thesis, I consider that music no longer exists exclusively in single geographical and contextual locations, but is socially and spatially mobile, fluid and reflexive due to contemporary factors such as migration and technology.

The music of the Kalinga provides an excellent example of this mobility as the music has not only spread to the nearby urban centres of Baguio City and Manila, but also to San Francisco, U.S.A. and Auckland, New Zealand ${ }^{7}$. Each music group in these different locations performs the music from the same tradition, and articulates their ethnic identity and solidarity through performance (Stokes 1996). The historical identity of the instruments is formed in the rural villages, and imbedded in indigenous rituals and ceremonies, and today, in urban locations Kalinga music is practised in new contexts such as in Catholic Mass, city festivals and school competitions, and is no longer played exclusively by Kalinga. This present study seeks to

\footnotetext{
${ }^{7}$ Beni's sister Connie is an active performer of traditional Kalinga music and dance in Auckland, New Zealand.
} 
investigate how the revival process and the maintenance of a music tradition, manifest and are experienced in both the rural and urban environment in grassroots communities.

I use the term 'grassroots communities' to describe the local communities that exist both in villages and suburbs found today in Baguio and Kalinga today. Aside from Beni, the members are not professional or specialist musicians, but music is an integral part of community life. The two features of these groups key to my approach, are the ancestral ownership of the music traditions, and their independence from national and global influences such as Universities.

\section{Revivals and tradition}

Although the instrument traditions were never completely abandoned, they are now being recontextualized in a variety of genres (Baes 2008). This revival has been developing for at least thirty years and began in the institution of University of the Philippines, endorsed by academics such as José Maceda through ethnomusicology and composition (ibid 2008). Today, through the agency of individuals such as Beni, the revival is shifting the practise of the instruments from academic institutions in the Philippines to the grassroots communities (Livingston 1999:69), and can be viewed as a political act, where the instrument traditions are made accessible to all and not restricted to a privileged few (Stokes 1994).

Participants in the revival process carry different concepts of tradition and authenticity (Copland 1993, McDonald 1996). In Kalinga and the Cordillera, the indigenous music traditions are thought of as immutable, and are connected with concepts of cultural heritage and ethnic identity. When traditional music is performed 'authentically' it articulates a link to a historical, rural past (Copland 1993:40). However, in practise, and as explored in the following chapters, 
the music traditions are dynamic and are constantly shifting organically in reaction to social and historical change.

In this thesis, I use the words music traditions to refer to the music as played today, but I do not include the use of the instruments in world music, popular music, and art music in this category. In contrast, I use the word traditional as conceptualised by the Kalinga, where traditional is thought of as original and authentic - played as it was 'before' (Benicio Sokkong, February 2007, correspondence). This use of the word traditional extends to other aspects of the music, such as the social contexts, functions and uses, the learning process, and instrument manufacture. All of these aspects are changing as the music traditions react to contemporary life.

\section{The Instruments}

This study also places emphasis on the musical instruments themselves as cultural and material objects (Baes, 2008). The revival of the music of the bamboo instruments includes a rediscovery of the knowledge of instrument construction: materials, art and craft, and a concept, whether it is traditional or contemporary, of the mechanics of the production of musical sound. Unlike revivals which involve instruments that are present in other contexts and cultures (Livingstone 1999), many of the bamboo instruments are unique to the Cordillera. The knowledge of material selection and construction is embedded in the larger musical experience, which include dance and performance ${ }^{8}$.

Recent ethnomusicology studies have shown that through the investigation of the ecological and spiritual connections of the materials and manufacture of the instruments, an understanding of

${ }^{8}$ See Richard Nunns and Allan Thomas' article 'The Search for the Sound of the Putorino: "Me te wai e utuutu ana" (2005) for an interesting investigation of an instrument and its historical and spiritual connections. 
the meaning of music can be found (Mora 1987, Yoshida and Toyoda 1998, Nunns and Thomas 2005). The research presented in this thesis reveals a number of interesting connections between the bamboo, music, and the spirit world of the Kalinga, and invites further investigation in to these areas. 


\section{Review of Literature}

\section{Music of the Philippines}

Philippine academics have contributed substantially to the study of the traditional music of their nation. Universities established during the American colonial period (1898-1946) created a strong academic environment. Research was, and continues to be, published in English, therefore connecting to the international academic community (Meyers 1993). José Maceda, Filipino composer, performer and pioneer of ethnomusicology in South East Asia, provided an environment which stimulated other Filipino researchers. Maceda's research began in the Muslim south with his dissertation on the instrumental and vocal music of Maguindanao (1971), and continued to focus on the traditional music or non-western music of the Philippines, covering virtually the entire archipelago, as well as other East and south east Asian nations $(1995,2001)$. Along with the extensive documentation of the traditional musics of the Philippines, Maceda called for further research and a developing and 'diffusion' of the traditions (1971: 79). Following late twentieth century practices in ethnomusicology, Maceda produced wide surveys, empirically measuring the physical dimensions and pitch and scales of instruments, then correlating the information in search of commonality (1990). A life time of his research material, in the form of audio and video recordings, photographs, field notes and instrument collections, form the archive at the University of the Philippines Center for Ethnomusicology in Manila. The product of this research is presented in Maceda's book Gongs and Bamboo: A Panorama of Philippines Musical Instruments (1998) where the variety of instruments are briefly described alongside photographs and drawing. Though containing a minimal amount of text, Maceda succeeds in defining the different ethnic groups of the 
Philippines and the uses and function of musical instruments. Although undoubtedly the most comprehensive single source available on the musical instruments of the Philippines, due to the scope of the book, it does lack information on the deeper function of the music within society. The research is also treated and presented in a historically static framework and without the larger political, social or individual contexts to the musical instruments.

Other researchers have investigated the wide range of traditional music of the Philippines, the majority also focusing on the Muslim south (Trimillos 1972, Cadar 1974, Otto 1985). More recent studies include Manolete Mora's interesting investigation of the connections between musical knowledge and spirituality and the natural and social world of the T'boli $(1987,2011)$.

Few resources exist on the popular music of the Philippines even though the quantity and variety is substantial: country, rock ballads, OPM (Original Pilipino Music), and hip-hop, to name but a few (Santos and Cabalza 1998). Music played an important role in the EDSA People Power movement which overthrew the Marcos dictatorship in 1986 and is discussed in a new book by Christi-Anne Castro Musical Renderings of the Philippine Nation (2011). Recent work by Yoneno Reyes investigating the popular Cordilleran song, Salidummay, discusses aspects of ethnic traditions and modernity (2010). Both of these studies suggest the value in further research into the relationship of politics and music in the Philippines.

\section{Early Descriptions and Anthropology}

A number of anthropological studies of the Kalinga have been produced by western researchers, initially by European missionaries and later by American academics. The earliest historical descriptions of the Kalinga are from the Spanish missionaries who ventured in the Cordillera Mountains in the sixteenth century and made cultural observations (Scott 1974, Keesing 1962). 
Due to geographical isolation, the Kalinga maintained much of their own culture and customs during the Spanish and American colonial periods. This, together with the history of tribal violence involving headhunting, and the peace pact (bodong) arrangements between tribes, has provided interesting and attractive subjects for researchers.

The first modern anthropological literature on the Kalinga was produced by Francisco Billiet, a Belgium missionary during the first half of twentieth century $(1930,1934,1935)$. The American anthropologist R. F. Barton focused specifically on the Kalinga with his book, The Kalinga: their Institution and Custom Law (1949), which addresses the peace pact, an institution unique in the Philippines. Dozier continued this line of inquiry with his ethnography The Kalinga of Northern Luzon, Philippines (1967), while Jules DeRaedt (1989, 1993) produced further research focusing on ceremonial aspects of Kalinga life and the symbolic nature of the acts involved in the rituals. A relatively recent and unique book describing many aspects of the Kalinga culture is The Kalinga Hilltribe of the Philippines by Miguel Sugguiyao (1990). Unlike the other anthropological studies mentioned, Sugguiyao is Kalinga, he writes extensively on his culture's beliefs and customs, and suggests that the Kalinga have been misrepresented in previous studies by outside researchers.

\section{Music of the Kalinga}

Although the music of the Kalinga features within a number of books and articles whose subjects covers the music of the entire Philippines archipelago (Corazon 2008, Maceda 1998), there are few detailed studies focused solely on the Kalinga music. The sung epics of the Kalinga (ullalim) formed the subject of the research by the Belgium missionary Francisco Billiet (1970) and the Filipina, Felicidad Prudente (1984). The flat gong ensembles (gangsa) also appear in a number of studies (Benitez 1983, Maceda 1994, Stallsmith 2007). Maceda's Gongs and Bamboo is by far 
the most significant work on the bamboo musical instruments of the Kalinga and includes classification, manufacture and taxonomy of the instruments, although the instruments also feature in a number of articles, videos and dissertations (Such 2000, Stallsmith 2007, Corazon 2008). Unlike many other bamboo musical instrument traditions throughout Asia (Zemp 1978, 1981; Yoshida and Toyoda 1998) there has yet to be an in-depth study solely focused on the Kalinga. The present study builds on existing research by providing a detailed ethnography of the instruments as they exist today, and includes the investigation of materials and construction, and places this information into the larger cultural contexts.

\section{Benicio Sokkong}

Benicio Sokkong, the central figure and primary resource in this thesis, has also appeared as a subject in recent academic articles. Using Beni as an example, Baes investigates the unique position of indigenous performers and how they negotiate the contemporary environment of cultural production and consumption (2004). Beni's participation in the Smithsonian Folkway Festival in Washington DC in 1998 features in a recent article by Ricardo Trimillos where issues of power within both the festival organizers and participants, and the Philippine-American historical relationship are discussed (2008).

These two academic articles indicate the importance of Beni within the multilayered landscape of Filipino music and culture, and also highlight the significance and power of specific individuals. This study recognises Beni as a key individual, facilitating musical processes around him in both a grassroots and an academic environment. 


\section{Outline of Thesis}

The structure of this thesis isolates three aspects of the contemporary context of the bamboo musical instruments of the Kalinga: the individuals and their communities, the music and the musical instruments, and the contexts of musical activities within these communities.

Chapter two introduces Benicio Sokkong and the two musical communities which form the main subjects of this thesis: the people of Tanglag from the rural villages of Sukiap and Liglilg, and the performance group Simit located in urban Baguio City. Through biographic information sourced from my interviews, I provide context to these communities who play the bamboo instruments today.

Chapter three describes and discusses the array of bamboo musical instruments and the musical processes that surround them. In an attempt to extend Maceda's documentation and classification of the instruments, I have re-presented the instruments as Beni presented them to me, and as I experienced in the communities discussed in chapter two. This chapter also includes information on the processes involved with instrument construction, the changing and developing repertoire, and musical learning.

In Chapter four I explore the context of the bamboo musical instruments within the two musical communities, Simit and Tanglag, by describing and discussing specific musical sites and events.

Finally, in the conclusion I brings together the main themes of the thesis: the influence of an individual on a reviving music, and the fluid contextualisation of a music tradition. 


\section{CHAPTER TWO}

\section{Benicio Sokkong and his Musical Communities}

It was on the veranda of a bamboo house, sitting with a group of Kalinga men, that I first heard the gentle sound of the bamboo flute, the paldong, in its ancestral home. The soft, woody notes drifted and diffused into the sounds of the nocturnal tropical mountains: the constant hush of the Chico River a few rice paddies away, the intense chirping of the night-calling cicadas, and the men quietly and occasionally commenting on the skill of the player. The weathered faces of the men appeared gaunt in the flickering light of the kerosene lamp placed in the centre of the veranda, alongside a jug of sugar cane wine, a cup, and drinking water in a disused detergent bottle.

It was July of 2007 and I had arrived with Beni, now my guide and teacher, at his ancestral family home in the remote village of Sukiap. It had been a two day journey from Manila involving freezing hi-tech air-conditioned buses, 1950's jeepneys skilfully driven on narrow mountain roads, and an exhausting walk down steep, rugged mountain tracks. Beni's family had gathered to welcome us to the village. Although it had been five years since his last visit, the reunions were spoken gently and no fuss was made. I could sense the significance of Beni's status in the mannerisms of the group; Beni was the holder of a bodong for the village, a peace pact assigned to an individual to prevent tribal war with its neighbours (Barton 1949, Dozier 1947, Sugguiyao 1990). Unlike the short hair and ropey, muscular build of the other men, Beni's physical presences also stood him apart; his long salt and pepper grey hair reaching to his waist and oriental goatee indicating a worldly awareness while maintaining local knowledge and authority. 
I first met Benicio Sokkong as an undergraduate student of composition and ethnomusicology in New Zealand in 2001 at Victoria University of Wellington where Beni held the position of artist in residence presenting workshops for both disciplines. At the time, it was the music of the bamboo that commanded my attention, specifically the sonic aesthetic properties of the bamboo instruments. These were sounds I had never heard before from instruments I had never seen: three foot bamboo tubes bounced on the ground to create gentle, resonant booms and split fork shaped tubes producing harmonic rich buzzing. The bamboo mouth flute, the paldong, constructed simply from a length of bamboo with 4 finger holes, made a particular impression on me: the musical depth of this small sound and the variation in colour and dynamic that could be drawn out of it by Beni's skilful playing. As a composition student, the challenge before me was to capture the essence of this precious music and re-contextualize it into a contemporary composition.

As I spent time with Beni during one-on-one workshops and rehearsals for both contemporary compositions and Kalinga music and dance, and also during his second visit in February 2007, I came to realize that it was not only the sounds and the instruments that were fascinating, but also Beni himself.

Without Beni as a multifaceted specialist - a performance musician, master instrument maker, teacher and researcher - the music of these instruments would not have reached my ears, nor many others. It became apparent to me that Beni plays an integral role in the survival and revival, and the national and international dissemination of this music. How did Beni come to be an exponent of his own culture? How did he learn the music and how to make the instruments? Was this music alive in the Philippines? What was his role within the Philippines and his own community? During my fieldwork with Beni, through formal recorded interviews and informal 
personal conversations both in New Zealand and the Philippines, I began to learn more about his musical life and his role as an agent of his cultural traditions.

Due to differing life experience, music carries different meanings and individuals experience music in unique ways. Biographical information provides insight into these different meanings and gives context to the place of music within a subject's life (Rice 1994, Stock 1996). Describing the musical life of an individual and focusing on a particular musical perspective, reveals underlying connections and meaning embedded in music (Stock 1996:162). Beni's role in the revival of music of the Kalinga, and specifically the way he has bought the music into new contexts, while at the same time keeping it relevant within the original communities, presents a case study: an example of what can be achieved through a multi faceted, multi-layered recontextualization of traditions. It is not strictly the music that is modified or modernized, nor the instruments, but a re-establishing of the practice of the music in environments and situations that are relevant today. The current practise of the bamboo instruments of the Kalinga features many identifiers of the process of revival ${ }^{9}$. Of these, the most relevant to this study is the significance of the individual within this process; Beni is that individual and he has created a community of revivalist around him.

It is also interesting to consider that in the past, the musical activities such as instrument making, teaching and performing, were not restricted to specialist allowing anyone to participate (Benicio Sokkong, July 2007, correspondence). Due to hegemony and technology throughout the last century, some of the musical traditions of the Kalinga lost relevance and the practice declined. Individuals have transferred the traditions in the current revival. The practice of the musical

\footnotetext{
${ }^{9}$ Tamara E. Livingstone (1999: 69) defines these as: ‘(1) an individual or small group of "core revivalists", (2) revival informants and/or original sources (e.g. historical sound recordings), (3) a revivalist ideology and discourse, (4) a group of followers which form the basis of a revivalist community, (5) revivalist activities (organizations, festivals competitions), (6) non-profit and/or commercial enterprises catering to the revivalist market.'
} 
traditions - the manufacture of instruments, repertoire, knowledge of uses and functions - has become focused on one individual, Beni, who is a single point of transmission. From this single point of transmission, the knowledge is being passed back to the community where the traditions are re-contextualized and are now, once again, practiced.

This process of revival highlights two important elements in Beni's approach to his cultural heritage and specifically the musical traditions: (1) in the idea of a living tradition where the music is not a historical artefact but is performed regularly and openly in a number of contexts, and (2) a grassroots revival where the music traditions and knowledge is not located only in academia or to a restricted to a few, but accessible to those who have a connection to the heritage $\mathrm{e}^{10}$. These two elements are essentially unified in aim: Beni works to revive the musical traditions in new and relevant contexts, thus creating living traditions within grassroots communities who have an ancestral connection to the music traditions.

In the description that follows I have used the information passed to me from Beni through both formal and informal interviews, to create a picture of how Beni presents himself to me as an musician, instrument maker, educator, researcher, and also a friend ${ }^{11}$.

\footnotetext{
${ }^{10}$ I use the idea of ownership here as Beni does; those who have an ancestral link to the cultural traditions. For discussion of musical ownership with communities see: Seeger, 1992; McLean, 1965.

${ }^{11}$ It should also be noted that although biographical information describing the musical and non- musical background of an individual can help reveal how music is experienced, it can never be exhaustive. An infinite number of life experiences influence our musical experiences and perceptions, and only a few of those are consciously acknowledged (Rice, 1994).
} 


\section{Benicio (Beni) Sokkong}

Benicio Sokkong was born in the province of Benguet where his father was working as a nurse at the Lapanto gold mines, located approximately 100 kilometres south of Kalinga, his ancestral home. The Sokkong family owns fertile land in Sukiap, Kalinga, giving his family social status and the financial ability for his father to look beyond farming and the village, and train as a nurse. As a bodong (peace pact ${ }^{12}$ ) holder, Beni's father would travel to other neighbouring villages to re-affirm the bilateral agreements between tribes to prevent tribal war. Beni would travel with his father on these journeys and be exposed not only to the responsibilities which would one day be his, but also the bodong ceremony involving public speaking, music and dance. Beni would become, like his father, fiercely proud of his cultural heritage and of being Kalinga $^{13}$.

After graduating high school in Benguet, Benicio returned to his ancestral home of Sukiap in the Barangay of Tanglag, Kalinga. It was during this period that Benicio began to absorb the music of the bamboo instruments form his elders and peers in the village. As a single male, he lived in the bachelor's quarters, where the bamboo solo instruments such as the tongali (nose flute), paldong (mouth flute) and kolitong (tube zither) were played in the evening after a physically exhausting day of farming.

Beni decided to continue his education as his father had and study dentistry in Manila. During this time he was living with his sister Rosalinda and her husband Ignacio Jacinto who was had

\footnotetext{
${ }^{12}$ See Barton, 1949; Dozier, 1967; Stallsmith, 2007

${ }^{13}$ Beni's Sister Rosalinda, told me of how Beni's father once went to the LaPanto Mines Company Christmas Party in traditional Kalinga dress including the g-string and headdress and danced with the American Managers American wife (Jacinto, personal correspondence, July, 2007).
} 
been asked by José Maceda to teach Kalinga Music and Dance at the University of the Philippines in Quezon City, Manila,. While in Manila, Beni and his brother-in-law experimented with different techniques for making the bamboo instruments, and also refining their musical skills playing them. Beni eventually took over the teaching position at the University of the Philippines from his brother in law 1987.

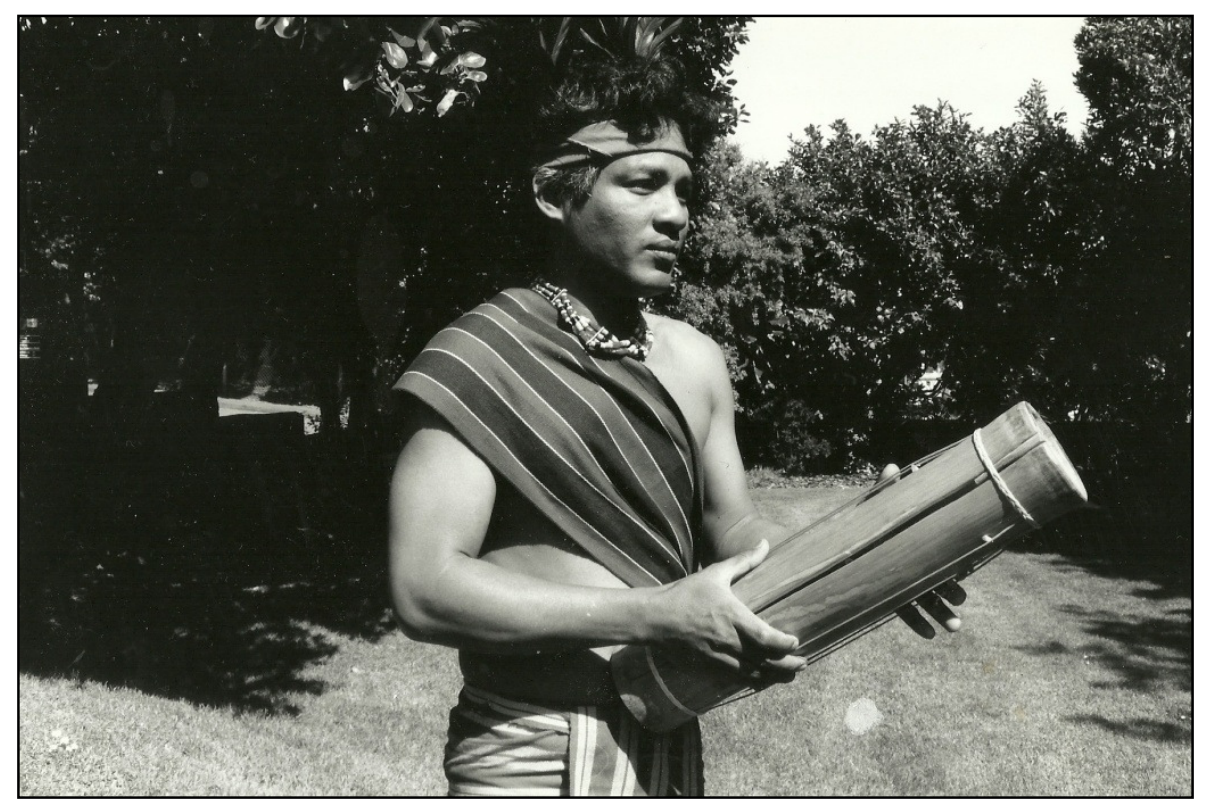

Figure 3: Beni Sokkong in traditional dress playing the kolitong (tube zither), (Image Services, Victoria University of Wellington, 1998)

Beni's involvement in the University of the Philippines at this time is located in the larger context of the Ethnomusicology Department and the work of José Maceda. During the 1950's the University had developed a strong interest and focus on the indigenous music of the Philippines led by José Maceda (upethnom.com 2011). As a result of his lifetime project of surveying the music of the Philippines (Corazon 1982), Maceda introduced courses on the Music of the Southern Philippines focusing on kulintang (horizontal bossed gongs), and the Northern Philippines focusing on Kalinga music which would be taught by Beni. Bamboo instruments 
also featured in contemporary compositions by Filipino nationals such as Maceda $(1963,1965)$, and his colleagues and students such as Ramon Santos (1978) and Jonas Baes (1999, 2007). The instruments also began to infiltrate popular genres as well, especially the recent world music trend, featuring in the music of artists such as Grace Nono (1993). If one had to pinpoint the beginning of the revival of the bamboo instruments, it would be during Maceda's early ethnomusicological research and composing, and from this point the revival has disseminated to other musical communities (Baes, 2008). As a teacher and performer of both the musical traditions of the Kalinga and in contemporary music, Beni was deeply involved in a variety of aspects of the process of revival.

\section{Pasiking}

During Beni's period of teaching at the University of the Philippines beginning in 1987, he formed a performance group consisting of his family members and close friends to enable him to present the music of the Kalinga throughout the Philippines and around the world. The group, which still performs today, is called Pasiking. The word pasiking is the name of the traditional rattan backpack which is found throughout the indigenous groups of the Cordillera. Beni explained the connection of the name to me as a means of holding on to your culture; a way of ... 'carrying your culture on your back wherever you may go' (Benicio Sokkong, June 2007, correspondence). Pasiking have performed in a number of festivals around the world, including, Japan, Taiwan, Amsterdam, Spain and the Smithsonian Folkways Festival in 1998 in Washington $\mathrm{DC}^{14}$. The pool of performers who form Pasiking are all Kalinga, and, like Beni,

\footnotetext{
${ }^{14}$ See Ricardo Trimillos' article: Histories, Resistance, and Reconciliations in a Decolonizable Space: The Philippine Delegation to the 1998 Smithsonian Folklife Festival, 2008 for an interesting exploration of the dynamics between festival organisers and performers.
} 
have grown up with the bamboo musical instruments and the other Kalinga music and dance traditions. These musicians and performers have developed their own specialties and formed groups of their own such as Beni's cousin, Fidel Tayawa and his sister, Constancia Pulgao. Fidel spent time living with Beni in Manila where he also began to make and design bamboo musical instruments and now sells instruments, helping Beni meet the demand. His playing specialises in the solo bamboo musical instruments and has developed a unique style which extends the traditional repertoire. Constancia now lives in Auckland, New Zealand where she is active in the Kalinga community and leads a traditional music and dance group of her own.

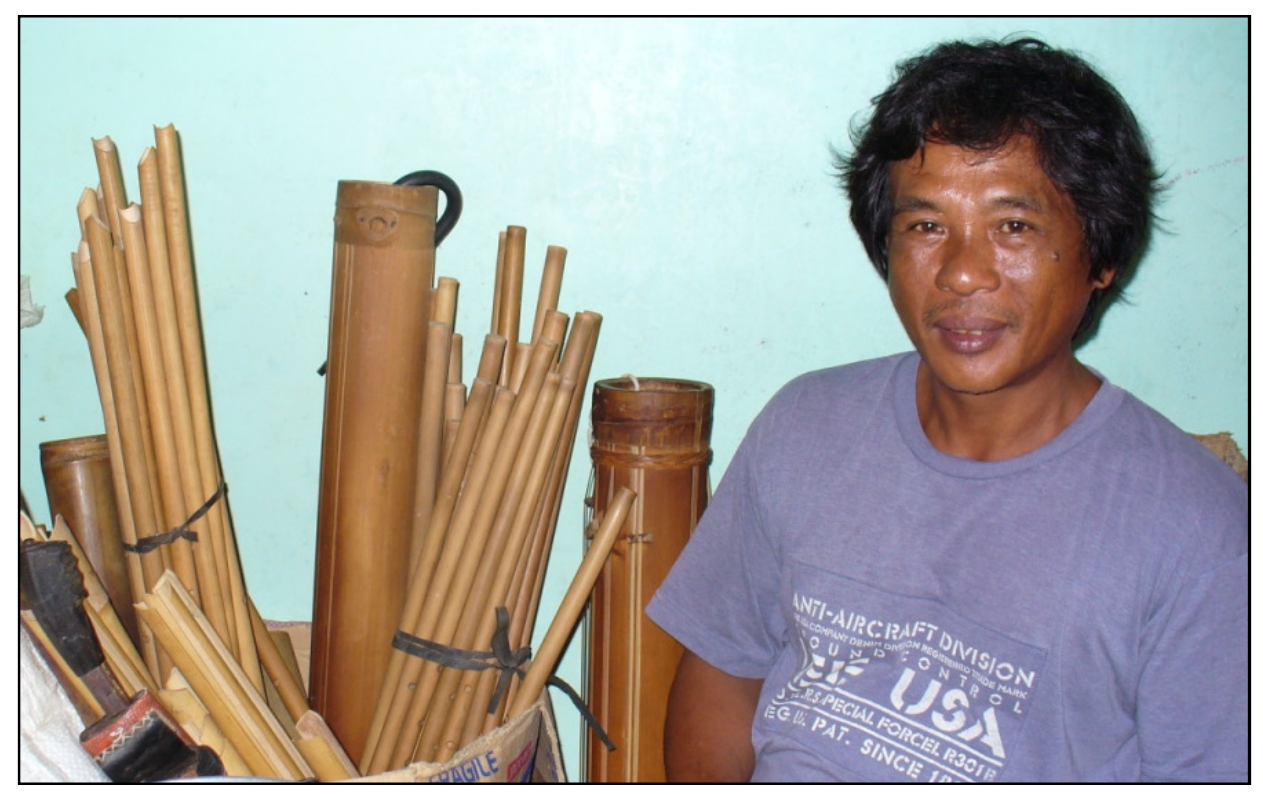

Figure 4: Fidel Tayawa with a collection of completed instruments. (Photo by author, July 2007)

\section{Cordillera Music Tutorial and Research Center (CMTRC)}

Although Beni was participating in the revival by teaching at the university and performing around the world, he recognised that the music traditions had become distanced from the actual 
people with direct social and historical connections; while Beni was teaching young students in Manila the music of Kalinga in Manila, the youth in Kalinga were losing knowledge of their music. This was the impetus for Beni founding the Cordillera Music Tutorial and Research Center (CMTRC) in 1998. The CMTRC is based in Baguio City, but also travels throughout the Cordillera teaching and researching. The centre, which continues to be active and expand today, provides a means to coordinate the preservation and transmission of cultural knowledge. The promotional information booklet outlines the aims and principles of the CMTRC:

\section{Guiding Principles:}

The CMTRC envisions a library, resource, research and coordinating center that will focus on the indigenous music and dances of the Cordilleras.

Training, workshops and programs in the music and the arts are aimed towards responding to the cultural needs of the participants, in the context of the school of living tradition.

Take an active role in the creation of networks and linkages of individuals, organizations, institutions and programs, both local and abroad for the preservation of Cordillera culture and traditions. (2003)

Beni has built a network of individuals from the wider Cordillera region who teach regular workshops on music and dance throughout the Philippines. Each of these individuals also has a unique connection with their indigenous heritage and are experts in their respective traditions. This enables the CMTRC to run workshops which include not just a generic presentation of the music and dance of the Cordillera, but detailed information on each region within the Cordillera: Benguet, Ifugao, Mt. Province, Abra, Isabella and Kalinga ${ }^{15}$. Although Beni's knowledge is focused on the music and culture of Kalinga, through his years of research and community

\footnotetext{
15 The CMTRC is recognized and part funded by the NCCA (National Commission for Culture and the Arts of the Philippines, and is also recognized by the UNESCO Intangible Heritage.
} 
involvement, he is also an expert on the music traditions from the six provinces from throughout the Cordillera region.

\section{Twin Peaks: Bamboo collecting and a Kalinga classroom}

Twin Peaks is the location of a plot of land owned by Beni and his family, approximately fortyfive minutes south of Baguio City in the area of Tuba, Benguet. This is where Beni harvests wild bamboo for instruments and where he has created a unique classroom in a rural environment. The CMTRC hold regular summer camps at Twin Peaks and students of all ages, including university professors, come to learn the music and dance, and other cultural traditions of the Cordillera.

At the top of the rocky ridge, a fifteen minute walk up a steep incline, Beni has built two houses in the traditional construction style of Kalinga and a large shelter for bamboo storage. The larger house is built in the octagonal design of those with status in a traditional Kalinga community (Barton 1949:9, Benicio Sokkong, June 2007, correspondence). Inside the octagonal house, the rafters above the fireplace are stacked with bamboo instruments, ballingbing (buzzer), tongatong (stamping tube), curing in the cooking smoke. The cross hatch of the bamboo wall behind the fire is adorned with the tail feathers from the chickens and the skull of a carabao (water buffalo) which have provided meals for the visitors. Outside, also on the small plateau, the rectangular house stands in the centre, also constructed with the traditional materials of bamboo and reeds. Looking out across the river valley, thick clumps of bamboo dot the landscape, recognisable from a distance by the lighter colour compared to the darker greens of the other flora.

Beni has created a type of living museum with this land; not only are the houses constructed in the traditional way, but daily life takes on a timeless feel, where food must be gathered, the uma 
(garden) must be tended, and there is no electricity or television. Twin Peaks provides a unique, authentic, thought provoking environment for teaching the traditional music of the Cordillera. It creates an almost fantastical world, where students are immersed in an environment which many of their grandparents grew up in, before migrating to Baguio City or Manila. 


\section{The Communities of Tanglag and Simit}

As noted above, Beni's musical activities and influence permeate throughout many aspects of the revival of the music of the bamboo instruments. In his role as a performer, researcher, teacher and instrument maker, Beni creates connections with a number of musical communities around him, reaching across social and geographical boundaries: from academic institutions in New Zealand, to his family in his homeland in Kalinga, to his own neighbourhood in Baguio City. This thesis does not solely focus on Beni as an individual, but also focuses on two of these musical communities that exist around him: Beni's friends and family who live in the rural community of Tanglag, Kalinga, and the urban musical group Simit comprised of young males from Beni's neighbourhood in Lucnab, Baguio City. These two communities, one urban and one rural, are connected through Beni, whose influence has provided them with the means to participate in musical activities and therefore, the revival. Simit and Tanglag also provide a case study of 'grassroots' communities' revival of the music of the bamboo instruments ${ }^{16}$.

The term 'musical community' is used to denote the social groups that are established through music making. I primarily consider the Simit and Tanglag's connections and interactions with music, although both of the communities exist as social groups outside of musical activities. The concept of 'grassroots musical community' is defined as those with an ancestral connection to the music traditions and not directly associated with state institutions (such as universities and cultural centres), or the commercial music industry.

\footnotetext{
${ }^{16}$ For other studies which feature grassroots musical communities and a comparative approach see Allan Thomas' study on the New Zealand Town of Hawera (2004), and Thomas Turino on the Conimeño musical traditions in Peru (1993).
} 


\section{The Community of Tanglag in Sukiap, Kalinga}

Nestled in a rugged valley above the Chico River, below the Bontoc - Tabuk - Tuguegaroa Highway is the village of Sukiap. Terraces of wet rice are held above the banks of the Chico River by ancient stone walls, and the thick green forest carpets the surrounding mountains and beyond. Amongst these fields, coconut and beetle nut palms spring up indicating the location of the village. If you look carefully at the larger landscape around the rice terraces, small but bright patches of the luminous green of bvulo culms (thin walled bamboo) can be seen. With even more effort, the tall feathery darker foliage of the bvuyog (thick walled bamboo) becomes apparent. These are the bamboos required to construct the bamboo musical instruments of the Kalinga: the culms embedded with a natural sonic abilities and musical possibilities.

The two villages of Old Tanglag, Sukiap and Liglig, have had bamboo musical instruments as long as the community has existed (Benicio Sokkong, June 2007, correspondence). A generation or two ago, the music of the bamboo instruments was a crucial ingredient in customary ritual and social contexts (ibid, 2007). Today, due to a number of influences such as technology, migration and access to national and international media, the instruments have lost the connection to these traditional contexts, however through the process of revival, new contexts are evolving.

The inhabitants of Sukiap are predominately farmers, growing the nationally famous Kalinga red rice and coffee, and vegetables for local consumption. The amount of rice produced is enough not only to feed the community, but also to feed those people of Tanglag who have migrated to the city. The majority of my time in Kalinga was spent at Sukiap, the smaller of the two villages with a population of approximately 100 to 150 residents (ibid 2007). Sukiap is Beni's ancestral home and although all the Sokkong family have migrated away to Baguio, Manila and 
throughout the world, they still have a house in the village. Liglig, where Beni's and his wife's mothers were born, is the other village of Tanglag, and is located a few kilometres downstream and across the Chico River with a larger population of approximately $300^{17}$.

Sukiap is a quiet place most of the year; during the school term all of the children and young adults, of approximate age 12 to 22 , stay with relatives in the nearby city of Tabuk where high school and tertiary institutions are located. In the summer months of May and June, however, the village is bursting with people and action, as this is the season for festivals and weddings where the gangsa (flat gong) can be heard reverberating throughout the valley.

${ }^{17}$ The Government of the Philippines records the population of Tanglag, which includes both Sukiap and Liglig, as 681 in 2007 (www.census.gov.ph). However, I was told by Beni and others that there where between one hundred and one hundred and fifty living in Sukiap and around three hundred in Liglig. These estimates did not include the children that where away at school. 


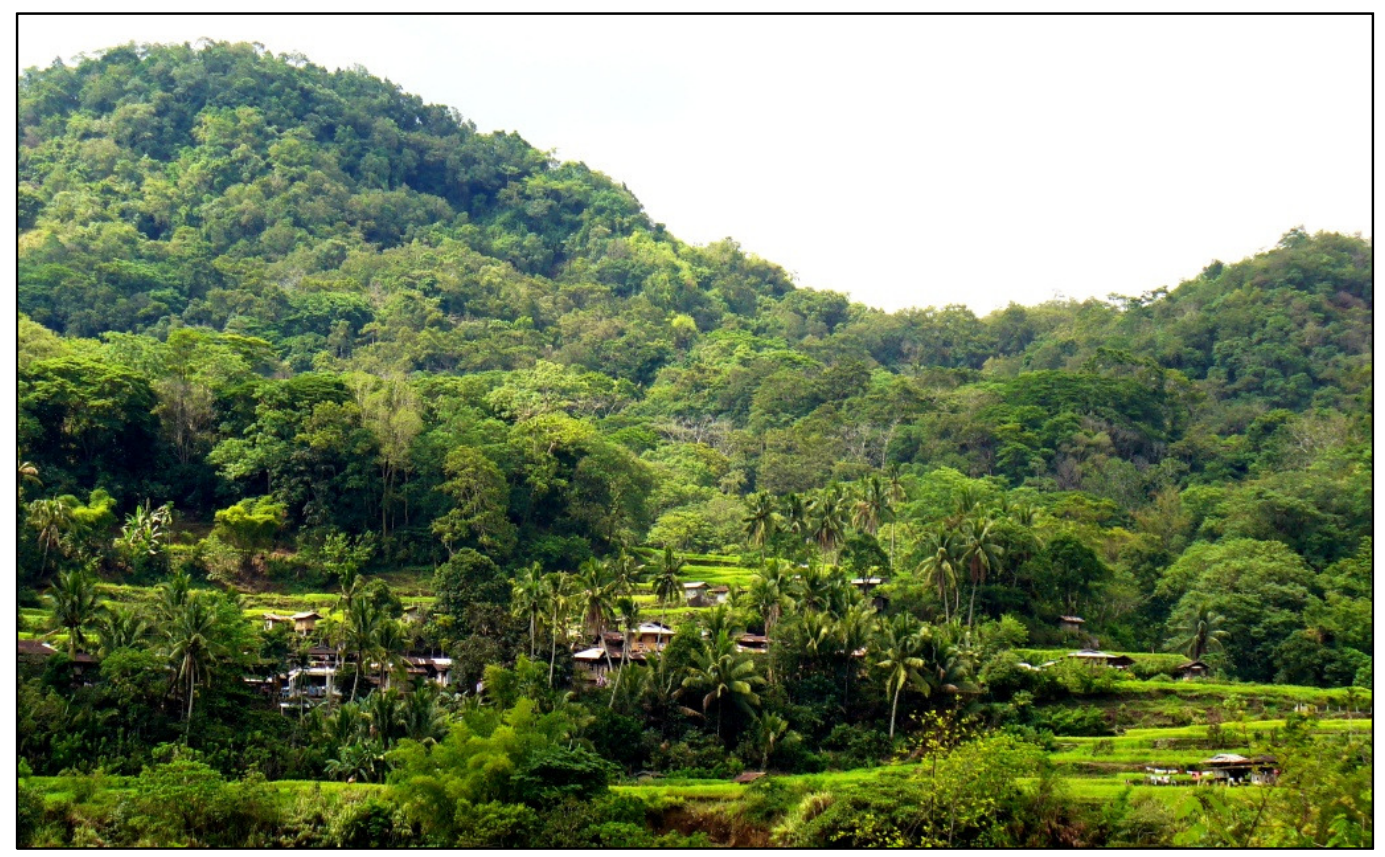

Figure 5: The village of Sukiap nestled amongst the coconut palms and rice paddies (note the plume of bvulo (thin walled bamboo) in the lower centre right of the photo.) (Photo by author, May 2010)

Access to contemporary media such as the internet and television, while ubiquitous in Baguio, has yet to become common in both the villages of Liglig and Sukiap. Electric lighting has been supplied to a few in Liglig and on some occasions, such in the fiesta season in summer, a generator will be used for a television and a DVD player. Battery powered transistor radios, however, are very common. The soap operas and music of the local Kalinga radio and the regional Cordilleran radio station can be heard throughout the villages during the working day. Mobile phones are the most prevalent modern communication technology and coverage is found in both villages. This technology is relatively cheap and enables family members to keep in contact across the world via SMS (text messaging), whereas in the past, a trip to a nearby town was required to use a conventional land line phone. 
Although geographically isolated, the people of Sukiap and Liglig are exposed to modern media and urban living through travel to the larger, more populated, centres. As previously mentioned, most children and teenagers will go to Tabuk, the Capital of the Provence of Kalinga, for high schooling and many young adults will go to Baguio and Manila for tertiary study. Those not pursuing study are also likely to live and work in the larger urban centres for a time before returning to the village to begin a family. It is also not unusual to have some member of one's extended family to be an OFW (Overseas Filipino Workers) working in a hugely diverse range of countries such as Saudi Arabia, Italy, the Cook Islands and New Zealand. This is the primary mechanism for an increasing global view which is found even within the remote villages ${ }^{18}$. This feature of contemporary life in rural Philippines has contributed to the changing significance of the musical traditions. It is now more common to be able to play the guitar than to be able to construct and play bamboo musical instruments. As the population is becoming more migratory, the boundary between urban and rural is blurred and the distinctions between them which once existed are less apparent. Musical performances considered authentic and traditional by Kalinga are no longer found only in rural communities in ceremonial contexts, but are more frequently heard in urban areas at festivals and church services due to the revival.

In previous generations music was not restricted to specialists and everyone within the community would have had some knowledge of instrument manufacture and musical skill (Benicio Sokkong, 20 February 2007, interview). Today however, this is not the case and fewer people have experience of the instruments. The people of Tanglag Beni introduced me to, and who spent the greater part of our time with, were those who hold some knowledge of the bamboo

\footnotetext{
${ }^{18}$ Beni told me the population of the villages is slightly declining as many young people once educated, remain in the larger urban centres and beyond to begin their careers
} 
musical instruments. These can be divided into two groups: (1) those of Beni's generation and younger where Beni's influence as a specialist in the bamboo musical instruments has permeated, and (2) those older than Beni who hold older knowledge of the instruments.

A number of the younger generation had spent time with Beni during his period in Manila and were exposed to the growing significance of the bamboo instruments within academia and contemporary media, and developed an awareness and interest in the revival. Alongside Beni, they developed their skills in playing and constructing the instrument. This is in contrast to the older members whose musical knowledge has stayed local and has not been as influenced by the revival, but have provided crucial information to Beni for his research for the revival. This group of men, both of Beni's generation and older, were the men that not only shared with me their knowledge of the bamboo instruments and music, but also hosted me in Sukiap and Liglig. The paragraphs below introduce the individuals of this group to provide context to the chapters where they feature that follow.

Benjamin Wacdag (Ben) is considered an elder of the village of Sukiap. Beni told me that Ben was his mentor while Beni was a living as a young bachelor in Sukiap, both in music and instruments, and also in social life. Ben was introduced to me as an 'expert' of making and playing the bamboo musical instruments, especially the kolitong (the tube zither). Ben's repertoire of tunes on the kolitong was the largest I experienced in Sukiap which included some five tunes and variations ${ }^{19}$.

Like Ben, Henry Linggayo an elder of Liglig, is also known for his abilities on the kolitong. I only met him once briefly, introduced by Beni, where he played the kolitong for me to record.

\footnotetext{
${ }^{19}$ Most of the kolitong players I met played only one or two different pieces of music.
} 
His son, Martin Linggayo (aka Lumayog), participated in all of the musical activities during my stay and is also a proficient kolitong (tube zither) player.

Lorenzo Damagon (aka Bagtang) is a first cousin of Beni and of the same generation. Bagtang spent time living in Manila while Beni was teaching at the University of the Philippines, and began to develop his skills in making bamboo musical instruments. Influenced by the new significance and relevance of the bamboo instruments he grew up with, Bagtang's interest grew and he is now a highly skilled instrument maker. Bagtang lost his arm during one of the frequent typhoons which sweep through Kalinga, this however, has not held him back for making instruments which most people would struggle making with two arms. As he introduced himself to me proudly: '...even with one arm, I can still make bamboo instruments' (Lorenzo Damagon, 12 July 2007, interview).

The others who were primarily involved in making the instruments were proficient on ensemble bamboo musical instruments, and some also played the paldong and tongali (mouth and nose flute). During my fieldwork, they all participated in the construction of instruments led by Beni. These were: Francisco Damagon (alias Gallang), Jesus Otal (alias Etos), and Ermenio Dong-as (alias Gallming). Along with Bagtang, these men are all of similar age and grew up together in Sukiap and Liglig and share close kinship ties.

This musical community also extends to the children of both the villages of Sukiap and Liglig. Although many of the teenagers are away, their younger siblings attend the local school and participate in musical activities not restricted to the festivals in the summer months. Indigenous music and dance is taught and practiced at these village schools, but of more interest to me, was 
their participation in the making of the bamboo instruments and the playing of music on the instruments for recreation.

\section{The Performance Group Simit}

In Ilocano, simit is the name given to the new shoots of bamboo which grow from the rhizome root systems lying beneath the ground. Beni explained to me that even when the all of the large bamboo culms are cut from a bamboo clump, new shoots will still grow. Simit is also the name that Beni gave to a group of six young men between the ages of seventeen and twenty who practice and perform the musical traditions of the Cordillera ${ }^{20}$. Simit is a metaphor of how Beni conceives tradition: knowledge of one's culture is always alive below the surface even when all the existing elements can no longer been seen. This is applicable to the traditions of a community, whether it is a nation, village or an individual. Many of music traditions had lost significance to the individual members of Simit and in some cases, were forgotten. With Beni's guidance, this forgotten cultural knowledge was rediscovered and created an empowered individual and collective identity based on ethnicity.

I first met members of Simit, Jayson and Rowell, on my initial arrival at the Baguio City bus station in July of 2007. It was late evening and Beni had sent them along to collect me. After welcomes, introductions and a bumbling conversation, they flagged a taxi and we headed off down the narrow mountain roads of Baguio, winding through tall pines forests and the cool, misty air.

\footnotetext{
${ }^{20}$ The ages of the members of Simit are with reference to the fieldwork period in 2007.
} 
We arrived at Beni's home, a four level house built on an almost vertical hill side, where I was greeted by Beni and his friends and family on his patio. Beni led me around the group introducing everyone, including other members of Simit: Ariel, Dexter and Edward. They were busy preparing pinikpikan ${ }^{21}$ (chicken soup) over a fire for my first culinary Cordillera experience and introduction to the culture. Meanwhile, illustrating the influence of global media, others in the group listened to someone strum a guitar and sing slow rock ballads, such as November Rain by Guns 'n Roses.

I could immediately identify with this group; although I was now twenty nine, at least nine years their senior, I could sense the camaraderie, or barkada as it is know in Filipino ${ }^{22}$, that exists between young men of that age, and was excited at the prospect of getting to know them further and learning of their musical experiences. It was not until the following day that Humby, Beni's wife, told me of how Simit came to be together.

\footnotetext{
${ }^{21}$ Pinikpikan is synonymous with the indigenous people of the Cordillera. Traditionally, preparation of the dish begins with the gentle beating of the wings of a live chicken. This is said to tenderise the meat and add flavour. The chicken is then bled, keeping the blood for pre- dinner snacks, and then the feathers are burnt off over an open flame which also browns the skin. The bird is then butchered and a delicious, slightly smoky, soup is made with the meat on the bone, and the offal is mixed with the blood, vinegar and fried (also delicious).

${ }^{22}$ Barkarda as defined by Trimillos is: a close knit association of primary social interactions' (2004: 33). Also described as group of friends (bansa.org)
} 


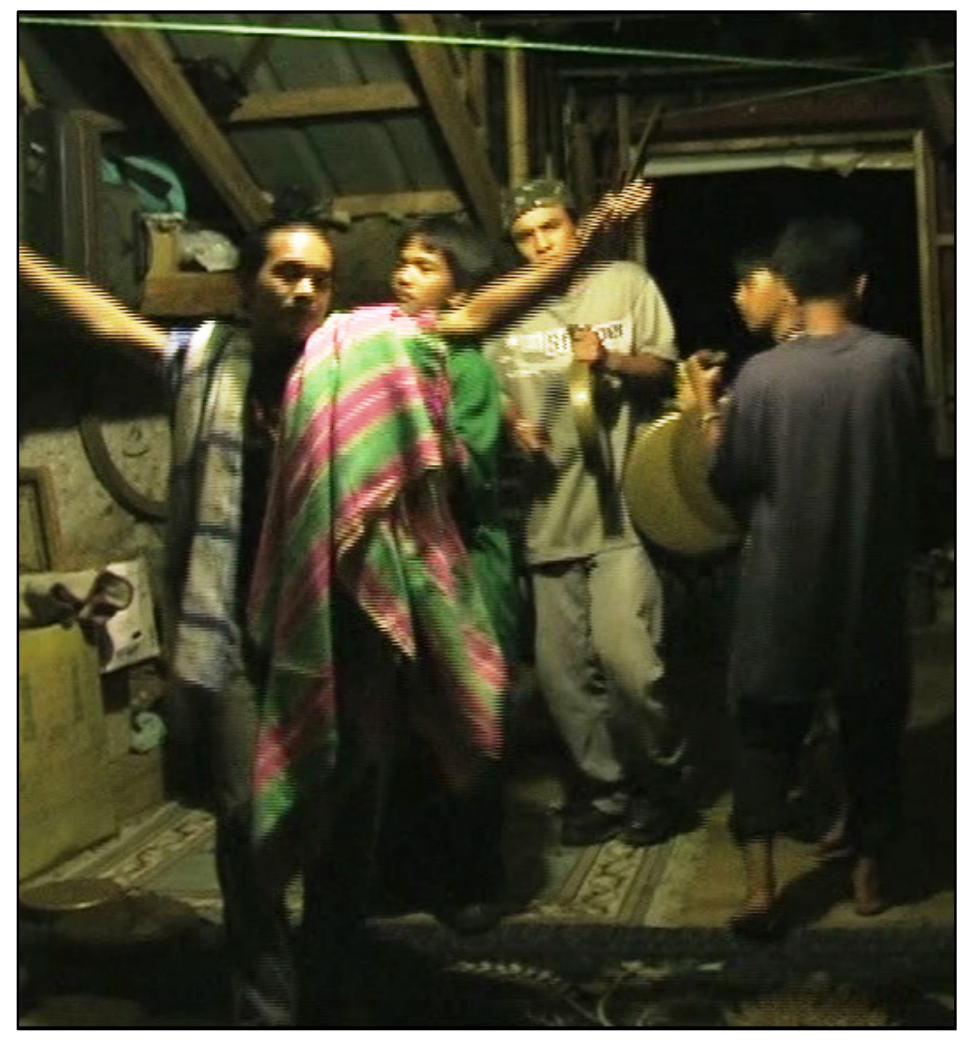

Figure 6: Simit playing gangsa: Ariel is dancing, leading Jayson, Edward, Dexter and Rowell playing the gangsa (flat gongs). (Photo by author, June 2007)

\section{The beginnings of Simit}

The family of Beni's wife Humby, has had close associations with the Mary Hurst Church ${ }^{23}$ for generations. This is the largest church in Lucnab and located less than twenty meters from the Sokkong's home. Humby devotes much of her time to church and community activities, assisting those less fortunate than her, and is well known and respected throughout the community of Lucnab. These activities include representing the church at weddings and funerals throughout

\footnotetext{
${ }^{23}$ Mary Hurst Seminary is located opposite to Beni's home and is a member of the Congregation of the Immaculate Heart of Mary CICM.
} 
Lucnab where the ceremonies are often a hybrid of the traditional beliefs and Catholicism. At one particular community occasion, Humby was introduced to a group of boys who were lurking around the fringes of the gathering, shy and dislocated from the group. Humby introduced herself and encouraged these boys to come to the LYM meetings (Lucnab Youth Ministry, associated with the Mary Hurst Church), which were held at Beni and Humby's home. It was during the group of boys' second visits to an LYM meeting that Beni asked the question: 'Do you know your own culture?'. This began their journey of rediscovery and the process of relearning and recontextualising the knowledge of their ethnic culture.

Prior to meeting Beni and becoming involved in the LYM, the members of Simit were viewed as at risk youth by the Lucnab community. Baguio, as a densely populated urban centre, faces many of the same youth alcohol and substance abuse issues as other cities around the world (Simit, August 2007, correspondence). Through Beni's teachings on the question 'knowing your own culture' the members of Simit, began the process of rediscovering their cultural heritage and redefining their individual identity. Beni, as a catalyst, reawakened an enormous amount of knowledge within them, and gave a contemporary and relevant context to this knowledge. In rediscovering their cultural identify ${ }^{24}$, a deep pride and sense of self worth developed, and solidarity was founded within the group.

The members of Simit grew up in Lucnab where their parents had migrated from the surrounding rural areas of the Cordillera Region in search of work and a better standard of living. Although life is highly urbanized and Christianized, with over $80 \%$ of the population Roman Catholic, many of the pre-colonial beliefs and customs remain (census.gov.ph 2003) and are practiced

\footnotetext{
${ }^{24}$ This could also be termed 'authoring the self through music' as discussed by Timothy Rice in 'Reflections on Music and Identity in Ethnomusicology' (2007:23).
} 
alongside Catholicism. Weddings, funerals, house blessings and baptisms all have strong elements of traditional beliefs which include music, dance and animal sacrifice. As children, the members of Simit would attend these events and be exposed to the music traditions, however, due to their age, they could not participate. Only adult men play the music required at these events and within this restricted group, there is also a hierarchy based on age and status.

As they grew into young men, the traditions and the music lost relevance and was dominated by the music most accessible to them: American popular slow rock and country. This music is particularly popular in Baguio City and throughout the Cordillera ${ }^{25}$, and it is very unusual for a Cordilleran male not to be able to strum a guitar and sing a few Kenny Rodgers or Neil Young songs. This led the boys to form a rock/country band, performing together occasionally for their peers but mostly just for themselves passing the time jamming. It was during this period that they met Humby and began relearning the traditional indigenous music of the Cordillera.

Another element that also prevented them from playing traditional music prior to meeting Beni was the taboo of ceremonial music played for recreation. Both their parents' generation and their grandparents' did not agree with traditional music being played outside of a ceremonial context. The most sacred of the Cordilleran instruments, the flat gongs (gangsa), could be heard throughout the rugged mountains; this sound always signified an event, a wedding or sacrifice, was taking place. When Simit began to practice the gangsa with Beni, their neighbours and relatives would remark that the gongs must not be played without a sacrifice ritual. Today, however, the gangsa can be heard reverberating around the valleys being played for purely for learning and recreation, and the only complaints from others are if it is too late in the evening.

\footnotetext{
${ }^{25}$ Cordilleran are often affectionately referred to of as cowboys by other Filipinos
} 
With Beni's guidance, the members of Simit realised that the gangsa can be played without offending the spirits, and without upsetting their parents.

The members of Simit live in Baguio City's barangay of Lucnab, however, their ancestral homes, the birthplace and residence of many of their grandparents, are located in the province of Benguet, which is the rural area surrounding Baguio City. Edward Pangod, the only member who is not from the province of Benguet, is from the municipality of Natonin in Mountain Province, a region with close cultural similarities to Kalinga.

\begin{tabular}{ccc}
\hline Name & Ancestral Home & Geographical Location \\
\hline Edward Pangod & Madukayyong & Natonin, Mt Province \\
Dexter Clemente & Kankanay & Benguet \\
Ariel Delim & Kankanay & Benguet \\
Rowell Martin & Kankanay/ Ibaloi & Benguet \\
Jayson Barcelo & Kankanay & Benguet \\
Shane Lindaoan & & Benguet \\
\hline
\end{tabular}

Table 1: Members of Simit's ancestral home

${ }^{26}$ Shane was not present and I did not meet him during the period of fieldwork in 2007. I did, however, meet him later on another visit in 2010. 


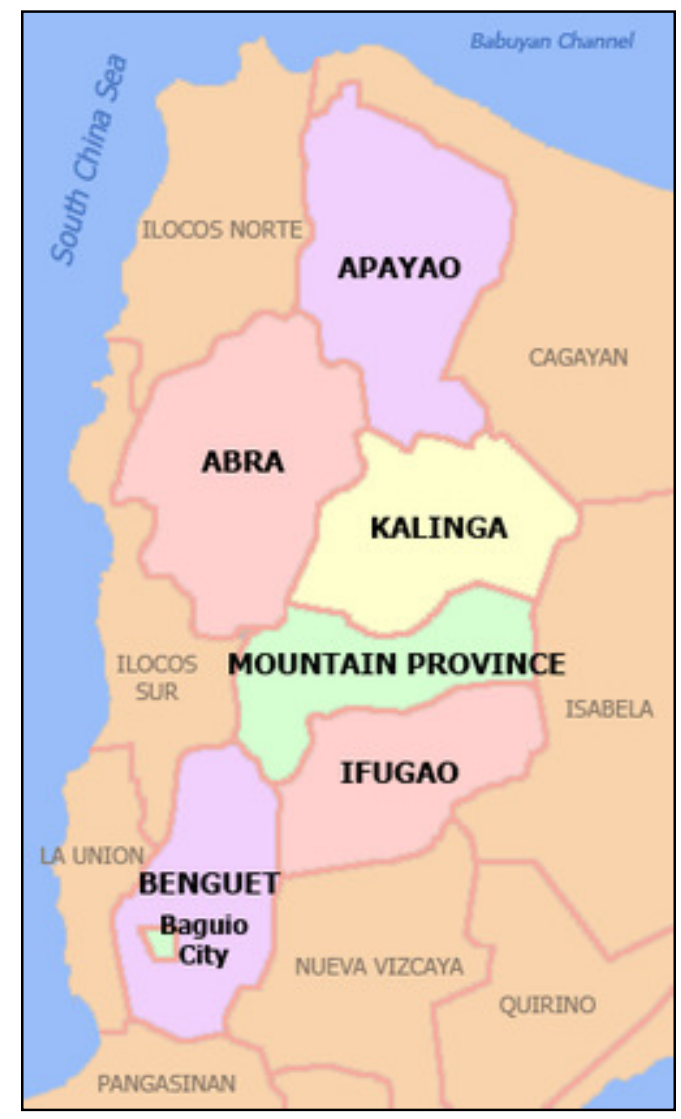

Map 2: Political Map of the Cordillera Administrative Region (Wikipedia.org 2011)

Each of the musical traditions of these ethnic groups differ slightly: the ensemble instrumentation and the rhythmic patterns (Maceda 1998; Benicio Sokkong, February 2007, correspondence). Beni has taught the group the music from all the regions from within the Cordillera, including his own traditions of Kalinga.

During one of the many nights 'hanging out' with Simit, I recorded a semi-formal interview ${ }^{27}$. We were at upstairs at Beni's home in Lucnab, in large open room which doubles as his

\footnotetext{
${ }^{27}$ Although they could all speak fluent English, it was apparent that they had difficulty articulating some of their ideas to me. I had not learnt the local language, Ilocano, and therefore they were forced to use their second language, English.
} 
instrument making workshop and performance practice area, the walls are lined with shelves full with bamboo tubes of all sizes ready to be crafted into instruments. The deep resonant sound of the tongatong (bamboo stamping tubes) could be heard from below where Beni was tuning up instruments, while outside the cicadas constantly chirped. Ariel, Dexter, Rowell, Jayson and I sat together and they told me how they came to be involved with Beni and their forgotten traditions (Simit, 14 July 2007, interview). The short dialogue below is a section of conversation from that informal interview which, their own words, captures their sentiments and ideas on music and Beni.

Rowell began answering how he had met Beni:

Before I met Uncle Beni, I did not know anything about my culture. That's why I am thankful to him, because now, I know how it will be done [my traditions], especially the music of my culture... One thing that comes from my mind just now is that the world is interesting... because of Mr Beni, I learnt about him and about music and about my culture that's why I am happy, for my life...I knew my culture a little, but when I met him something was added about knowing my own culture. (Simit, 14 July 2007, interview)

Ariel:

When I was eighteen, I graduated in High School and began with the Lucnab Youth Ministry [on Humby's suggestion]. We began playing only guitars and then they bought out the bamboo instruments, I could not play the bamboo instruments, only the guitar. Then I was taught how to play the bamboo instruments. After that, Mr Beni brought out the gongs then they played. I was interested to play these too, so he taught me how to play. After that, the next time we came to practise, he said 'do you know your own culture?. (Simit, 14 July 2007, interview)

Rowell:

That's Mr Beni's question. (The group all laugh at this). (Simit, 14 July 2007, interview) This dialogue illustrates the following elements: (1) the status and respect that Beni receives from the members of Simit, (2) how they recognise the influence of Beni on their lives and the 
substantial paradigm shift created by the importance Beni places on 'knowing your own culture', and (3) the conscious acceptance of the music traditions as collectively their own.

Today, Simit play the music of the bamboo instruments of the Kalinga as well as other music and dance from throughout the Cordillera in a number of performance venues: Sunday Mass at Mary Hurst Seminary, Concert for a Cause community gatherings ${ }^{28}$, and City Festivals such as Cordillera Day Celebrations Flowers. They also participate in the traditional ceremonies which are still held in the Lucnab community such the $\operatorname{canao}^{29}$ (ceremony honouring ancestors) where the gangsa (flat gong) and the sulibao and kimbal (cylindrical drums) and the takik (metal chime bars).

\section{Summary}

This chapter has shown that there is an underlying political theme to Beni's approach to the maintenance of the music traditions: he does not want the music to become divorced and distanced from the grassroots communities who have ancestral connections to it. His life and career have provided him access to obtain a holistic view of the musical environment of the bamboo instruments, where the music and the revival is placed within the different venues of academic institutions, national and international performances, local festivals and churches. Beni's commitment to the maintenance of the music in grassroots communities, and attempting to extend the academic method of transmitting knowledge to include grassroots communities,

\footnotetext{
${ }^{28}$ The Concert for a Cause community gatherings are small festivals held in Lucnab organised by the local community to raise funds for community members in need.

${ }^{29}$ For further information on the canao see the work of Susan Russell (1989)
} 
manifested in the creating of the Cordillera Music Tutorial and Research Centre (CMTRC) in 1998.

Unlike the urban music group, Simit, the rural communities of Tanglag contain individuals who have experience and knowledge of the bamboo instruments which was not solely transmitted by Beni, but was already present in the memories and life experience of the elders of the community. Tanglag's younger generation, those of similar age to Beni, also have knowledge of the bamboo musical instruments, however, it is through Beni's influence that the knowledge has been encouraged and developed. Although the village of Sukiap is located rurally, the movement of community members and the development of modern technology has caused the bamboo musical instruments to feature less than guitars and American influence country and rock within the day to day lives of the community.

The passion which Simit have absorbed knowledge and practise of the music traditions shows that there is a want and need for individuals to articulate their identities in highly ethnically diverse environments, such as Baguio City. The music, and the community it forms, is a vehicle for defining and self-authoring, ethnic identities.

The appropriation of music for the construction of identity in the case of Simit is self not initiated, but was motivated by a single individual within the community - Beni Sokkong (Rice 2007, Stokes 1994, Giddens 1991). In this way, individuals, often older members of communities with knowledge, nurture and shape the identities of the youth. In influencing the members of Simit in this way, Beni has succeeded his most passionate aims: (1) to socially protect the youth of his own community through encouraging positive values of ethnic identity and community, and (2) to share his knowledge of the music traditions and ensure the maintenance and 
transmission to future generations. Beni has used the positive values perceived in cultural traditions as a tool for the social benefit of his own community. This is a feature of revivals identified by Tamara Livingstone which aims to "to improve existing culture through the values based on historical value and authenticity expressed by revivalists" (1999).

Unlike the community of Simit in urban Baguio, in the rural community of Tanglag the social environment does not produce the same necessity for a conscious defining of ethnic identity. The dense population and the negative social pressures that are created in Baguio City, such as youth unemployment, drugs and alcohol, and crime, do not feature in Tanglag. In the villages of Sukiap and Liglig, the music traditions form a deeper, less conscious, part of life in Kalinga. 


\section{CHAPTER THREE}

\section{The Bamboo Musical Instruments}

The Kalinga have a unique and intense concentration of bamboo musical instruments. Bamboo culms $^{30}$ are cut into sections to make stamping tubes, flutes and pipes, shaped and split to make xylophone bars and percussion tubes, half split to make buzzers, and the fibres are lifted to make zithers. The variety of construction is equalled by the sonic diversity of the instruments: harmonic rich buzzing, deep resonant booms, sharp and clear clacks, gentle pizzicato, and melodic breath. The manipulation of bamboo into such an extraordinary collection of instruments, and the unique timbre and textures they create, was the impetus for the original research for this thesis. This chapter explores the Kalinga bamboo musical instruments found in musical contexts where Beni Sokkong is an agent of the music traditions.

Through the revival process, Beni has actively influenced the music and construction of the bamboo instruments in a number of ways. Beni uses a specific repertoire for teaching the bamboo instruments, which is rooted in his experiences of growing up in Kalinga, as well as his own research as an adult. The method of the instruments' construction has also undergone development; the instruments Beni makes are not designed to be disposable as in the past, but are built for longevity. By investigating the instruments, their construction, and the music, I will show how these features of the revival cause formalisation and transition of musical traditions, thus, highlighting the influence of an individual, Beni Sokkong, on a reviving tradition.

\footnotetext{
${ }^{30}$ The culms of a bamboo plant are the woody, hollow aerial stems from which all of the musical instruments are made.
} 
I begin this chapter by briefly exploring the connections between bamboo and the indigenous beliefs of the Kalinga, and the use of bamboo as a musical material. By describing the bamboo species used in instrument manufacture, and Beni's method of selection and preparation, I aim to highlight his unique knowledge, which is crucial to the maintenance of the instrument traditions, and also as a means to promote further study into bamboo as a musical material. Next, I introduce the bamboo musical instruments in two categories Ensemble Instruments and Solo Instruments and describe the physical features, the method of playing, tuning and timbre, and the repertoire. Finally, I provide a brief overview of the learning process and the specific concepts of the music which Beni articulates in his teaching of the traditions. 


\section{Bamboo}

The connection between bamboo as a material and the musical instruments of the Kalinga raises a number of interesting questions. Is bamboo chosen as a suitable material because of the plant's physical form, which lends itself so conveniently to musical instruments? Is this strictly a pragmatic choice or are there other reasons bamboo is used to make music? Does living bamboo have connections to Kalinga indigenous beliefs? I sought to answer these questions during my fieldwork with Beni, collecting bamboo and travelling throughout Kalinga, and also through research of written and recorded resources.

The multitude of bamboo's practical applications are well documented, and it has even been described as the 'the most valuable tree in the world' (Porterfield 1933). The symbolic connections of fertility and growth associated with bamboo are represented in a creation myth of low-land Filipinos which tells the story of the first man and women emerging from a bamboo shoot (Francisco Demetrio 1968). Manolete Mora describes how the spirit of bamboo is transferred from the living plant into the musical instrument amongst the T'boli people of south west Mindanao, in the Philippines. Mora writes: '... the spirit of the object from which the material is taken - trees, bamboo, etc. - inhabits the instrument' (1997: 3). In Kalinga and the Cordillera, a link between bamboo and the indigenous beliefs can be found in certain ceremonies

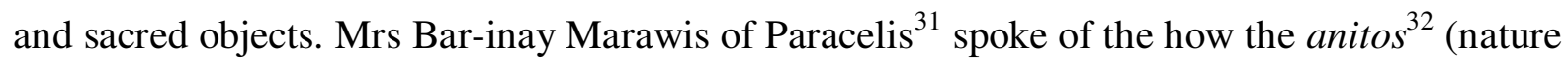

${ }^{31}$ Paracelis is a municipality in Mountain Province, bordering the province of Kalinga.

${ }^{32}$ Anito is the name given to the nature spirits throughout the Cordillera and the Philippines. In both Baguio and Kalinga anitos are invited to feasts, alerted to strangers visiting, informed of timber and bamboo being felled, and are present in many other parts of both ceremonial and daily life. Anitos are offered a portion of meat at ceremonies, and also the first drink of any bottle of alcohol opened, whether or not it is an official occasion. They are both good and bad depending on their demenor and how they have been treated by the community in the way of sacrifice and respect (Junker, 1999; Scott, 1974). 
spirits) need bamboo. The sound of certain species of bamboo is used to entertain the anitos, to distract them from meddling in ceremonies and causing bad luck and harm. For example, in Paracelis the music of the tongatong, which is made from the bamboo species kawayan ${ }^{33}$, is required during the pangudan ${ }^{34}$, the ceremony when a child is given his or her name (Mrs Barinay Marawis, 1 July 2007, interview).

When they put the pangudun on the child, when they bestow the name of the child, they go and get kawayan...Because the anitos need bamboo, need kawayan...They play the dongadong [tongatong] so when the anitos hear the dongadong, they will be very happy, they will be dancing so they will not be disturbing the child. Because if the anito disturbs the child it will get sick...The dongadong is the gangsa of the anitos. When you play the dongadong the anitos are very happy. There are some occasions [when certain species are used], for example, for the paungadun it is the bvulo that they use. For the guppok, it is the kawayan. That is what the anitos want. (Mrs Bar-inay Alit Marawis, 1 July 2007, interview)

This interview suggests that the sounds and music of bamboo are essential within the indigenous beliefs system. The material of bamboo is also used to construct a home for anitos. Small bamboo baskets, approximately $10 \mathrm{~cm}$ long, are made as a place for an anito to reside within Kalinga houses. I saw these miniature cradle shaped baskets in many homes I visited in Sukiap. Mrs Bar-inay Alit Marawis explained:

There is a house, a place where the anitos live; for example, a piece of cloth, a jar or bamboo. It is where they stay; this is why they put it at the top of the house so nobody can be touching. They are there. (Mrs Bar-inay Alit Marawis, 1 July 2007, interview)

Although bamboo is used to entertain and house nature spirits, the actual physical objects of the musical instruments are not prized and are considered disposable. Historically, the instruments were constructed only for specific occasions, for example, if they were required for a chomuchong (child dedication of a name), and were then thrown away, perhaps even used as

\footnotetext{
${ }^{33}$ In this instance kawayan is the thin walls bamboo which Beni calls bvulo.

${ }^{34}$ Pangudan is the naming ceremony in Paracelis. In Sukiap the naming ceremony is referred to as chomuchong.
} 
firewood (Benicio Sokkong, July 2007, correspondence). Unlike other bamboo instruments in Asia, such as the shakuhaci of Japan, bansuri of India, and the instruments of the T'boli of the southern Philippines (Mora 1997: 3), the Kalinga instruments were not stored and treasured, but used once then discarded.

\section{Bamboo species and collection}

Beni's land at Twin Peaks in the rural area surrounding Baguio provides the necessary materials to make the entire range of the bamboo instruments of Kalinga and the Cordillera. These materials are rattan cane and two different species of bamboo: bvulo and bvuyog. The thin walls and long internodes of the bvulo culms provide natural sonic resonant chambers which are easily tuned, and bvuyog (also called kawayan in Filipino), has thick walls and strong fibrous skin which can be cut and lifted to create strings. The table below shows a list of the instruments included in this chapter, their Kalinga name as described by Beni, the instrument type, and the species of bamboo as referred to by Beni ${ }^{35}$ :

\footnotetext{
35 The names of both the instruments and the bamboo species vary throughout the Philippines. For further information on the variation of names of the bamboo instruments, see José Maceda's book Gongs and Bamboo (1998).
} 


\begin{tabular}{ccc}
\hline Bamboo Species & Instrument & Instrument Type \\
\hline bvulo (thin walled bamboo) & tongatong & stamping tubes \\
& pattatag (gallupak) & xylophone blades \\
pattanggok & quill shaped percussion tube \\
ballingbing & split tube buzzer \\
saggeypo & individual lip valley pipes \\
paldong & lip-valley mouth flute \\
buyog (thick walled & tongali & nose flute \\
& tambi & paired string zither \\
& kolitong $(k o l i b i t)$ & six string tube zither \\
& kulibaw & jaw harp \\
\hline
\end{tabular}

Table 2: Bamboo Species36

\section{Bvulo (thin walled bamboo ${ }^{37}$ )}

Bvulo is a thin walled bamboo whose culms ${ }^{38}$ grows rapidly to full height in approximately one to two years. From a shoot, the culm will take three to five years to mature ready for harvesting for instruments. To determine the suitability of a bvulo culm for musical instruments, Beni used two main indicators: the colour of the culm, and the sound it produces when tapped with a machete. The younger shoots are a darker green with softer skin and the culm sheaths are firmly

\footnotetext{
${ }^{36}$ The botanical names of the bamboo species have not been positively identified. However, an expert at the Carolina Bamboo Gardens in the Philippines, Mrs. Carolina Gozon Jimenez, informed me that bvulo is most likely to be Gigantochloa levis and Bvuyog is thought to be Bambusa species 1 (Carolina Jimenez, October 2010, correspondence).

${ }^{37}$ The phrases 'thin walled bamboo' and 'thick walled bamboo' are the author's descriptions.

${ }^{38}$ The internode of a bamboo culm is the section of bamboo tube between the nodes.
} 
attached. Culms are paler green and 'yellowish' when mature, as Beni described to me while collecting bamboo:

While this one is very mature because it is a little bit yellowish, and by touching it with your machete [Beni taps the mature bvulo] the sound is a little bit hard, whereas this one is soft [tapping the younger bvulo]' (Benicio Sokkong, June 2007, correspondence).

The 'hard' sound of the mature bvulo is not resonant and does not contain a pitch, but is very sharp and bright, evidence of the extreme hardness of the outer skin in comparison to the soft younger bvulo .

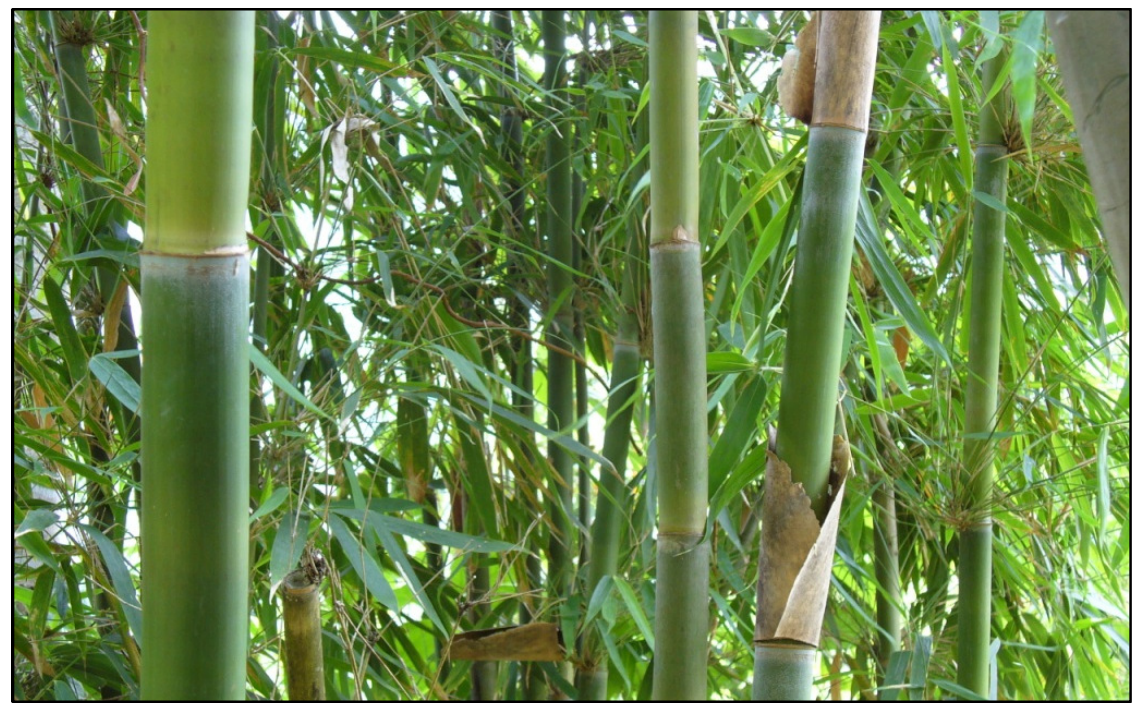

Figure 7: Bvulo culms (Photo by author, June 2007)

The culms, up to ten meters in length, are trimmed of the foliage leaf blades and the small unusable tips, and are then ready to be left for drying. Around six months later, the dried culms are cut to lengths appropriate to the instrument they are to become. Each culm lends itself to an instrument type depending on length and thickness. For example, the larger diameter lower internodes are cut below the bottom node to make tongatong (stamping tubes). Ideally, a set of 
six tongatong can be made from six internodes; the decreasing size of each piece naturally suggesting the intervallic tuning.

Pattanggok (quill shaped percussion tube), ballingbing (buzzer) and the tongatong (stamping tubes) are all formed from an internode with a single closed node at the bottom end. Other instruments made from bvulo, such as the pattatag (xylophone blades) and paldong (mouth flute) are made from two sections of internode with a node between them. The culms are cut to approximate length according to Beni's experienced eye, and then stacked on a rack covered from the elements by a simple corrugated iron shed to dry further, until Beni is ready to transform them into musical instruments.

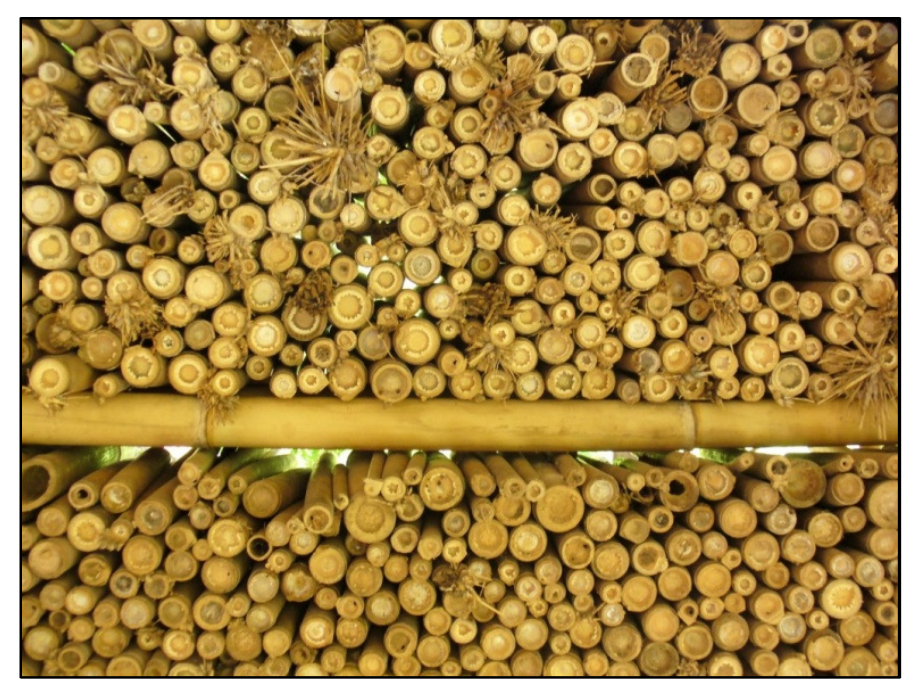

Figure 8: Stacks of bvulo cut to approximate length. (Photo by author, June 2007) 


\section{Bvuyog (thick walled bamboo)}

Bvuyog is a common building material for both traditional Kalinga housing and contemporary furniture. Its strength is far greater than that of bvulo because of its thick walls, which can be up to two centimetres in width. The internodes are shorter and the diameter is larger than bvulo. Bvuyog culms are prepared in much the same way as bvulo: they can be harvested after two to three years and, although thicker, drying takes a similar amount of time, around six months. The bvuyog internodes define the instruments length in the case of the tambi (two string, tube zither) and kolitong (six string, tube zither), both instruments having closed nodes at each end. The kulibaw (jaw harp) is carved from any piece of bvuyog of appropriate length.

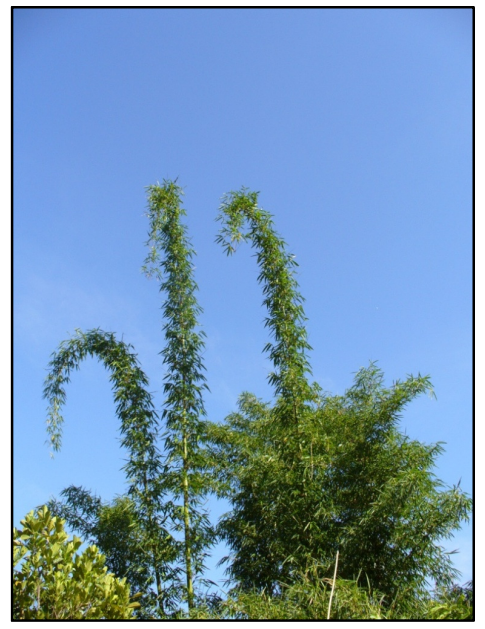

Figure 9: Feathery bvuyog culms, reaching up to eight metres in height.

(Photo by Author, June 2007)

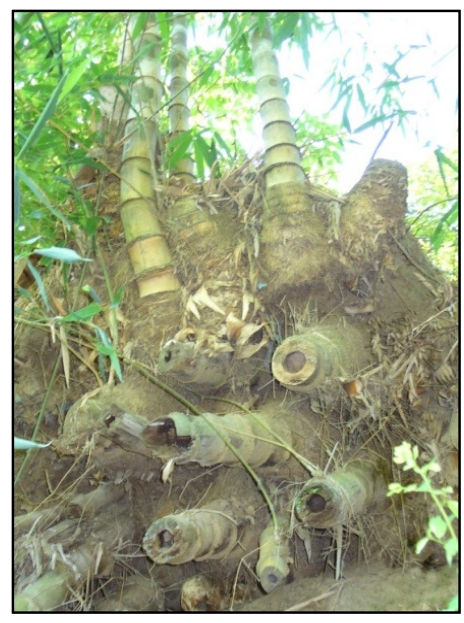

Figure 10: The base of the bvuyog where Beni has harvested culms for instruments. (Photo by Author, June 2007) 


\section{The gangsa (flat gongs)}

Before discussing the bamboo ensemble instruments it is useful to provide an overview of the gangsa (flat gong) ensemble. The musical structure and aesthetic of the gangsa is closely connected to the music of the bamboo ensemble instruments, and in teaching the music, Beni would often reference the gangsa, comparing both the desired sound and the playing technique. In addition, the gangsa provided me with the opportunity to participate in the music and dance of a traditional wedding ceremony in Kalinga.

Beni and I were invited to the wedding of his distant cousin in Gobgob, an area near Tabuk City where many people from Tanglag have settled ${ }^{39}$. We had travelled from Sukiap and arrived the night before the wedding, and immediately joined the hundred or so friends and family in prewedding celebrations. The music and dancing was located not far from the Catholic Church, where the wedding was to be held, under a pagoda constructed from bamboo poles, tiger grass and a tarpaulin. In the centre of the area, lying around the central pole, there was a set of six gangsa. The festivities were being co-ordinated by an MC, who, with his painfully loud PA system, was inviting and encouraging the various family groups to step up and play the gangsa. A call requested the Old Tanglag group (those from Sukiap and Liglig), so Beni, myself and the others who had travelled with us, picked up the gongs and played Pattang (an ascending cyclical pattern) and danced in our line, while the women, also from Old Tanglag, danced between us.

Beni led the group with his subtle, controlled actions, the rest of us following and imitating him.

\footnotetext{
${ }^{39}$ The settlement of the Tanglag people in Gobgob, Tabuk, are referred to as New Tanglag. Old Tanglag refers to the villages of Sukiap and Liglig. Both settlements are in the Province of Kalinga.
} 
The gangsa continued to be passed around family groups throughout the night, the music continuing until the early hours of the morning.

Today, the gangsa remain an integral part of many ceremonies which are central to Kalinga life, and there is no indication that the use of the instruments is declining. In Kalinga and the Cordillera they are thought of as the most important musical instrument, and are considered an ethnic identifier within the Philippines (Benicio Sokkong, July 2007, correspondence). During my fieldwork in Kalinga and the Cordillera region, I heard the music of gangsa most often, and hold it to be the strongest indigenous instrumental tradition today. Whenever I inquired about music culture throughout Kalinga and the Cordillera, the gangsa was the first mentioned, always before any bamboo instruments.

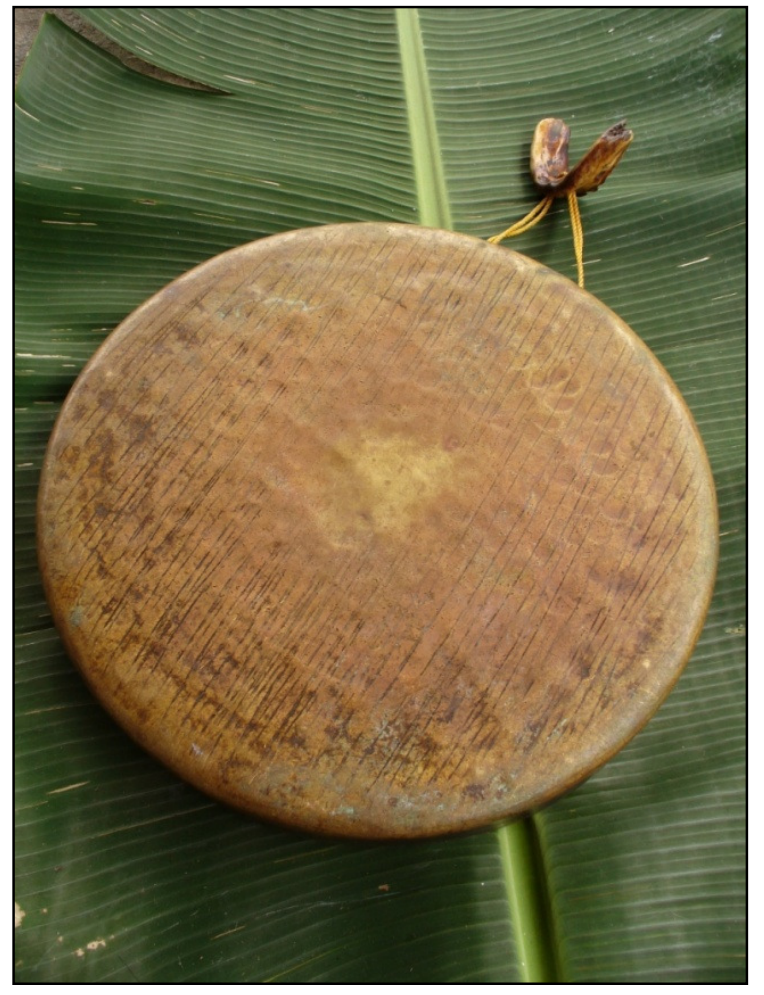

Figure 11: Gangsa (flat bronze gong). (Photo by author, July 2007) 
The gangsa ensemble consists of six flat gongs of graduated size and pitch, and is played in two ways: Pattang - using a wooden beater and played while dancing; and Tuppayya - played with the palms of the hands while kneeling. In both cases, each gong is played by an individual and patterns are created by the group. The gongs are named according to size and pitch as follows (lowest to highest): (1) balbal, (2) kadwa, (3) katlo,(4) kapat, (5) opop (kalima), (6) lalat (or kanom) (Benicio Sokkong, February 2007, correspondence).

Each player in the Pattang plays an identical four beat pattern: a strong, resonant note, followed by a short strike muting the first, then two pulse beats. The balbal (the largest gong) begins, defining the volume and pace of the ensemble. The kadwa (the second largest gong) then joins in with the same pattern, but one beat behind; the strong beat of kadwa lands on the muted beat of the balbal. This continues with the remaining gongs and results in an ascending cyclical ostinato (see figure 16) (Benicio Sokkong, February 2007, correspondence).

The word Tuppayya describes the playing method: 'played with the palm'. Each player kneels with the gong in front of the body resting on his thighs, the handle of the gong tied to the belt to prevent the gong sliding away. The player then strikes the gong with his right hand in the centre to produce a resonant, accented beat. This is immediately muted by the left hand slapping and sliding down the left hand side of the gong, producing a sharp ring from the near the rim and bending the note upward in pitch. This is repeated, although with a gentler accented right hand beat. The four beat rhythm cell is repeated as the fundamental pattern of the four lowest pitched gongs: balbal, kadwa, katlo, kapat. Opop, the fifth highest pitched gong, plays the pulse with 
short muted strikes, while the lalat (kanom) provides a rhythmic improvisation ${ }^{40}$ (see figure: 17 below) (Maceda 1998: 12, 13; Benicio Sokkong, February 2007, correspondence).

Beni described the Tuppayya of the gangsa as '... the breath of the gangsa' (Benicio Sokkong, 28 February 2007, interview). Relating the music to the indigenous past, he explained the excitement and anticipation that would be generated by the gangsa before a head hunting expedition: the pulse and movement of the Tuppayya building up the strength, energy and courage for the adventure.

Historically, the gangsa were played only by adult males, and only when in a ceremonial context, such as pre and post wedding (piyanos and kasey) and peace pact celebrations (bodong). The role of the women at these events was to dance to the gangsa music performed by the males. Today, however, outside of traditional ceremonial contexts, anyone may play the gangsa. Playing gangsa is now no longer restricted to ceremonial contexts, and performances are found in a range of venues, such as church, schools, festivals, competitions and popular music.

\footnotetext{
${ }^{40}$ For a more detailed description of the gangsa see Kristina Benitez's master's thesis by Toward an Understanding of Gong Ensembles in South East Asia: A Study of Resultant Melodies in the Music of Two Gong Ensembles from the Philippines (1983).
} 


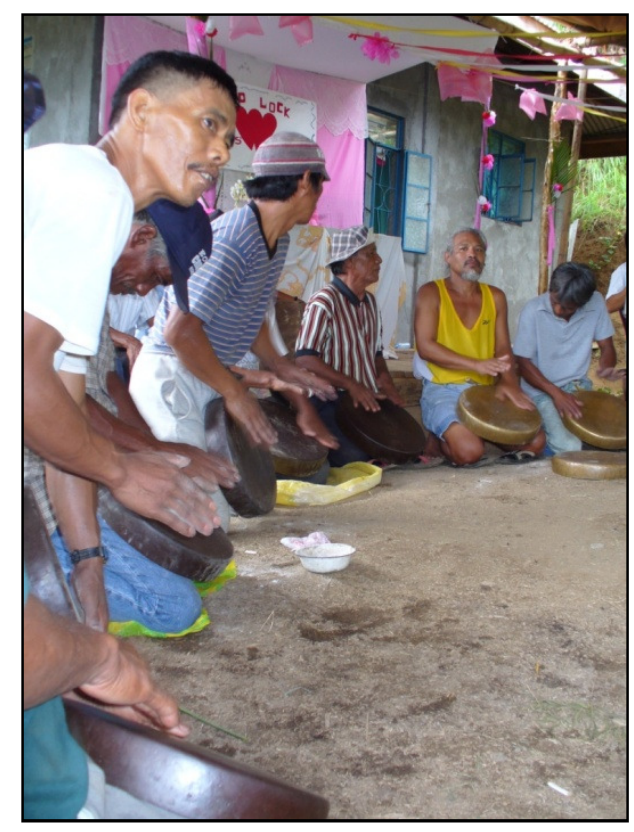

Figure 12: A gangsa ensemble performing Tuppayya. Beni is playing balbal of the second set. (Photo by author, June 2007) 


\section{The Bamboo Ensemble Instruments}

Historically, Kalinga ensemble bamboo musical instruments had specific uses and functions within ceremonies such as weddings (piyanos and kasey) peace pacts (bodong), and rituals such as house blessings (chumchumog). The instruments were used while walking between villages to prevent the possibility of witnessing a bad omen, a certain bird (ijo) or a certain snake (uyog), which could have detrimental effects on the marriage or political agreement. Playing the instruments had the practical purpose of frightening away these bad omens, thus ensuring a prosperous journey and a successful celebration. The sounds of these instruments would have once echoed through the valleys of Kalinga indicating to all there was an important occasion, and a community was on the move, and no bad intentions were meant - no violence intended (Stallsmith, 2007: 57). Beni teaches the past uses and functions of the bamboo instruments, as he believes it is important to understand the historical context of the instruments, and allows for a more meaningful musical experience.

Although the historical uses and functions of the instruments are consistent throughout the province of Kalinga, the method of construction and music differ. Slight differences, such as the method of shaping the instruments and musical patterns, are found between itangyeg (tribes). Beni's method of constructing the instruments draws from research throughout the region, and years of trial and error. He has refined traditional designs for sets of ensemble instruments, carefully crafting them for longevity and musicality.

\section{The Instruments}

The bamboo ensemble instruments are similar to the gangsa in three fundamental ways: (1) each ensemble consists of six similar instruments of graduated size and pitch, (2) each instrument 
sounds an accented, pitched note (bvungog) and a muted note (okak), and (3) the music played by the ensembles is based on the same ascending cycles of the Tuppayya and the Pattang.

\section{Tongatong (bamboo stamping tubes)}

The tongatong require the least amount of modification from a bamboo tube to construct. Tubes are simply cut from a single pole of thin walled bamboo called bvulo, the largest tube being approximately one metre in length, and the smallest 40 centimetres. Each of the six tubes is cut from the pole a few centimetres below each of the closed nodes, the other end being left open. The natural graduation in length of each internode ${ }^{41}$ provides a set of instruments that require only fine tuning. Some sets of tongatong will be greater than one internode and will have the centre node punched out to provide a resonant cavity the full length of the tube.

The individual player pounds, or stamps, the instrument onto the ground, whether it is earth, wood, or concrete (although concrete can be damaging to the instrument), holding it gently in one hand to allow the tube to resonate. The two timbres of the tongatong are produced by either closing the tube with the free hand - producing a muted note (okak); or leaving the tube open producing a pitched, resonant note (bvungog) (CD Track:1).

\section{Pattatag (or gallupak) (bamboo xylophone blades)}

Pattatag are xylophone blades made from dried, split bvulo culms. The tubes are first cut into graduated lengths to create a tuned set of six, and then split in half lengthways. Small amounts of bamboo are then shaved off the length and end off the instrument to fine tune further, and achieve the desired interval set. Each blade, played by a sitting individual, is placed on the thighs

\footnotetext{
${ }^{41}$ The internode denotes the section of a bamboo culm between two nodes.
} 
with the legs spread to achieve the most resonant, pitched sound (bvungog). The non-pitched sound (okak) is produced by muting the blade with the palm of the free hand. The extreme hardness and the thickness of bvulo produce a clear, crisp note when struck with a beater, often made from bvuyog or coconut wood.

Beni described the pattatag (xylophone blades) as the first instrument on which children would learn to play the basic alternating pattern of Ginallupak. The children could easily make the instruments themselves and play, practise and imitate the sounds of the gangsa played by their fathers (CD Track: 2).

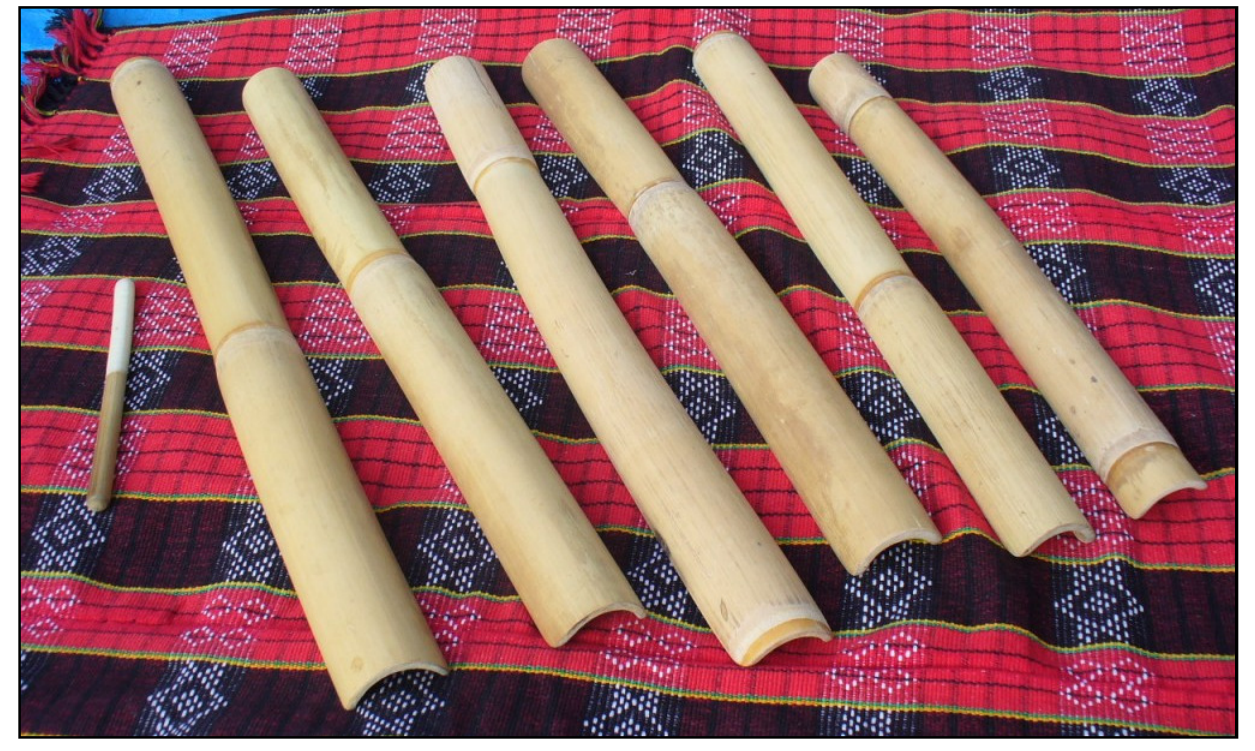

Figure 13: Pattatag or gallupak (bamboo xylophone blades). (Photo by author, August 2011)

\section{Pattanggok (quill shaped percussion tube)}

The pattanggok, also made from bvulo, combine the construction elements of the pattatag and the tongatong. The quill shaped instrument is a bamboo tube with a closed node at one end. It is a complete cylinder for approximately half the length, and only a tongue (jila) is left for the 
remainder of the length. The resonance of the tube is reinforced by the tongue, increasing the volume. The instrument also has a thumb hole near the base of the tube section where the instrument is held. A piece of hard wood, such as coconut, or a head axe as Barton noted (1949: 180), is used to hit the pattanggok with a flick of the wrist, near the centre of the instrument. Opening and closing of the thumb hole produce the okak and bvungog sounds, respectively.

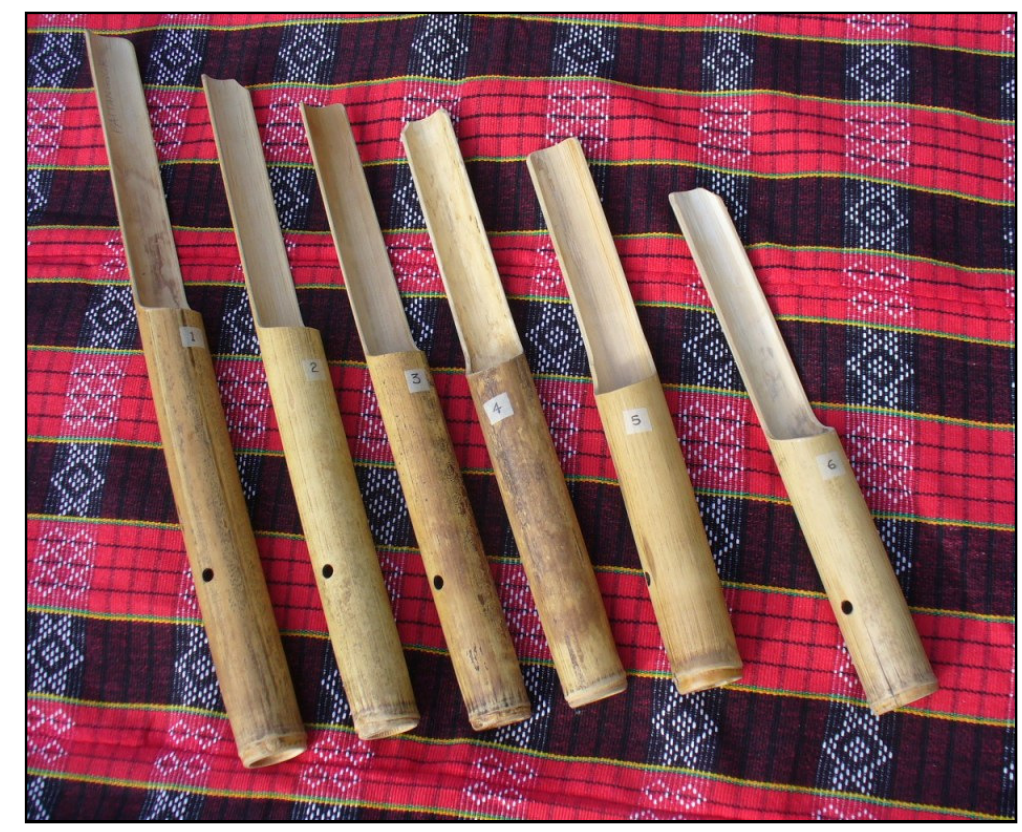

Figure 14: Pattanggok (quill shaped bamboo percussion tube). (Photo by author, August 2011)

\section{Ballingbing (split tube buzzers)}

Ballingbing is a buzzer made from a cut and dried length of bvulo with a closed natural node at one end. Strips are cut out of the side walls along the upper part of the tube to create a tuning fork shape. A thumb sized hole is cut below the tongues where the player grasps the instrument. The tube is gently split lengthwise to create a crack between the two tongues near the closed node. A rattan band is placed around the base to prevent the buzzer from splitting further and cracking all the way down to the end node. 
To sound the ballingbing, the instruments are held in the hand at the base of the instrument near the closed node. The thumb hole should be located where the thumb would naturally sit. The ballingbing is struck onto the palm of the free hand above the wrist where it is firm, yet padded. Although rich in harmonics, a well played and well made ballingbing should have a clear resonant pitch and long sustain ${ }^{42}$.

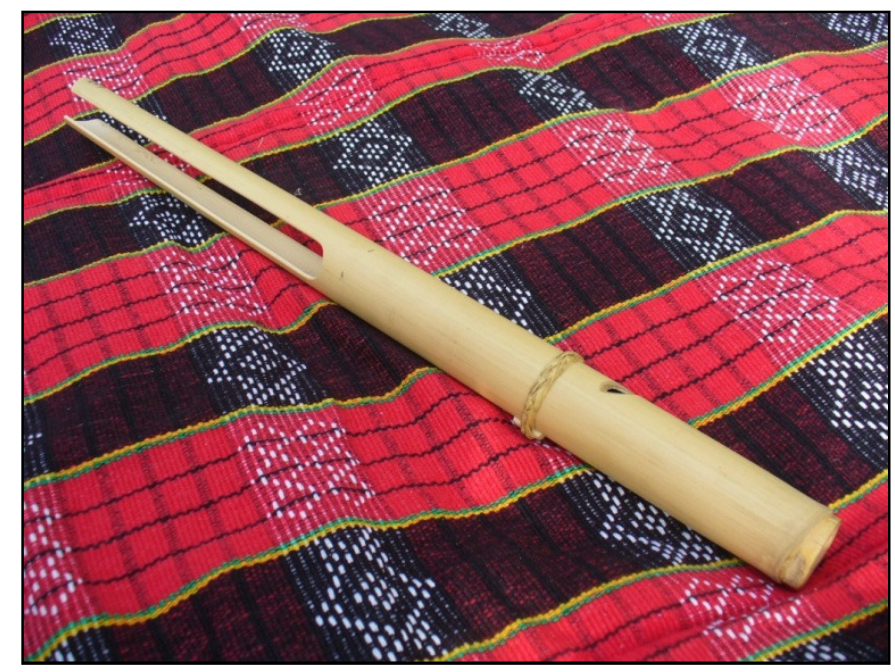

Figure 15: A single ballingbing. (Photo by author, August 2011)

Although the resonant pitch is audibly identifiable, the most intriguing musical feature of the ballingbing is the buzzing harmonics and the way these decay. As the energy of the vibration in the tongues decreases, the pitch bends upward creating a note which seems to bounce through the

\footnotetext{
${ }^{42}$ During my fieldwork I witnessed a variety of methods for making ballingbing. Ben Wacdag made set of ballingbing using the simplest method (Sokkong, correspondence, June 2007). Ben simply took a single pole of bvulo and using a pachil (machete) cut the pole below each node producing six tubes of bamboo with decreasing length and diameter. The tongues were formed with a few strokes of the pachil and shaped. Below the tongues, where the split was to be made, Ben scraped away the outer skin layers, perhaps $2 \mathrm{~mm}$ deep, forming a rectangle below the where the tongues meet. This prevents the tube from spitting too far down the length, therefore, no rattan band is required. Ben completed a single instrument from the complete pole in about 5 minutes and the only tool required was a pachil. Once Ben had completed the set of six ballingbing Beni fine-tuned the pitches using the lowest, balbal, as the reference.
} 
'tuned' pitch. When the six ballingbing are played as an ensemble in Ginallupak (alternating pattern), the collective result is loaded with overlapping harmonics (CD Track 3).

\section{Saggeypo (closed ended, individual pipes)}

The saggeypo are another of the bamboo instruments that require very little modification from the raw material. A set of saggeypo consist of six individual, end blown, closed pipes. The narrow tips of bvulo, around two to three centimetres in width, are cut below the closed nodes as with the tongatong, pattanggok and ballingbing. The blown end is cut on two opposing, asymmetric diagonals, the long edge to be placed against the bottom lip when played. Unlike the percussion instruments (tongatong, pattatag, pattanggok, ballingbing), the saggeypo can be made of dried or freshly cut bvulo as the instrument does not rely on the hardness of bamboo for a percussive sound. The set of six saggeypo are tuned to the same relative pitches as the other ensemble instruments, and are also played in an alternating sequence, Ginallupak, with one player per pipe (see musical example: 1, below). Unlike the percussion instruments, however, the breath can be more expressive in sounding the note. (CD Track: 4)

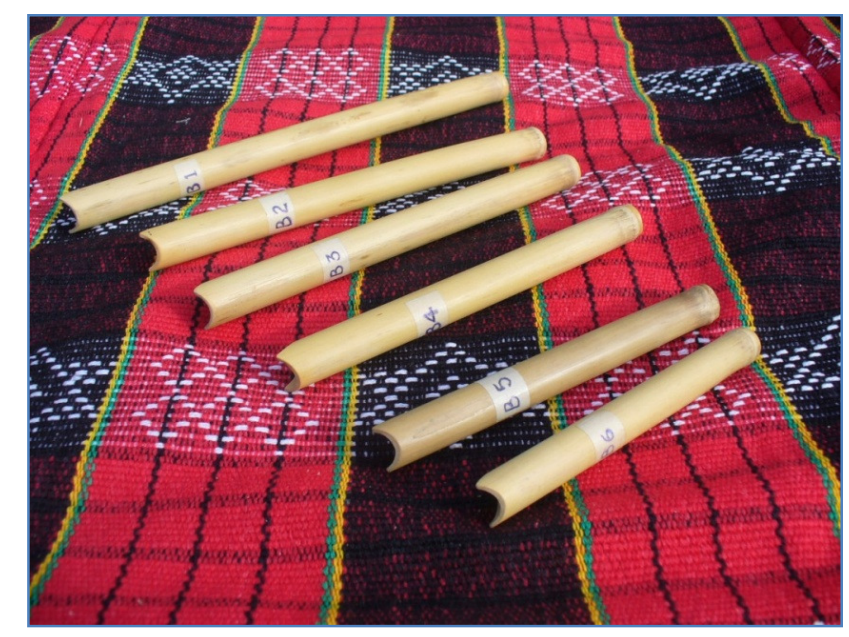

Figure 16: Set of saggeypo (note Beni's labels - the letter B refers to the set). (Photo by author, August 2011) 


\section{Tambi (two string, tube zither)}

The tambi ensemble consists of six, two string zithers. These are more sophisticated in design than the other ensemble instruments, and use the thick walled bamboo, bvuyog. The fibrous skin is carefully carved out and lifted from the body forming two strings. A bamboo striking pad is fitted between the two strings, which are raised using small bamboo bridges. When the pad is stuck the strings resonate and are amplified by the tambi's hollow body via a sound hole below.

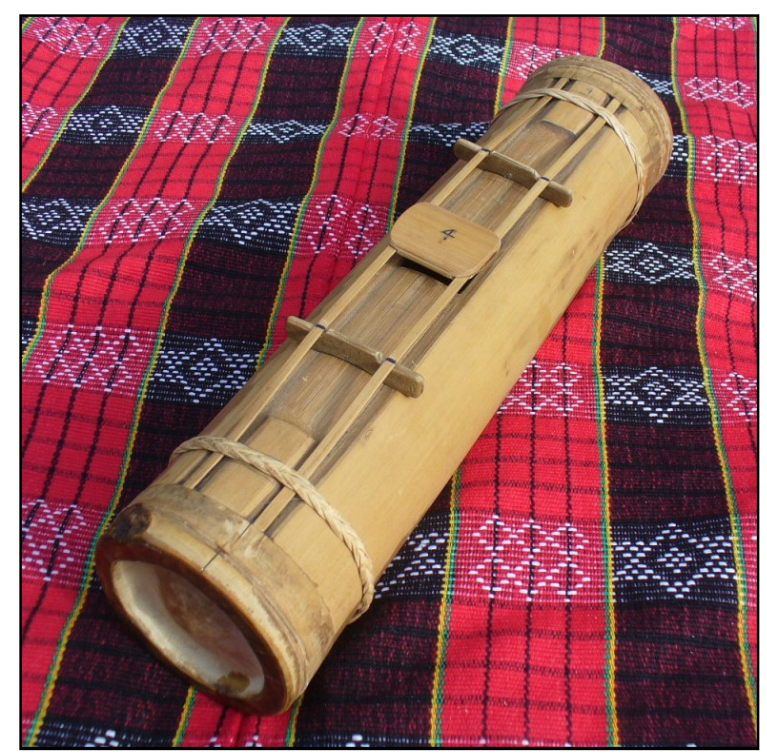

Figure 17: Tambi (two string zither). (Photo by author, August 2011)

\section{Intervallic relationships and timbre}

The process of constructing the bamboo musical instruments allows for the control of two fundamental musical elements: pitch and timbre. Each individual instrument must be crafted for the correct timbre independently from the group, and then tuned to the correct pitch to become an element of an ensemble. Pitch and timbre are conceived as one; the word na suklit is used to describe an ensemble when both these musical elements are correct. This allows for variations of 
the interval relationship of each instrument within an ensemble if the collective, resulting aesthetic is correct.

Each instrument within the ensemble is named as in the gangsa ensemble: balbal is the lowest pitched instrument of the group, and the highest is lalat. Beni also often referred to each instrument by number: number one being balbal and number six being lalat. The sets of instruments are tuned to an anhemitonic pentatonic scale, with interval relationship largely dependent on instrument maker. Beni tends to tune his instruments to a scale defined by the intervals: $\mathrm{T}^{1} / 2, \mathrm{~T}, \mathrm{~T} 1 / 2, \mathrm{~T}, \mathrm{~T}$. In this case, the octave is found between pitches one (balbal) and six (lalat), shown as Interval Relationship A in Table 1 below. However, some of the instrument sets Beni produces have intervallic relationships which do not quite reach the octave, and seem to have the number (1) instrument, (balbal) lifted in pitch by up to a semitone (see relationship B column in the table below). 


\begin{tabular}{|c|c|c|c|}
\hline $\begin{array}{c}\text { Instrument } \\
\text { Number }\end{array}$ & Instrument Name & $\begin{array}{c}\text { Approximate Interval } \\
\text { Relationship A }\end{array}$ & $\begin{array}{c}\text { Approximate Interval } \\
\text { Relationship B }\end{array}$ \\
\hline \multirow[t]{2}{*}{1} & balbal & & \\
\hline & & $\mathrm{T} 1 / 2$ & $\mathrm{~T}$ \\
\hline \multirow[t]{2}{*}{2} & $k a d w a$ & & \\
\hline & & $\mathrm{T}$ & $\mathrm{T}$ \\
\hline \multirow[t]{2}{*}{3} & katlo & & \\
\hline & & $\mathrm{T} 1 / 2$ & $\mathrm{~T} 1 / 2$ \\
\hline \multirow[t]{2}{*}{4} & kapat & & \\
\hline & & $\mathrm{T}$ & $\mathrm{T}$ \\
\hline \multirow[t]{2}{*}{5} & opop (or kalmia) & & \\
\hline & & $\mathrm{T}$ & $\mathrm{T}$ \\
\hline 6 & lalat (or kanom) & & \\
\hline
\end{tabular}

Table 3: Intervallic relationship of instruments

Each set of instruments has slightly different intervallic relationships, and the pitch is only one factor in the success of an ensemble sounding correct (na-suklit); the timbre and texture both play an equally important role in the desired musical aesthetic ${ }^{43}$. The instruments are tuned as a

\footnotetext{
${ }^{43}$ I attempted to tune a kolitong (six string, tube zither) to what I thought was the required scale a number of times but never seemed to be able to find the correct pitches to please Beni. When I tuned the instrument to the scale as defined in Table 1: Interval relationship A, Beni did not like the sound, and raised the balbal (number 1), by a quarter tone to improve the sound and to declare the instrument na suklit.
} 
group; the length of balbal defines the pitch of the entire ensemble. Therefore, the individual instruments cannot be transferred to other ensembles as their pitch will be incorrect. With the instruments' revival, Beni is often requested to tune ensembles (sets of six like instruments) to specific pitches, enabling them to be used alongside guitars and other equal tempered tuned instruments.

\section{Bvungog (pitched, accented sound) and okak (non-pitched sound)}

Although each of the instruments within an ensemble plays only one defined pitch, they all have two sounds of differing timbre: a resonant, accented sound (bvungog) with definite pitch, and a muted sound (okak) with a less defined pitch. It is these two sounds of different timbre that articulate the melodies within the ensemble's cyclic patterns. These two sounds are created using a combination of playing method and construction. The ballingbing (buzzer) and pattanggok (quill shaped percussion tube) both have a finger hole in the body of the instruments. When this is closed, the instrument sounds the fundamental pitch of the resonant cavity of the body bvungog. When the finger hole is open (okak), the pitch sounds a major third higher in the case of the ballingbing, and only a sharp 'clack' of indefinite pitch for the pattanggok. To create bvungog sound on the tongatong (stamping tubes), pattatag (xylophone blades) and the tambi (two sting zither) the player allows the instrument to freely resonate; and for $o k a k$, mutes or dampens the sound with the hand. The saggeypo (closed ended, individual pipes) relies on the articulation of the note to produce an accented or unaccented note. The pitches of both notes are the same, but the player must emphasize, or imitate, the two notes by phrasing with the breath (CD Track: 4). 
Although the instrument ensembles share the same repertoire of musical patterns and pair of differing sounds, each of the instrument types have completely distinct timbre. For example, the ballingbing (buzzer) has a sound rich with bending overtones, and when the ensemble of six are played together, these overtones overlap and interact creating a dense wall of granular buzzing. This is in contrast to the tongatong (stamping tubes) which produce clear, resonant fundamental notes with few harmonics, forming clear melodies in the ensemble. (CD Track: 3, CD Track: 1)

Traditionally, the instruments are always played in ensemble of like instruments only; ensembles of different instruments and timbres were not considered (Benicio Sokkong, June 2007, correspondence). However, this restriction is now relaxed as the context of the instruments changes from traditional ceremonies to new environments, such as church music and cultural displays, where various instruments are played together and also in groups including guitars and keyboards.

\section{Repertoire}

Investigating the repertoire of musical pieces which Beni performs and teaches reveals a concentration and formalisation of the reviving musical tradition. Beni has formed a repertoire for the bamboo ensemble instruments from collecting the different patterns played throughout Kalinga. Unlike the gangsa patterns Tuppayya and Pattang, which are played the same throughout Kalinga, the patterns played on the ensemble bamboo instruments are different from region to region, and are conceived by Kalinga as an identifier of place (Benicio Sokkong, 10 March 2007, interview). Although Beni has a vast knowledge of musical patterns from Kalinga and the Cordillera, he uses only a small collection for teaching and performing which exemplify the music of the Kalinga region. The musical pieces do not have individual titles, but are referred 
to by the name of the instrument of which the ensemble consists. For example, if a person from Sukiap says 'let's play pattanggok', they would play their local pattern on the pattanggok. However, if that same ensemble wanted to play music from a tribe of another location, they would call the piece binubut, meaning: 'from the place Butbut ${ }^{44}$, As Beni explained:

Every piece ... is a piece from this place, a piece from this place, although they are all Kalinga. So we each have our own piece, but we don't know who made this piece. It's just been transferred from each generation until now. So what we are also doing is transferring this kind of music to the younger ones. And I hope they will still be doing that after our work [the revival]. (Benicio Sokkong, 10 March 2007, interview)

Beni uses his collection of musical pieces to teach and perform to a range of audiences; from young school children and church youth groups in the Philippines, to Kalinga living overseas, to international jazz musicians and academics.

In this way the music has multiple contemporary functions: the music is taught to Filipinos to maintain the tradition of their home land, and in the case of Universities, the music is used to provide an experience of another culture's musical tradition.

The university audience can be divided into two categories: students of ethnomusicology, and students of composition. Although each group has a different approach to the music, Beni uses the same workshop format teaching both sets of students the same repertoire. Composition students, however, tend to focus more on the sonic characteristics of the instruments and their possible use in contemporary music. Beni's pragmatic approach encourages this use of the instruments as a way of reviving and disseminating Kalinga music, however, he does insist on

\footnotetext{
${ }^{44}$ Butbut is a municipality in the province of Kalinga
} 
students learning the Kalinga musical patterns first, and understanding and appreciating the music's historical contexts.

We are composing for a new approach of how to re-educate these people from the city who do not know [what] their culture is. They don't even know how to play. And how are you going to get them into this kind of re-education is to play a new composition. This is entertaining to them and acceptable. Before doing that you have to play first the traditional. (Benicio Sokkong, 10 March 2007, interview)

In the above quote, Beni acknowledges that many young Kalinga living in urban centres are unfamiliar with their cultural heritage. By featuring the bamboo instruments in contemporary music, young Kalinga are introduced to the music traditions in an accessible way.

\section{The musical patterns}

The ensemble patterns of the bamboo musical instruments are based on an alternating pattern between pitched and non-pitched (or muted) sounds, resulting in a repeating ascending melodic cycle, which in its most basic form is called Ginallupak. This is closely related to the gangsa patterns, Tuppayya and Pattang.

\section{Ginallupak}

Ginallupak is played by each player alternating between the bvungog and the okak sounds at a given two beat pulse. The instruments balbal (1), katlo (3) and opop (kalima) (5) all sound their accented (pitched) note (bvungog) on the down beat, while kadwa (2), kapat (4) and lalat (kanom) (6) on the upbeat. This results in a melodic texture produced by the accented, pitched notes, and numerous overtones, depending on the instrumentation. The most significant resultant melody is of ascending pitches as each instrument sounds the pitched note. The pattern is always 
begun by balbal, which defines the meter and the volume. In a traditional context, the music will continue until the dancing, walking or ceremony is complete.

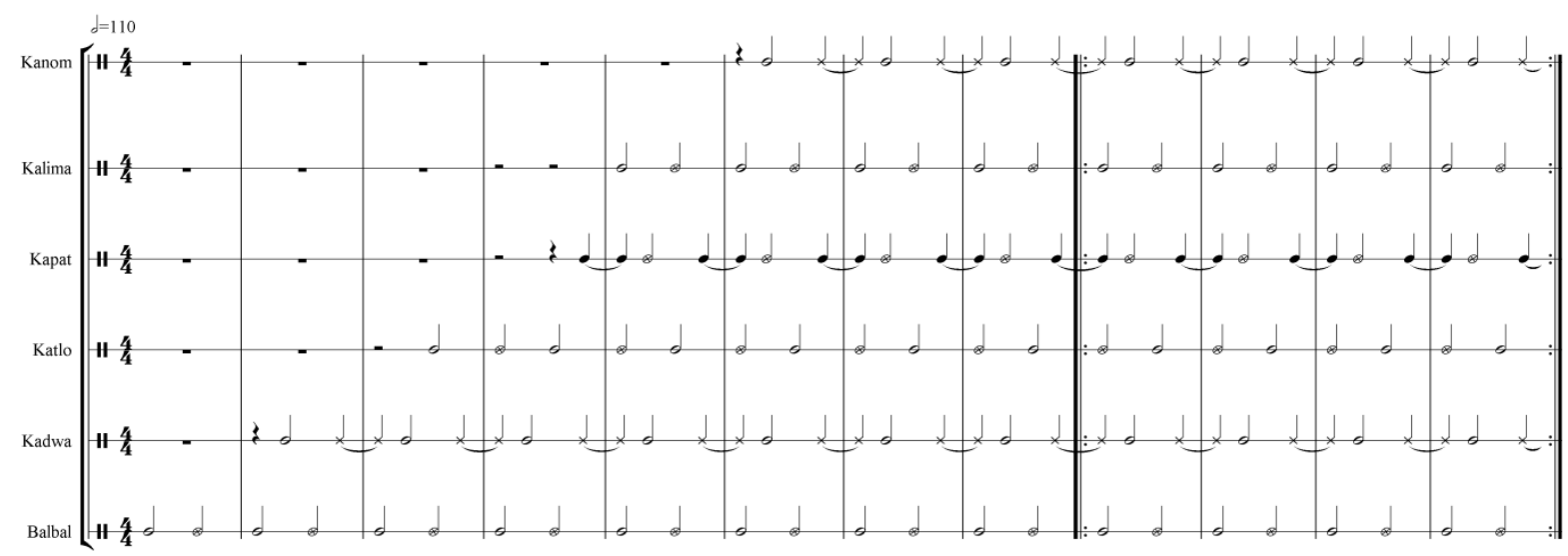

Musical Example 1: Transcription of Ginallupak (Alternation)

\section{Tuppayya and Pattang}

The Tuppayya (flat gong pattern played with the palms of the hands) and Pattang (flat gong pattern played with a wooden beater) patterns are also an alternations, offset by a beat. However, unlike the Ginallupak, the fundamental pattern of Tuppayya and Pattang has a four beat pulse where the accented beat is the first beat, followed by three muted beats as shown in Figure 11 below. Beni will often use this as a starting point when teaching both the ensemble bamboo instruments and solo instruments, such as the kolitong (six string tube zither). 


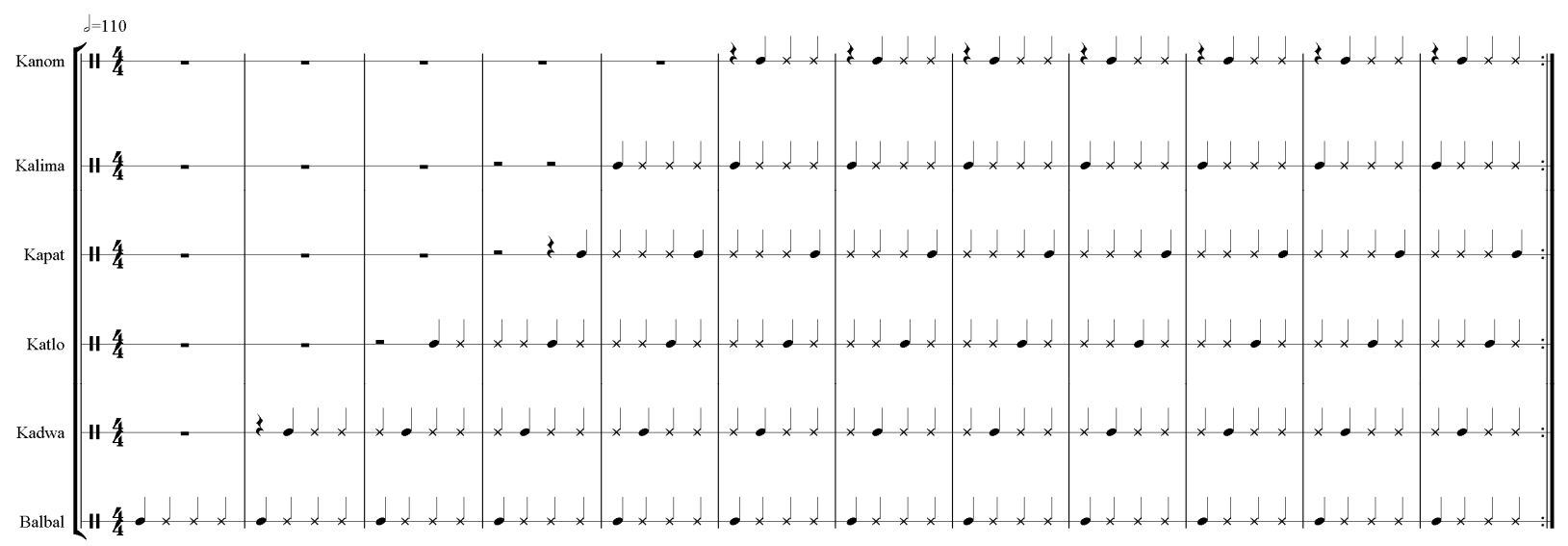

Musical Example 2: Fundamental pattern of the Tuppayya and Pattang

The example above shows the fundamental pattern where the ascending cycle is extended throughout all the instruments. In practise, however, the two highest pitched instruments, opop and lalat, will play slightly different patterns. The accented (pitched) note of opop will sound in the first and third beat of the bar, and lalat will improvise on the basic pattern. These two instruments articulate the melody and set it apart from the ostinato of the lower three instruments. The greater shape and form of the music is created by variations improvised by certain players: balbal (1) and lalat (6). Balbal leads the ensemble by defining the volume and meter of the music, and also where accents are placed within the four beat cell. For example, the balbal will often accent (by sounding the pitched bvungog note) the fourth beat of the cycle every four cycles or more, depending on the intensity of the music. Lalat articulates the resulting melodies by playing an eight beat phrase. The most common rhythm of this phrase is shown below, however, the player of lalat can provide variation (Benicio Sokkong, 28 February 2007, interview). 


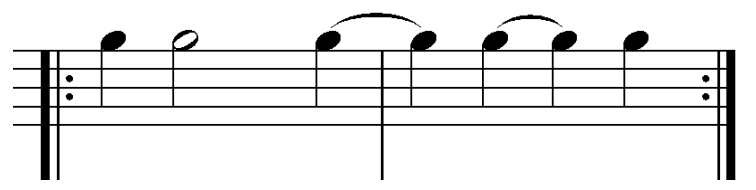

Musical Example 3: lalat eight beat phrase

\section{Binutbut}

Binutbut translates to 'from the place Butbut' (Benicio Sokkong, 10 March 2007, interview), and is a pattern where balbal, kadwa and katlo play the alternating rhythm pattern, similar to Ginallupak, but consisting of all accented, pitched notes (bvungog). The upper three instruments form a two bar (eight beat) phrase.

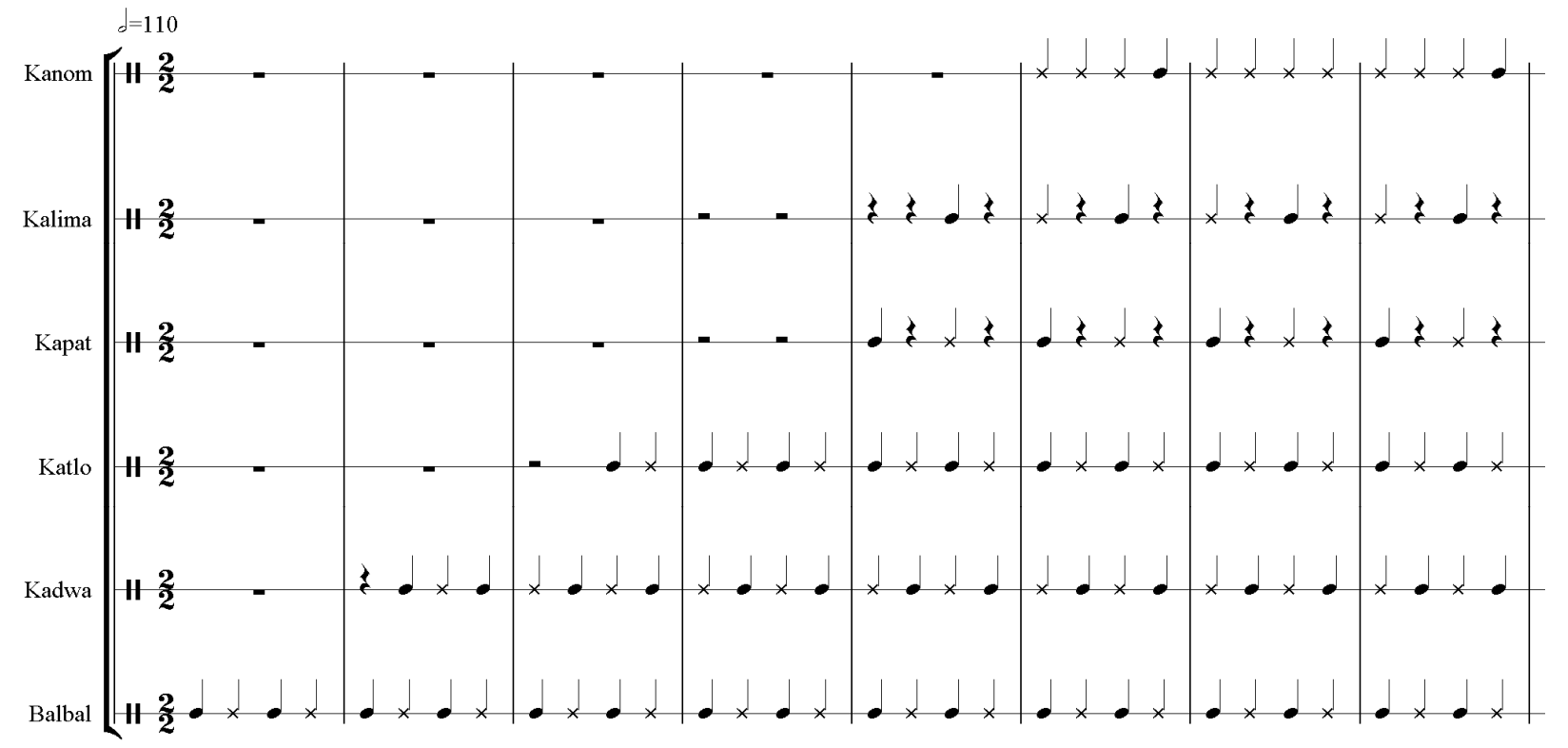

Musical Example 4: Transcription of Binutbut pattern 


\section{Tinglayan}

Like Binutbut, the pattern Tinglayan takes its name from a municipality in Kalinga. Tinglayan is also played with a similar constant two beat pulse where all players sound the pulse with the indefinite pitch sound (okak). Then the leader of the group, playing balbal, will sound (bvungog) two beats, indicating for kadwa player to sound his two on the two following beats. This round continues until the sixth, lalat, is sounded with a phrase of a beat, two half beats, and a beat (as shown below). Tinglayan is very game-like: everyone quietly sounds their instrument with the muted okak, together articulating the pulse, while listening for the cue to begin the ascending pattern. It is quite easy for a player to miss the cue (the previous pitch sounded), and therefore miss their sounded beats. (CD Track: 1)

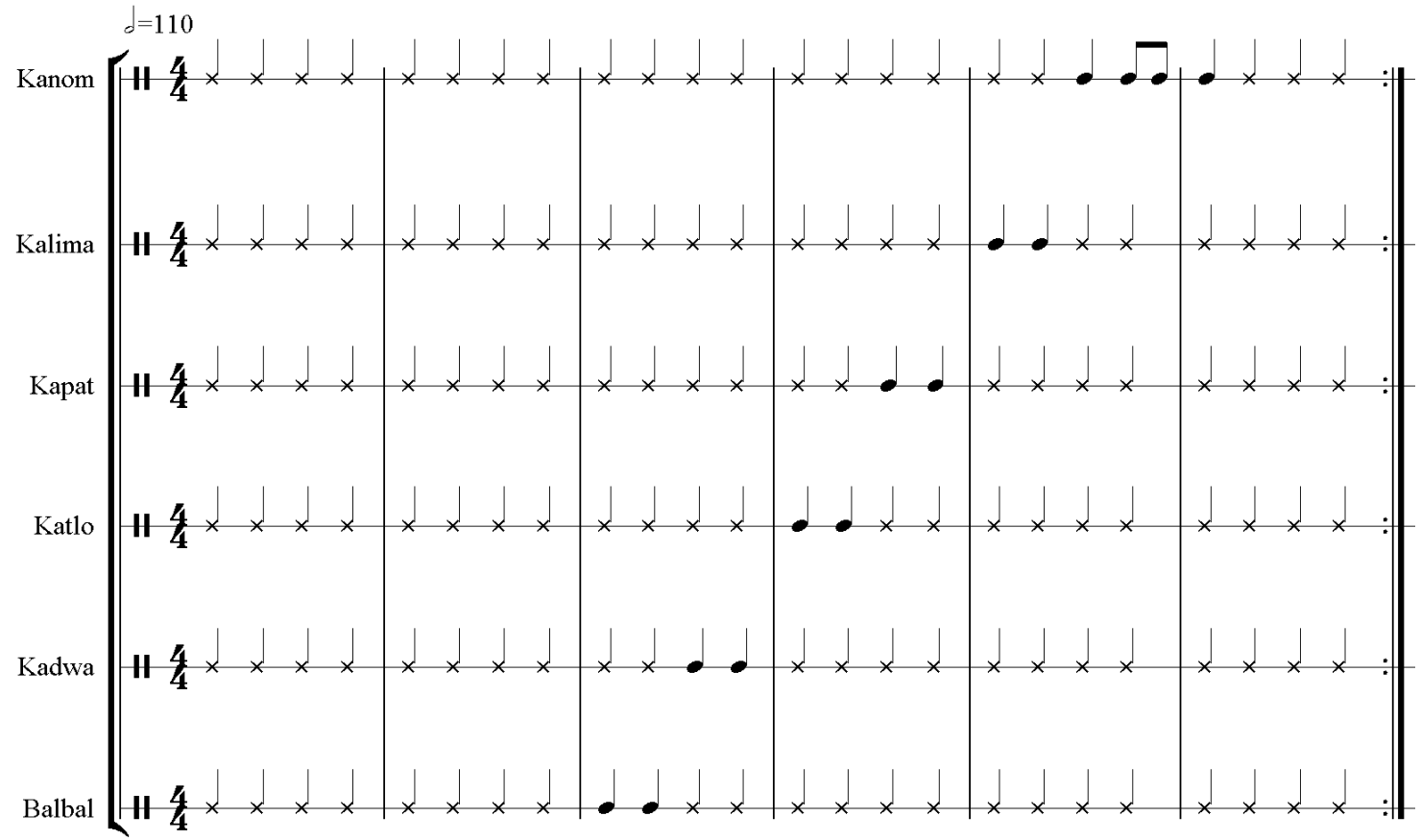

Musical Example 5: Transcription of Tinglayan pattern 


\section{Resultant Melodies}

When an ensemble is said to be na suklit (sounding correct), a larger shape and form can be heard in the ensemble music. The sounds of the individual instruments interact and become grouped by the listener's ear. Although the entire ensemble articulates an ascending melody in all of the musical patterns described above, the music can be decomposed into two components: melody created by the upper voices, and a pulsing ostinato in the lower voices. How these voices are divided into melody and accompaniment determines the individual patterns and what makes them identifiable. I use the term melody as Beni does when describing the tune in the upper voices of the ensembles. These are usually variations on pre-prescribed rhythmic patterns where the players together articulate different melodies. These variations give the musical patterns long-term shape and form by controlling the intensity of the music. Gentle quiet tapping of regular rhythms in the upper voices create periods of calm in the music, while loud, constant variations of the rhythms patterns heighten the excitement of the music, and therefore the dancers and audience ${ }^{45}$.

\footnotetext{
${ }^{45}$ José Maceda suggested South East Asian music is a combination of drone and melody, where drone can be an ostinato of gongs, and melody articulated with wind instruments (1986:12-15, 1998:57-58). These characteristics can be found in the musical patterns of Kalinga ensemble music. Although the entire ensemble consists of a repeating pattern or ostinato (what Maceda would term drone), certain notes escape the whole, and articulate melodies.
} 
In the transcriptions below, the upper melody (upper stave) arcs over the accompanying ostinato (the lower stave).

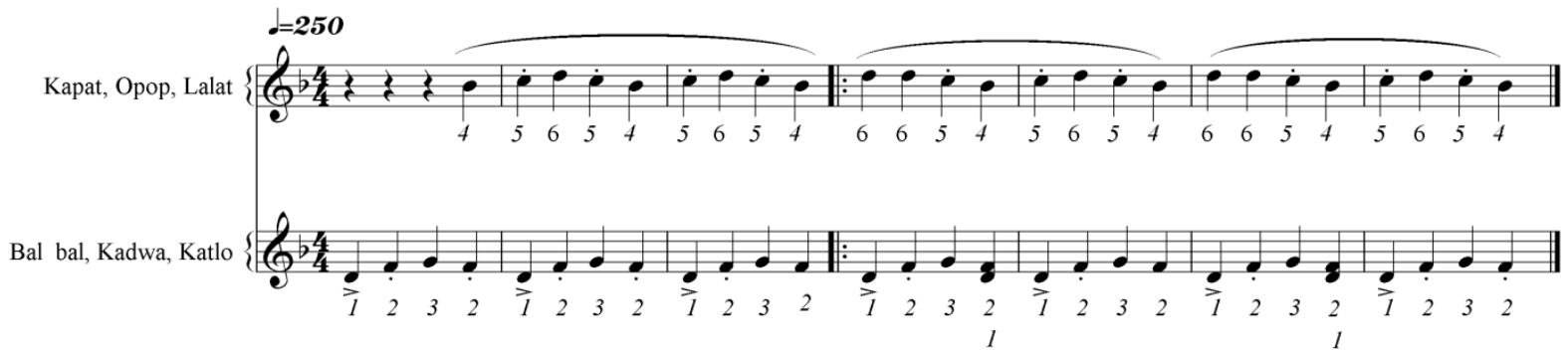

Musical Example 6: Resultant Melodies of Tuppayya

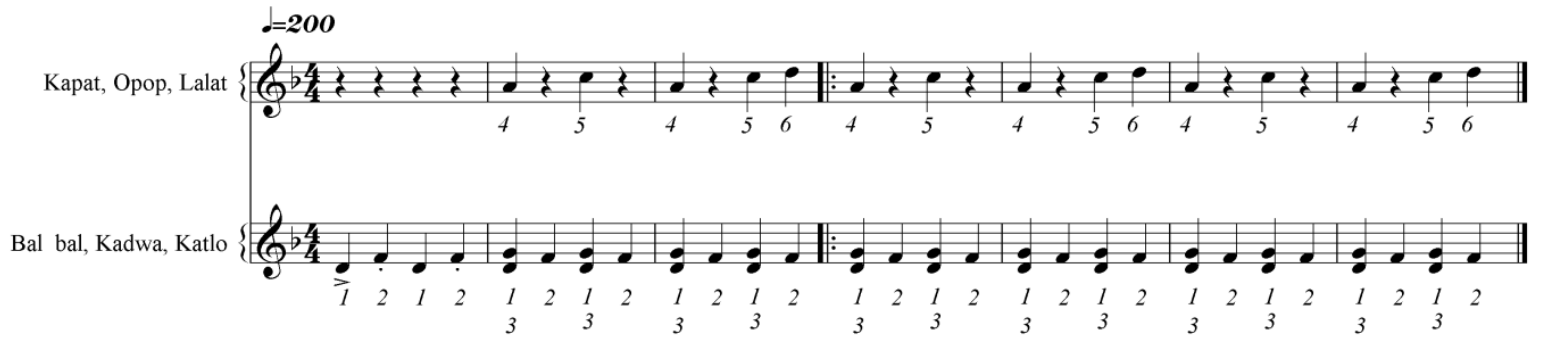

Musical Example 7: Resultant Melodies of Binutbut (CD Track: 6)

Musical Example 8: Resultant Melodies of Tinglayan (CD Track: 1) 


\section{Representation, Meaning and the Aesthetic}

One of my first insights into the deeper connections of ensemble music with Kalinga society was clearly articulated during Beni's introductory workshops on the bamboo ensemble instruments, in Wellington in 2007. Beni described the six instruments of an ensemble as a representation of the community, each instrument representing participants within it: elders, fathers, mothers, unmarried men, unmarried women, and children.

\begin{tabular}{ccc}
\hline Degree of scale & Name & Representation \\
\hline 1 & balbal & elders \\
2 & kadwa & fathers \\
3 & katlo & mothers \\
4 & kapat & unmarried men \\
5 & opop (kalima) & unmarried women \\
6 & lalat (kanom) & children \\
\hline
\end{tabular}

Table 4: The Musical Community

Beni went on to explain how the instrument balbal (the lowest pitched instrument) could steer the music by manipulating the volume and pace of the music, therefore controlling the intensity. Balbal also begins the music and will play a number of cycles before the kadwa enters at the volume and pace defined by balbal. He explained that the elders control 'the dynamics of community life... they decide when to do the [musical] variation' (Benicio Sokkong, February 2007, correspondence). This led me to assume that the player of balbal is the most important, but Beni corrected me explaining that the music '... means nothing without all of them present...All of them [the instruments of the ensemble] are important' (Benicio Sokkong, 10 March 2007, interview). This reflects the social interaction of the Kalinga community at multiple levels, 
where the decisions of the community are shaped by the elders, but finally determined by the group through open discussion where everybody is entitled to have their say (Benicio Sokkong, July 2007, correspondence). Without the entire community playing their part, the ensemble cannot make music, and each individual instrument played alone is meaningless.

This concept of community in the Philippines has been acknowledged by Ricardo D. Trimillos, a Filipino-American ethnomusicologist (2004). Trimillos identifies this feature within Filipino society and music making as pagkapwa, 'the continual awareness of others'. Pagkapwa 'emphasizes identity of an individual in relation to a group rather than the individual as a social isolate $^{46}(2004: 32)$. Trimillos finds a musical example of this in the Spanish-Filipino tradition of rondalla, a plucked string band.

Each musician, through 'peripheral hearing', is constantly aware of the totality of the ensemble and able to adjust to any changes or developments, whether caused by design or chance (2004).

Thomas Turino describes a similar concept when explaining the ensembles of Peruvian Altiplano. Turino writes:

When the Conimeños say that a good ensemble is one that "plays like one instrument" and that no individual instrument should "escape" from the dense, integrated fabric of the ensemble's performance, they are talking about sound, but they are also articulating a certain vision of the relationship between the individual and the community... (1993:55)

This concept of pagkapwa is articulated by the members of the community when playing the ensemble music of the Kalinga. A player within the ensemble must listen intently to the musical whole and constantly modify his or her playing to feedback into the fabric of the music. As Beni explained to me while teaching the bamboo ensemble instruments:

\footnotetext{
${ }^{46}$ Pag is translated to: co-operation, and Kapwa is translated to: fellow being, in the book The Philippines: a global studies handbook by Damon L. Woods (2006:233)
} 
You have to respect the others sounds... you cannot go louder than him. There is the understanding of the music (Benicio Sokkong, 28 February 2007, interview).

The ensemble music is an expression and re-enforcement of the concept of community

(Chernoff, 1979). Individuals participate in the activity by each playing a single note within a collective melody. Although playing the same instrument and essentially the same musical pattern, the player must articulate their part within the ensemble. To do this, they must also conceive of the music as a whole, and the group must play as one. As Beni explained, there is no music if only one instrument is played. 


\section{The Bamboo Solo Instruments}

The function of the bamboo solo instruments is entirely different from the ensemble instruments. Unlike the ensemble instruments which are associated with rituals and ceremonies, the solo instruments are played while relaxing in the evenings or serenading a potential marriage partner. In the case of the bamboo flutes, the music is related to the voice and songs, and the kolitong (six string tube zither) and the kulibaw (the jaw harp) imitate the melodies of the gangsa ensembles.

\section{The Solo Melodic Instruments}

\section{Paldong (lip-valley mouth flute)}

The paldong is a bamboo mouth flute made from bvulo using two sections of internode with a single node. The section of bvulo is taken from the tips of the dried culms where the diameter is one to three centimetres, and the internodes are long, 30 to 50 centimetres. Three finger holes and a thumb hole are located in the lower half of the upper internode, the thumb hole is placed halfway between the node and the mouth piece. A small hole is also made through the node within the flute. This hole allows less breath to be used to sound the flute. The mouth piece is formed by two opposing diagonal cuts creating an asymmetrical peak, known as lip-valley flute (Maceda, 1998:19). The flute is played by placing the lower lip on the longer of the cuts, the resonance created by the breath over the opposing edge. 


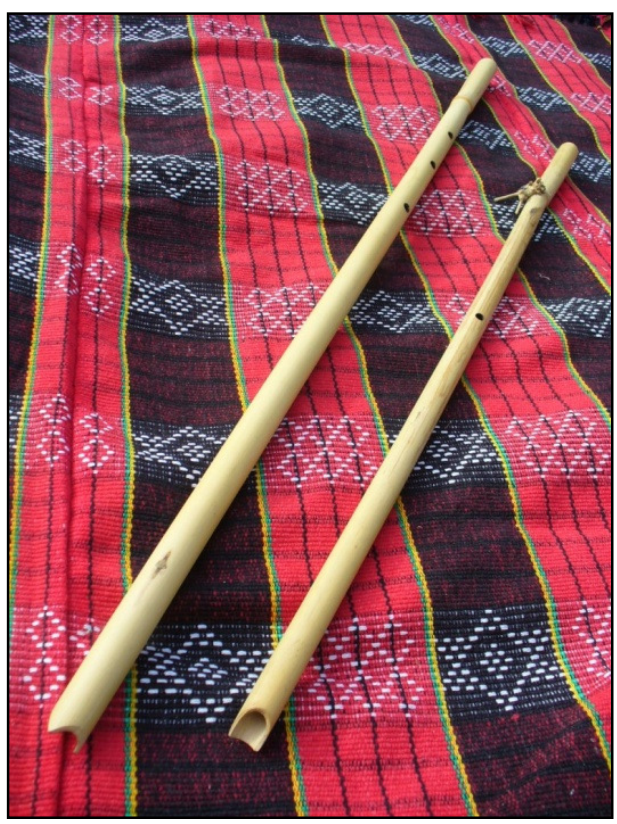

Figure 18: Paldong (lip valley flute). (Photo by author, August 2011)

\section{Tongali (nose flute)}

The tongali is a bamboo nose flute. The word tongali is derived from $e$ ungay - for the nose.

Like the paldong, the tongali is also constructed from the long thin tips of the bvulo culm, although the section used is a single internode with a node at each end. A small hole, approximately $5 \mathrm{~mm}$ in diameter, is made through the closed node to create the blown end. The node at the other end is opened completely.

To sound the tongali, the flute is held at an angle to a single nostril, and easily sounded with gentle breath. However, sounding the flute with volume while controlling pitch takes a significant amount of skill and manipulation of breath. 


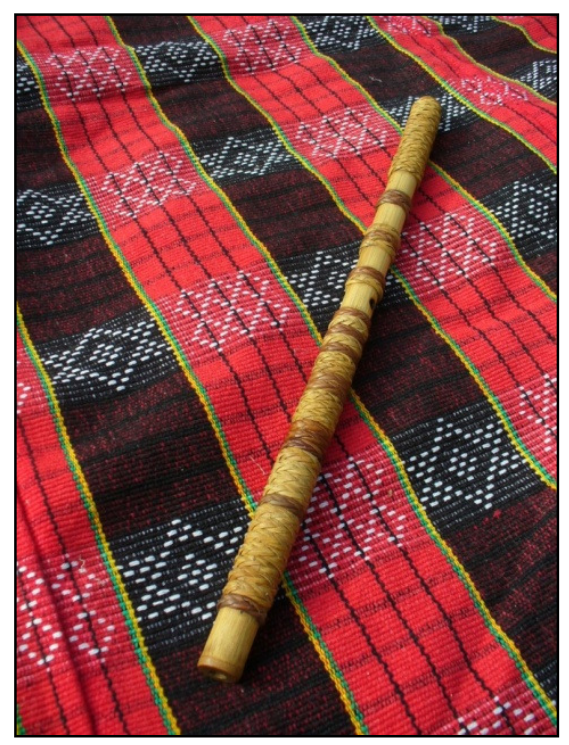

Figure 19: A tongali (bamboo nose flute) made by Fidel Tayawa (the weaved rattan rings are decorative). The back side is shown with the thumb hole visible. (Photo by author, August 2011)

The measurements used to determine the spacing of the finger holes of both the paldong (mouth flute) and the tongali (nose flute) are based on finger spans and eye ${ }^{47}$. Beni uses techniques which he has refined through years of manufacture, as well as discussions with other makers. Although it is roughly based on a rule of finger widths, Beni also uses his experience to determine the actual locations of the holes. Beni's method is to divide the total length in half to locate the thumb hole, and then the finger holes are measured from there. The first is two finger widths below the thumb hole, the second is three widths below the first, and the third and final is two widths from the second, as shown in figure 20 below. This method of construction produces flutes with a range of variations of anhemitonic pentatonic tuning, as is also the case with the ensemble instruments.

\footnotetext{
${ }^{47}$ In an attempt to expose differences and similarities in the tuning systems found throughout the Philippines, José Maceda investigated the pitches of bamboo flutes (Maceda, 1990). In the article presenting the research, In Search of a Source of Pentatonic Hemitonic and Anhemetonic Scales in South East Asia, Maceda compares the tunings of a variety of mouth flutes and describes a divisive system of defining the pitches.
} 


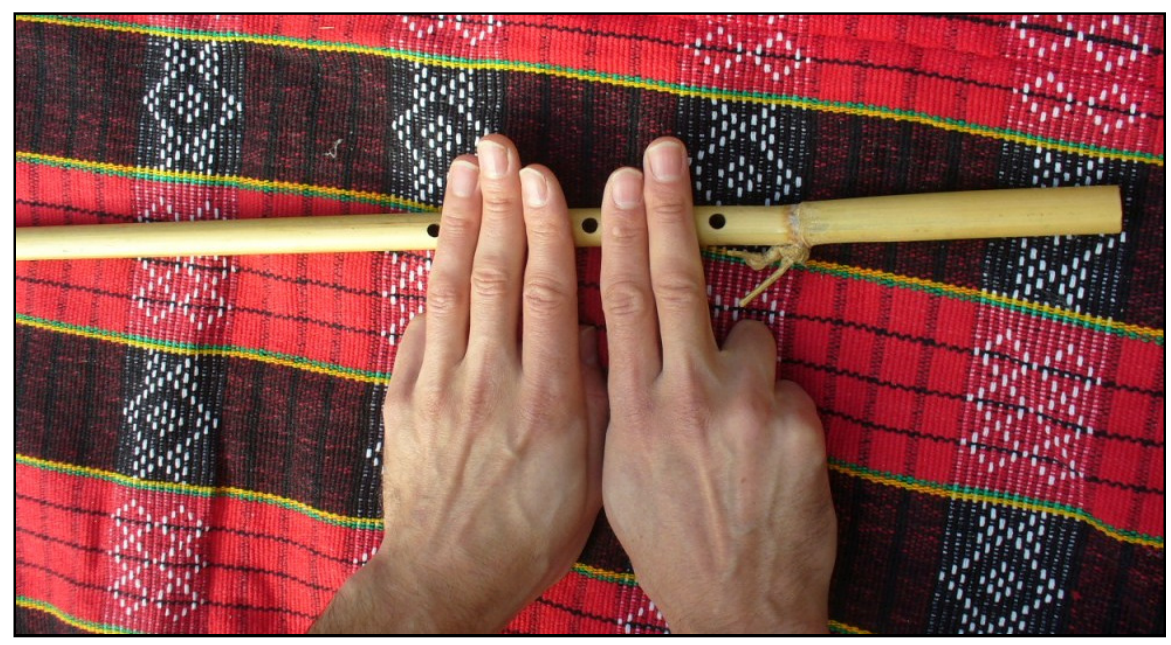

Figure 20: Paldong hole spacing using finger widths as a guide. (Photo by author, August 2011)

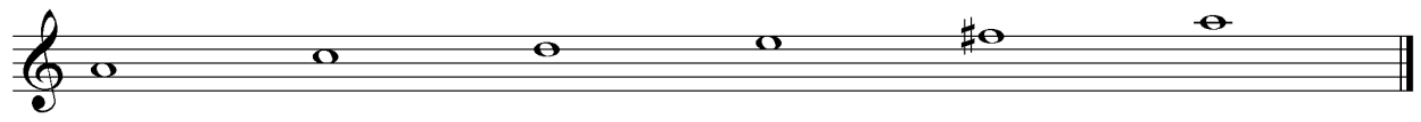

Musical Example 9: Example of paldong tuning made by Beni (CD Track: 7)

\section{The melodies}

The melodies played on both the paldong and tongali draw inspiration from traditional songs such as Ullalim (CD Track: 15) and Uggayyum (CD Track: 1) (Benicio Sokkong, February 2007, correspondence). Both the paldong and the tongali have the ability to convey individual emotion. A common melody is Annoywoy which Beni described as the 'crying tune'. I heard Annoywoy played most often, in the evenings in Sukiap, though each performance was personalised by the player. This personalization is a type of variation on a set tune; the melody is always apparent, although the phrasing, meter, and in some cases, ornamentation differs. During the relaxed 
sessions on Gallming's veranda in Sukiap ${ }^{48}$, the players I heard varied widely in ability, which was reflected in their individual interpretations of Annoywoy. (CD Track: 7)

The repertoire of musical pieces for the flutes is increasing and becoming more diverse as the contexts of the flute music change from historical rural locations to urban performances. New melodies are formed through imitation of folk song and participation in new genres. An interesting example was a performance by Beni’s cousin, Fidel Tayawa in Gobgob, Kalinga during my fieldwork. As a member of the performance group Pasiking, Fidel has travelled and performed internationally, and has worked with Beni making instruments. Beni's influence has enabled Fidel to recognise the significance of the instrumental traditions and become a specialist allowing him to devolve his repertoire of the flute music. Fidel played an interpretation of the Ullalim, a form of song-poetry which tells the traditional epic stories of the Kalinga ${ }^{49}$. The same piece also includes the popular folk song in the Cordillera, Salidummay (CD Track: 8). The piece does not directly imitate either the Ullalim or Salidummay due to the tuning of the flute, but is an interpretation, perhaps an improvisation, on the musical themes. In a local, context Fidel is mixing music considered to be traditional and authentic with new contemporary musical ideas, to develop the complexity of the music and extend the repertoire ${ }^{50}$.

\footnotetext{
${ }^{48}$ See Chapter 4

${ }^{49}$ See Francisco Billiet The Kalinga Ullalim: Studies on Kalinga Ullalim (1970).

${ }^{50}$ Alex Tumapang of Pasiking, is also involved in the development of the flute music, playing the tongali in the Baguio ethnic/reggae band P'tune along with guitar, bass, drum kits and gangsa.
} 
As a specialist musician and teacher, Beni is required to perform authentic, traditional flute music to both local and international audiences. To do this, Beni draws on his musical knowledge as a Kalinga, and years of researching in the field ${ }^{51}$.

In contrast to traditional flutes performances, Beni is also involved in contemporary compositions and collaborations of improvised music. During the 2007 Asian Composers League Conference in Wellington, Beni performed in art music concerts, played as a guest musician with a New Zealand group using Māori instruments (taonga puoro) and guitars, and in a free improvisation session with the Māori instrument specialist, Richard Nunns, in a jazz club. In these performances, Beni navigates the musical contexts by drawing on his experiences in the academic world and international travel, where he has been exposed to western concepts of improvisation and art music, and amalgamates them with his knowledge of the traditional music.

\section{Solo Percussion Instruments}

\section{Kolitong or kolibit}

The kolitong is a bamboo tube zither made from the thick walled bamboo bvuyog. The six strings of the zither are carefully carved and lifted from the tube and raised with small bridges to allow free vibration and tuning. The six strings are divided into two groups of three; one group played by the left hand and the other the right. The kolitong is held between the heels of the player's hands allowing the free fingers to pluck the strings. The music of the kolitong imitates the music

\footnotetext{
${ }^{51}$ Recordings of Beni playing the traditional melodies Oynasi and Nan ani are on the CD which accompanies this thesis. (CD Track: 9, CD Track: 10)
} 
of the gangsa and therefore is tuned to the same intervals as bamboo ensemble instruments (as shown in Table 2 above).

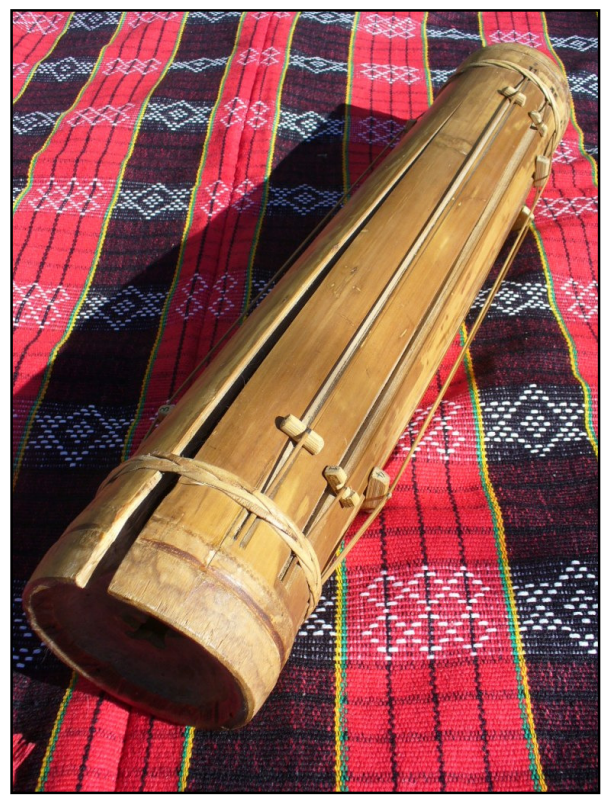

Figure 21: Kolitong or kolibit (six string bamboo tube zither). (Photo by author, August 2011)

\section{Kulibaw}

The kulibaw, the bamboo jaw harp, is also carved and scraped from the thick walled bamboo, bvuyog. Beni's kulibaw are typically around twenty centimetres in length, with the tongue approximately ten centimetres long. The wide flat end of the instrument is held in the hand with the mouth centred on the thin vibrating tongue in the centre. The other hand is used to flick the thin stem at the opposing end which sends the tongue into vibration. 

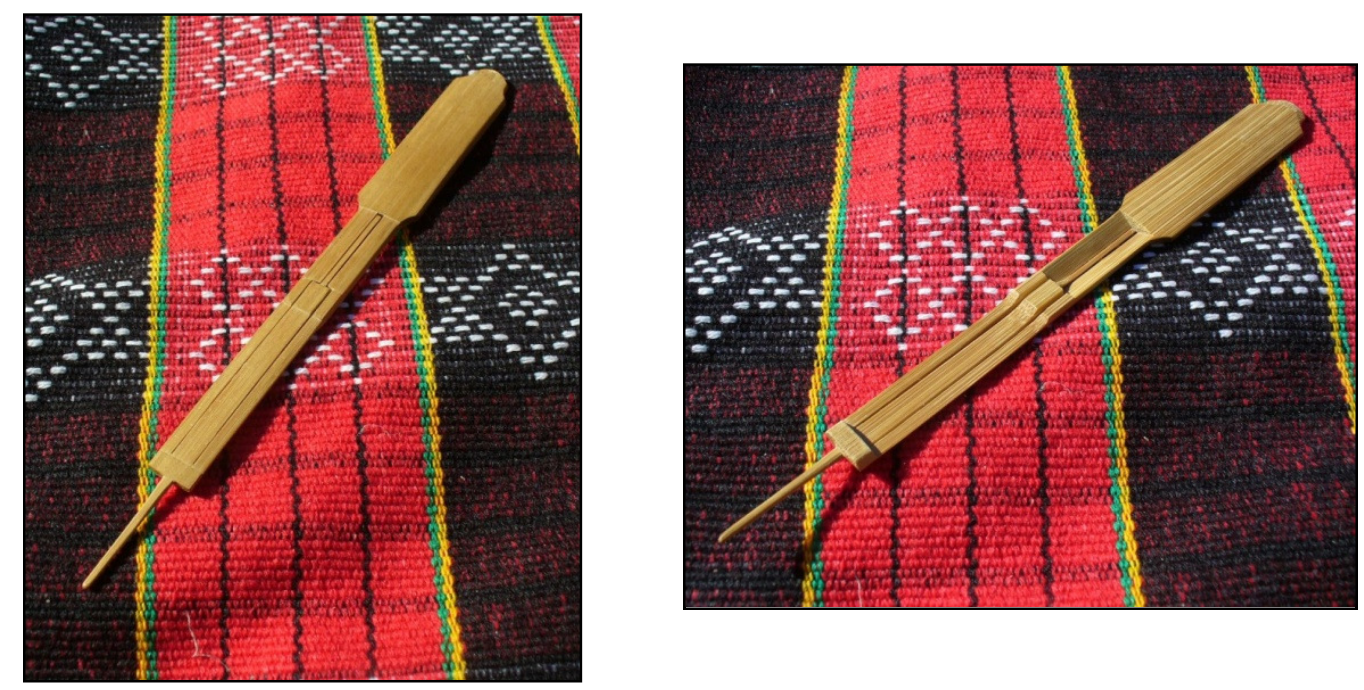

Figure 22: Kulibaw outer face (left), and inner face showing construction (right). (Photo by author, August 2011)

\section{The music of the solo percussion instruments}

The music of both the kolitong (six string tube zither) and the kulibaw (the jaw harp) imitate the gangsa ensemble. The desired sonic and musical effect of both instruments is the cycling ascending melodies of the gangsa. The kulibaw is the most common solo instrument which people 'have a go' at performing an interpretation of Tuppayya of the gangsa. The rhythms can easily be played, however, articulating the melody is far more difficult. Accentuating the overtones by manipulating the mouth and throat cavity to form the melody requires many hours of practise, and trial and error (Benicio Sokkong, February 2007, correspondence). Accomplished players, such as Fidel Tayawa and Beni, can freely articulate the Tuppayya, improvise on the pattern, and create the sound of the gangsa (CD Track: 1).

Each string of the kolitong is tuned to one of the gangsa ensemble's six pitches and is played in the exact pattern of the gangsa music: Tuppayya (CD Track: 12, 13). Players of the kolitong vary 
the accents and dynamics of the patterns throughout a performance just as a gangsa ensemble does. These personalised and improvisory aspects of a kolitong performance are found in the left hand playing the pitch numbers five, six and sometimes four, as in a Tuppaya performed in an instrumental ensemble. 


\section{Learning the Music: imbibe and imitate}

Learning a music tradition is a complex and dynamic process, and interpreting this process is key to understanding a music culture and an individual's experience of music (Merriam 1964:145; Rice 2003:66). In Timothy Rice's study of Bulgarian music, learning is viewed as a social process which defines who plays music and why, and therefore, how traditions are maintained (Rice 1994:42, 64). In the case of the Kalinga music, the motivations for learning the traditions are changing, along with the musical contexts. Individuals and communities now learn the music traditions for different reasons than their ancestors, however, the social practise of learning retains historical or traditional elements, which involve demonstration, observation, imitation, and peer learning. Beni uses elements of both traditional learning and modern teaching methods, and, unlike in the past, where such a position did not exist within Kalinga communities, his role as a teacher is acknowledged. Whether the audiences are ethnomusicology students at a university, or members of his own community, Beni employs traditional methods of learning such as demonstration and imitation, allowing students to learn through trial and error. However, in university environments, Beni also uses various forms of notation, graphical representation, and explanation, which are not used in his own community.

Throughout my fieldwork, Beni used two words to describe the learning process: imbibe and imitate. Beni translated imbibe as 'elong $i$ : to put inside'. Historically, an individual's life would be punctuated by ceremonies and ritual involving music, such as a child's dedication ceremony, weddings and house blessings. Through these experiences, the music patterns are absorbed through repetition and become familiar. 
The motor skills involved in playing the instruments are developed through imitation - hearing and seeing the music played by adults at these events. Imitation is a means of learning found in all aspects of life in Kalinga. It is not common to see parents and adults engage directly in the teaching of the instruments, or other daily life skills, so children rely on imitation and peer learning to develop musical skills (Benicio Sokkong, 10 March 2007, interview). As Timothy Rice identifies in his book May it fill Your Soul, the bamboo instruments were traditionally 'learned and not taught' (1994).

Beni uses the terms imbibe and imitate to differentiate from the western, institutionalised methods of learning such as notation. Although in workshops and classrooms Beni introduces and teaches the music of the bamboo instruments within three or four workshops using institutionalised teaching methods, he always places emphasis on a deeper understanding of the music, which can only be achieved through living with the music or having an ancestral connection. This deeper understanding includes not only a wider knowledge of the historical contexts of the instruments but also the power they embody in creating a contemporary ethnic identity.

\section{Verbal Transmission}

My first formal interview question to Beni was to ask him the Kalinga terms for the English words 'music' and the word 'bamboo'. As with other cultures, I was aware that these words might not exist and, of course, Beni's answer was that there is no single word for either 'music' or 'bamboo'. As my research developed and I learnt more about the Kalinga music traditions, I came to realise that language was not the primary means of transferring the music and only a 'limited' vocabulary of words relating to music existed, and none, with exception of the names of instruments and repertoire, are exclusive to music. Words used to describe physical features of 
the instruments are derived from the human body such as jila which translates to tongue, and long-eg translating to body. The words describing the two different sounds produced by a single ensemble instruments okak and bvungog are onomatopoeic.

Beni uses one particular word to describe aspects of the music: suklit. This word functions on a number of levels within the processes of music-making and is in embedded in the aesthetic concept of the music held by Kalinga. The word suklit is used to denote the correct tuning of an instrument whether it is a single gangsa (flat gong) or a complete ballingbing ensemble (bamboo buzzers). There is no distinction between desired timbre and desired tuning; both of these musical elements are merely parts which result in the complete sound. Suklit also is used to describe when the melody and tuning is correct in both an ensemble of bamboo instruments, and a solo bamboo flute. Benedict Damagon is a cousin of Beni's, a member of Pasiking, and a maker of bamboo instruments. He translated na suklit as '... when you can find the different sounds of the kolitong...or if you can find all the sounds, and it's ok: na suklit' (Benedict Damagon, 1 May 2010, interview). During a conversation with Beni’s sister, Imelda, I also inquired about the translation of suklit, without suggesting the context of music. Imelda explained you would say na suklit when you are weaving a pasiking (rattan backpack) and the pattern was correct. Although Beni uses few Kalinga words when teaching and discussing the instruments, the term suklit does suggest a complex concept of sound and aesthetics held by the Kalinga. Beni and his colleagues share this knowledge, and, although it is not directly articulated in the teaching of the music, pass on the concept of suklit through other means, such as demonstration and imitation. 


\section{Traditional means of learning}

Before the current revival of the bamboo music, the ensemble instruments were a component embedded in specific ritualistic or ceremonial events. The music at these events was not restricted to specialised musicians, but was played by all members of the community; everyone participated in the music making in some form, depending on sex and age, and therefore everyone in the community learnt the traditions (Sokkong, personal communication, 2007). The learning of these traditions was part of life in the community, and can be considered a process of encultration where music is 'learned and not taught' as Timothy Rice described with reference to Bulgarian music (1994, 2003: 74).

Beni's first memories of music are of seeing and hearing the gangsa (flat gong ensemble) being played while with his father during bodong celebrations (peace pact). After seeing them played, he would then sneak the gangsa away with his friends and play in imitation of his father (Benicio Sokkong, 20 February 2007, interview; Fidel Tayawa, 20 June 2007, interview). This is similar with many aspects of life in Kalinga, where young boys learn through watching carefully and then imitating their fathers. In the case of the gangsa this imitation is often kept secret as Beni said 'You have to steal the flat gongs. I'd go with my cousins to a place where we can't be heard by the others' (2007). This method of transferring knowledge from father to son is an unspoken agreement. Fathers do not openly encourage their sons to learn the ensemble instruments because the music should not be played out of the context of a certain rituals, thus there is no official opportunity to learn. As Beni said 'my father would say 'these cannot be played [gangsa], we aren't going to butcher something'. However, the children must practice and imitate to learn the traditions. When asked Beni if his father would actually articulate his disapproval and if he would get in trouble for 'stealing' the gongs, he replied 'Not exactly, my father would say 
“NO!”, but in our house we were doing it anyway' (Benicio Sokkong, 20 February 2007, interview). So the children would practise the instruments in pseudo secrecy until they were confident and proficient, then they would join in the music making at ceremonial events. This is a process of peer learning (Rice 1994:44-45) where the children teach each other by friendly competitiveness, never shy to comment if a player does not play his instrument well, and through the want of participation. As Beni said when explaining childhood learning:

You can learn that when you're in a group like the pattatag. This is a play thing for the children and it is easy to make. And they could group themselves, and make their instrument and have entertainment. And a lesson for each other, or they could imitate from what they have heard. (Benicio Sokkong, 20 February 2007, interview)

During my stay in Sukiap I witnessed these processes of learning as described by Beni numerous times: on Bagtang's veranda, and during the instrument making at the granary (see chapter five). The young boys, who were almost constantly around the instrument making group, would be watching their fathers' activities intently, and immediately grab every opportunity to imitate them.

In contrast to the ensemble instruments, players of the solo bamboo instruments are more specialised due to the greater dexterity and technical ability required to play the instruments with confidence. Learning the instruments is not restricted, however, and anyone can decide to learn the tongali, paldong, kolitong and kulibaw, but natural ability, practise and patience mean some players are more proficient than others. Although the solo instruments do not have the strict ceremonial connections as the ensemble instruments, they do share similar characteristics of the learning process: imitation and isolated practise before being played publicly. The traditional sleeping arrangements in Kalinga, where young bachelors share a house, provide an environment for learning the solo instruments: 
We have this bachelors sleeping quarters, so when we sleep there my relatives would be playing that and hearing it, and you can play it yourself and imitating them. That's how we get our education in music. (Benicio Sokkong, 20 February 2007, interview)

To learn an instrument the child must either borrow the instrument without permission from the adult, or make their own, and then spend time on their own imitating and practising far from the ears of the community. Then once he (the solo instruments were all traditionally played by males only) felt proficient in the instrument, he could play publicly without embarrassment or ridicule. Beni describes learning the solo instruments as a process of careful listening and patient practise and imitation:

Hear and imitate. As very near or as perfectly as the one you've been listening to... listen to them, imbibe the music, then do your own thing. You have to feel the notes and look for it. (Benicio Sokkong, 20 February 2007, interview)

Although my own experiences of learning the music traditions included some of the features discussed above, I was primarily taught directly by Beni. I spent many hours observing Beni both making and playing the instruments in attempt to 'imbibe' the music, but I always felt our relationship was that of teacher and student. As a researcher, I accepted this learning relationship and recognise that this method of learning was most appropriate to my study. My most active period of learning the instruments was while Beni was teaching in Wellington as an artist in residence, prior to travelling to the Philippines. Beni's use of graphical notation, demonstration, and participation made the music accessible and understandable, and I could easily grasp the basics of the instruments. During this time, I focused on the kolitong (six string tube zither). Beni showed me the basic elements of the instrument and the most basic form of Tuppayya. From there, Beni left me to practise alone and develop my playing, only occasionally commenting when he heard me practising. 


\section{Summary}

This chapter described the bamboo instruments of the Kalinga, explored the material of bamboo, the musical repertoire, and aspects of learning process. All of these elements feature in Beni's participation in the revival and maintenance of the music traditions.

The process of bamboo selection and preparation for manufacturing instruments is crucial cultural knowledge used in the maintenance of the music traditions. Although explored here only briefly, research suggests that investigating the plant and material of bamboo within Kalinga ecology and indigenous beliefs may contribute to a deeper understanding of the instrumental music.

Beni has formed a repertoire of music for both the ensemble and solo instruments which he teaches to all of his audiences, whether academic or his own community. The repertoire of the solo instruments is expanding as specialist musicians, often Beni's colleagues, integrate ideas from other forms of music outside of those perceived as traditional.

Beni also acknowledges the structure of the music symbolically represents the community. In presenting this concept, Beni uses the music to reinforce the positive social values embedded in the music: those of solidarity and community. 


\section{CHAPTER FOUR}

\section{Musical Sites}

An integral element in the process of Kalinga's bamboo musical instruments revival is the creation of new musical contexts. The revival process has created an environment that now encourages a diverse range of new contexts for the bamboo instruments: from art music performances to world music recordings, classroom concerts to rural festivals, and each carries different meanings for those who participate. Beni Sokkong's role in the revival finds him participating in many of these musical activities. This thesis, however, focuses on the contexts of the bamboo instruments in two specific two communities, who have close connections to Beni: his ancestral home in the rural setting of Tanglag, Kalinga, and his neighbourhood in Lucnab in urban Baguio City. These social groups provide an example of revivals at a grassroots, local level, instigated by an individual and his immediate communities, in contrast to a revival at a national level, influenced by larger institutions such as universities.

During my field research the musical environment of the bamboo instruments played in Sukiap and Lucnab was not as I had expected, and proved to be far more complex and intriguing than I could have initially imagined. Although I was aware of the revival, and the use of the instruments and music in new contexts, isolated from the historical traditions, I was not aware of the multitude of different roles and agency in the music. For example, it became apparent to me that where the sound of the tongatong (bamboo stamping tubes) was once only associated with a specific ritual imbedded in the complex of Kalinga's spirituality (Benicio Sokkong, 10 March 2007, interview), it now carries meanings of autonomy, solidarity and identity. 
This chapter focuses on musical sites where I experienced the music of the bamboo instruments during my fieldwork. In the discussion below, musical sites are considered locations in space where musical activities occur (Wallach 2008). These locations are not venues strictly for musical performances or for musical activities, but where the music is present within the larger social and cultural contexts, for example: during the activity of instrument manufacture or relaxing in social groups ${ }^{52}$. In this approach, I have been influenced by Anthony Seeger's analysis of the performance event in Why Suya Sing (1987), and also Jeremy Wallach's investigation of locations in the study of production and consumption of popular music in Indonesia (2008).

The sections of descriptive writing in this chapter are developed from my field notes written on location, and also through reviewing video and audio recordings. By including descriptions of musical sites, I aim to convey a sense of continuity and shape of the event both socially and musically, and my own interaction within it. It is also my intention to specifically engage with and present some of my personal experiences, purposely using a reflexive approach to ethnographic writing (Kisliuk ). I have also employed '.... a street level perspective, engaging with the concrete details of the everyday lives of individuals in specific social settings' following Jeremy Wallach's approach (2008).

This chapter connects the individuals and communities, with the bamboo instruments and their music discussed in the preceding chapters through exploring the context of the music. I begin by investigating the musical gatherings which occur during periods of relaxation in the evening after work at both Beni's home in Lucnab and in the village of Sukiap, Kalinga. These gatherings

\footnotetext{
${ }^{52}$ This is not to say the music is simply a by-product, but is integral to the environment. For further reading on Kalinga music and the construction of place, see Glenn Ress Stallsmith (2007).
} 
provide venues for playing both the solo and ensemble bamboo musical instruments. I then explore the sound, music and social environment created by constructing bamboo instruments. Finally, I provide a brief description of the lewliwa fiesta held in Sukiap, where performances of the bamboo musical instruments were the focus of the event.

\section{Musical Activities During Relaxation}

During my fieldwork in Baguio City and Kalinga, there were regular periods of relaxing and socialising where people gathered together, often in the late afternoons and early evening, where they discussed daily life, and played the bamboo musical instruments. This section describes musical activities which occurred in the urban setting of Beni's home in Lucnab, and on the verandas of houses in Sukiap, in rural Kalinga.

\section{Standby: Music in the afternoons and evenings at Beni's home}

In Baguio City, Beni and the members of Simit referred to this daily period of socialising as "standby". The word is rooted in the American-Filipino slang that is embedded in many of the

local languages, and is also pronounced "tambay" ${ }^{53}$, a Filipino adaption. Although this word can have negative connotations of laziness and loitering, the members of Simit use the term to describe the down-time when they have nothing specific to do, whether it is work or otherwise. I would liken their use of this word to my use of "hanging out" as used in New Zealand and throughout the English speaking, Western world. During periods of standby, the members of Simit often spend time at Beni home in Lucnab, helping him to construct bamboo instruments

53 "Tambay" is translated to by-stander (pinoyslang.com) or loiterer (ordonie.tumblr.com). 
and also play music. Beni's home provides a location for Simit, members of the LYM (Lucnab Youth Ministry), and the other friends and relatives to socialise, hangout and make music. The gatherings would sometimes involve organised rehearsals in preparation for performances at the Mary Hurst Chapel or festivals. Below, I have described a typical afternoon with the members of Simit, which was one of many similar occasions I experienced during my fieldwork.

\section{Ensemble music with Simit}

It is late afternoon on my first day in Baguio where I am staying with Beni and his family, when Simit members Ariel and Rowell drop by after their classes at college. Most days on their way home, they call in to Beni's for what they refer to as 'stand by'. I introduce myself to Ariel and Rowell, inquiring about their music, and explaining how I had met Beni in New Zealand. I tell them about learning to play Beni's instruments, and how the sounds and music of the bamboo instruments had intrigued me. After their initially shy reaction, Ariel and Rowell seem to relax. Soon they are overwhelming me with facts about their music and dance: what instruments are from where, and which involves dance and ceremony. Encouraged by my interest, they decide it is easier to explain though demonstration.

We go upstairs into a large room where Beni stores his bamboo and instruments. Ariel and Rowell explain the music of Benguet, their ethnic group, as I know little about Cordilleran music traditions outside of Kalinga. They bring out three sulibaw (log drums), two gangsa (flat gongs) and one takik (two small metal rods which are tapped against one another) and begin to demonstrate. With only two players, they can only show me elements of the ensemble, which gives me a chance to hear and understand the instruments individually. 
As the hot afternoon fades into the luke warm evening, more of the local Lucnab youths drop by the house. Soon Ariel and Rowell are joined by their Simit colleagues Edward, Dexter and Jayson. Shortly, the new arrivals pick up the instruments and the music continues; this time with a full ensemble. Not long after the full ensemble gets going, Simit, being all males, are joined by Beni's daughters and other girls and young women from Lucnab. With females dancing to Simit's music, the performance is now complete. The energy of the complete ensemble, together with dancing, creates an overwhelming first impression of the music, and the close sense of community it engenders.

Eventually the music and dancing disintegrates into loud laughter and chatter, and a set of Beni's tambi (two string zithers) are brought out from the stack of instruments lining the walls. The members of Simit pick up the tambi and immediately begin playing the throbbing rhythm of Tuppayya. Ariel leads the group of five males around the room in the subtle pulsating movement of the Kalinga tradition, stepping with beat and flicking their ankles behind them.

The music and dance continues through the evening until around ten o'clock when participants of the gathering begin to drift toward home. The enthusiasm and pride with which Simit introduced the music to me is astonishing, and Beni's concept of living tradition is clearly articulated in experiencing this impromptu performance. The context is not frigid and located in historical past, but is dynamic and contains contemporary features of socialising that were relevant to young people today. (Lucnab, Baguio City, 5 June 2007) 
In the urban gathering described above, the music has multiple functions. It is an activity which facilitates socialising, and actively articulates connections of individual and collective cultural heritage. The music creates a social environment where the activity of music making is fun and playful in nature, a way to impress prospective partners, and present musical skills. I recognised that they were conscious of me as an audience, and this was reflected in the performance, which became serious and intense at times, demonstrating their pride in the music. The music and the movement seemed to develop organically with little direction, although the group did communicate with occasional visual gestures, such as the nod of a head, indicating a change in direction or the leadership of the dance.

Simit's musical repertoire illustrates multiple layers of identity formation. At an individual level, each member of Simit identifies with their own ancestral ethnic group within the Cordillera. When I spoke to Ariel, he proudly told me 'my blood is Kankanay', and then described the music, rituals and even personalities associated with the Kankanay ethnic group (Simit, July 2007, correspondence). At a regional level, the members of Simit collectively identify themselves as Cordilleran. This collective identity is contemporary, formed in part by urban migration to Baguio City during the past century, and represented by features common to the separate ethnic groups, such as certain music and myths.

Beni teaches the regional music to Simit, as Cordillerans, which includes music from Kalinga, Kankanay, and all of the other ethnic groups from the Cordillera. As a group, Simit have a collective identity which is articulated in the musical repertoire and knowledge of Cordillera traditions. Beni encourages them to gain both a strong understanding of their individual cultural heritage, and also form a collective identity through knowledge of the traditions throughout the Cordillera. 


\section{Solo instruments in Sukiap, Kalinga}

The musical instruments I heard most often played in Sukiap were the solo bamboo instruments: the tongali (nose flute), paldong (mouth flute), kolitong (tube zither), and the kulibaw (jaw harp). These instruments were played while relaxing on the verandas of houses in the cool of the evenings, and after midday, when the heat is too intense for work. The verandas serve as gathering places where many discussions, both gossip and political, take place. As with Beni's house Lucnab, the verandas are where people passing by stop and chat, catching up with the day's happenings.

The verandas are built as a platform out from the door of the house, approximately two metres above the ground, and are openly visible to neighbours and people passing by. During my stay in Sukiap, I spent most of my time on the verandas of Beni's cousins, Gallming and Bagtang. Gallming's veranda was often the site of socialising in the evenings, while Bagtang's veranda was where children would play bamboo instruments in the afternoons. The music I witnessed in the evenings on Gallming's veranda occurred every second or third night. A group of men would gather, discuss the day and larger issues of the community and occasionally play the bamboo flutes.

\section{The bamboo flutes on Gallming's veranda}

It's evening, and Beni and I have just arrived from Baguio City. We are being hosted by Gallming for our stay in Sukiap. Gallming's veranda seats about ten men on bench seats built into the railing, facing inward. From the veranda you can see the other village houses surrounding the central plaza or basket ball court. In the opposite direction, you 
can look out toward the Chico, where the rice fields cascade down the gentle slope toward the river.

This is the time for relaxation - after the day's farming work is completed and before returning to families for dinner, which is usually served late in the evening. Bayjus (rice wine) and pulutan (drinking snacks), are often served by the host and sit in the centre of the group on the floor; the bajus in an old plastic bottle alongside water with a single cup to be shared, and the pulutan in a coconut shell. This tradition of drinking together, from one vessel and one cup, is integral to the Kalinga community, and this element is found in ceremonies, such as the bodong (peace pact).

As darkness falls, Gallming and Beni's friends and cousins drop by and join us on the veranda. There is a group of about nine men, ranging in age from early twenties to elders of the community. As Gallming is the host, he has provided the bajus and pulutan. Everyone present is quietly chatting. Beni grew up with these people and shares many memories. Although he has not visited for a number of years, no fuss is made, only quiet acknowledgments of welcome. This, I come to realize, is a characteristic of the reserved Kalinga personality.

Beni introduces me and explains my intentions and motivations for being there. Bagtang, Beni's first cousin, leaves the group, and re-appears with a decorated tongali (nose flute) and paldong (mouth flute). He proudly shows me the tongali on which he had carved an image of a man playing the bamboo flute serenading a prospective partner. The instruments are passed around to anyone who wishes to play. Some only play a few fragmented phrases, and, accepting their unpolished performance, pass the instruments 
on to others. There is often laughter from the player and the group, and gentle heckling indicating when the melodies do not go as intended.

Etos, Beni's second cousin, plays the paldong confidently. He plays the Annoywoy ${ }^{54}$ tune as I had heard Beni play it in Baguio and Wellington, although with less ornamentation. Beni does not play the solo instruments at all this evening, but leaves it to his friends and family. I sense the others are aware of Beni's presence as a musical specialist, and are perhaps a little shy and self conscious. (Sukiap, 16 June, 2007)
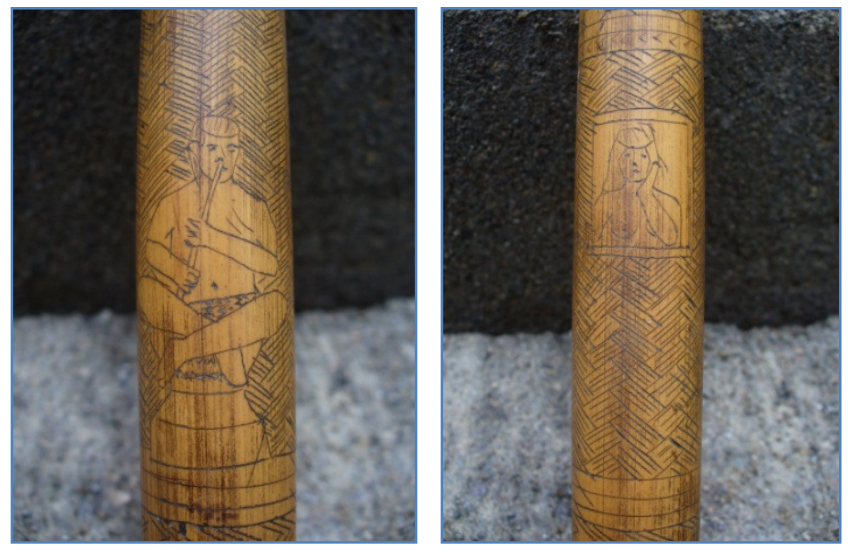

Figure 23: Bagtang's decorated tongali. The picture represents the traditional function of the instrument, used to serenade a prospective wife from outside her house.

(Photo by author, June 2007)

${ }^{54}$ Annoywoy is the name of a popular melody played on both the paldong and tongali. See Chapter Three for further details. 


\section{The kolitong (six string tube zither) on Gallming's veranda}

Another significant gathering during my stay in Sukiap, described below, was on my last night in the village when Beni and I hoped to record Ben Wacdag, an expert kolitong player. Ben is an elder of the community, and was a Beni's mentor in music while growing up. Unlike the bamboo flutes, the kolitong (the tube zither), requires more dexterity, skill, and practise to play well. Because of the difficulty, there were only a few kolitong players in the group of men from Sukiap, and Beni referred to them as experts (CD Track 13).

Gallming's veranda is particularly crowded, with the usual group of men sitting around the veranda bench, and also children scattered down the stairs, peeking over the edge. The intention is to make a mini-disc recording of Ben playing the kolitong, as he is the most skilled player and has the largest repertoire in the village. The atmosphere is different from the other occasions on the veranda, and quite different to my experiences on the first night in Sukiap. Tonight there is a feeling of a final performance, or a leaving party; everyone is far more relaxed with my company than when I first arrived, and a sense of brotherhood, (barkada) has developed.

An empty cooking oil tin with the lid removed is brought out to provide passive amplification for the quiet sound of the kolitong. Ben rests the end of the tube of the kolitong on the tin and plays a collection of tunes. He speaks little in between playing, and, although he is an expert, seems shy, occasionally giving a little chuckle when missing a beat. The others present are quieter than in past gatherings; the fact we are recording the music seems to change the environment from the usual casual chatter to that of a more formal audience. Lumayog joins Ben on another kolitong, and they begin 
to play a Tuppayya as a duet with interlocked parts (CD Track: 14). (Sukiap, 16 June 2007)

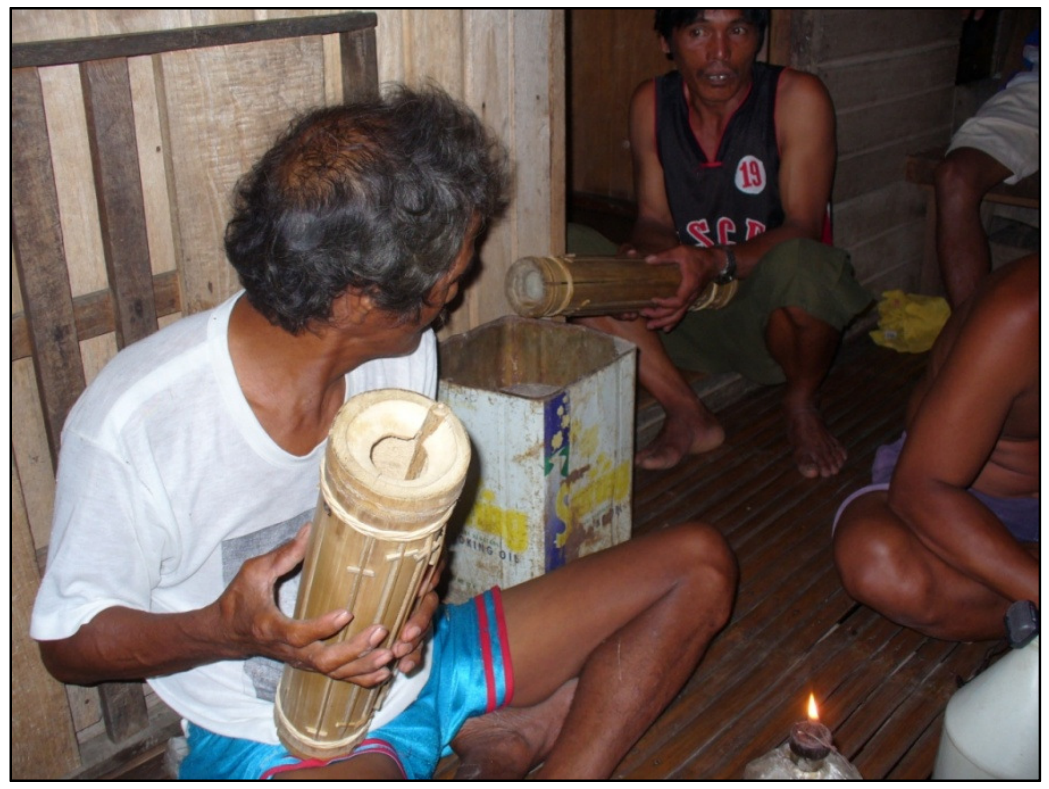

Figure 24: Ben (left) and Lumayog (right) playing a kolitong duet. (Photo by author, June 2007)

During the evening the verandas are venues for male gatherings, where the solo bamboo instruments are played. The group of men which gather have close family ties, usually first or second cousins and work together during the day. Although women are not actually restricted from the location, my impression was that they were not interested in such gatherings and had other tasks to do. The music played on the bamboo flutes and the kolitong create a sonic backdrop to the social activities of discussion and drinking.

These gatherings do not display the same conscious articulation of ethnic identity as found in the urban gatherings within Beni's community in Lucnab, but do indicate the musical expertise and cultural knowledge of individuals. From my discussions with Beni, it seemed to me that many of 
the skilled players of the solo instruments are elders and those with status within the community. A proficient flute player is able to suggest the expressive nature of Kalinga vocal music, and a well-played kolitong captures the sounds of the gangsa. Having the ability to play an instrument well is associated with cultural and historical knowledge, which is valued within the community.

At both gatherings described above, Beni's presence was significant, and all were aware of his position as an expert in the bamboo musical instruments. Although it is common to play the instruments during downtime in the evenings, Beni and I being there encouraged the instruments to be played more often. Beni did not comment on anyone's playing, or play the instruments himself, but let the music develop as the group saw fit. Using this approach, Beni indirectly encourages the maintenance of the music traditions: his presence alone increases the awareness of the music culture which is owned by the community, and in not actively teaching, the music continues from the existing knowledge of the community held by elders and other individuals. This highlights the music traditions continuity with the past, where Beni awakens the music in his community.

\section{Children's musical activities on Bagtang's veranda}

This afternoon, while Bagtang is absorbed in making a kolitong, his children and their cousins play a variety of bamboo instruments for me. Having realised my interest in the instruments and the music, the children have sought out any bamboo instruments they can find from various houses throughout the village. The instruments gathered do not form complete sets of six, but are a collection of single instruments or pairs: two tambi, a kulibaw and three tongali. Once the instruments have been appropriately distributed amongst the group, the children begin striking out the rhythm of the Tuppayya as they would have heard being played on the gangsa by the adult males of the community. 
Together, as an ad-hoc musical group of a mixture of solo and ensemble bamboo instruments, they continue to play the pulsating rhythm, shaping the intensity of music through metre and dynamics. The children also hint at the dance as they play, rocking gently and lifting their feet in time to the music as the dancers would do. After playing for a while, a friendly bustle breaks out leading to an exchange of instruments. Eventually the ensemble is reorganized with different players and the music starts up. (Sukiap, 17 June, 2007)

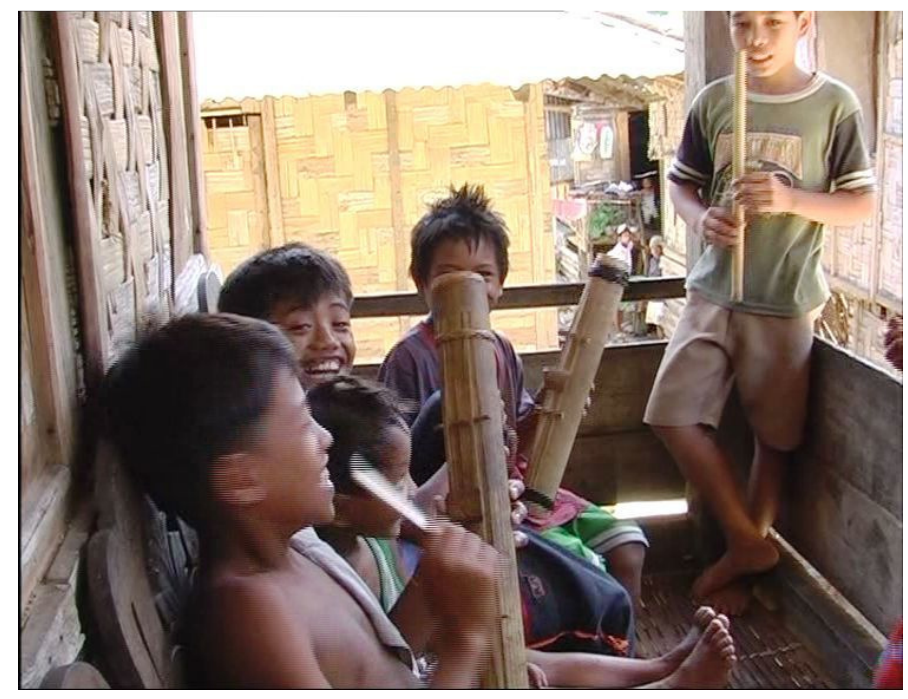

Figure 25: Children of Sukiap on Bagtang's veranda (Photo by author, June 2007)

The children of Sukiap are always free to play any of these bamboo instruments after school and when their chores are done. I often saw groups of boys playing instruments and dancing in imitation of their fathers, and even if they had no instruments, they would vocalize the music, capturing the pulse of the ensemble music.

By watching and listening to the children, I began to understand what Beni had meant back in Wellington five months ago when he had referred to the music being 'imbibed. In asking him how the music is learned, he told me: '...imbibe the music, then do your own thing...' (Benicio 
Sokkong, interview, 10 March 2007). Beni always stressed that this came from playing and hearing the music all your life and growing up surrounded by the music traditions. The activities of the children playing the bamboo instruments illustrate this means of learning and absorbing the sound and the rhythms through imitation, trial and error, and peer learning (Rice, 2003:74). Children do not focus on single instruments, or have regular practise schedules, as in other music traditions, such as western art music. Nor is there a single teacher who evaluates their progress on the instruments and encourages further practise. The motivation for learning the instruments is found in the desire to become an adult and a valued and useful member of the community: within the ensemble, individuals become an integral part of the community - without all the parts, the music is not complete (Benicio Sokkong, correspondence, June 2007).

Another aspect of the music revealed in observing the children was the playful, game-like structure of the music. Because of the strict order of pitches which create the music's ascending pattern, a player must sound his part correctly to articulate the collective melody: if one person loses the rhythm or his particular accent, the music will not sound good. If this happens, the ensemble will stop and there will be a rearranging of instruments between participants, and then the music will start up again. 


\section{Instrument Making}

The practice of crafting musical instruments is itself a creative and musical act. At every step of the design and manufacture, music is made: the sounds of scraping, sanding and tuning, and the shaping of the timbre of the instruments. Sound is used as an indicator throughout the process of creating a musical instrument from a bamboo culm. In the selection of bvulo (thin walled bamboo), the pole is gently tapped: the sharper and louder the 'clack', the more mature the bamboo is. After six months, once the culm has dried, Beni again taps the bamboo pole before cutting it into lengths for instruments. Once these lengths are cut, the bamboo culm begins its life as an instrument in the form of a stamping tube, and now the tone and pitch can be identified by gently pounding on the ground. As the bamboo tube continues to take the shape of an instrument, a diverse array of sounds create a complex sonic environment ${ }^{55}$.

The activity of making bamboo instruments not only creates a unique sonic environment, but also a social environment where the process of learning and group dynamics become apparent. How knowledge is shared amongst men and boys, and how Beni presents this knowledge, can be seen in these gatherings. I experienced the social and sonic elements inherent in making the bamboo musical instruments at Beni’s home in Lucnab, Baguio City and in Sukiap, Kalinga. In the section below, I describe the environments and discuss the differences in the social dynamics, the presence of learning, and the sounds and music that exist.

\footnotetext{
55 In Sound and Sentiment, Steven Feld identifies the significance of the sound and environment in understanding the symbolic concepts of the Kaluli of Papua New Guinea (1982). In the description below, I intend to highlight how the sounds produced by the process of instrument making create a sonic environment which can be experienced musically.
} 


\section{Instrument making at Beni's home in Lucnab, Baguio City}

I wake to the woody notes and crisp clack of bamboo tubes being gently manipulated into musical instruments. As always, Beni is up before me, chewing moma ${ }^{56}$ and crafting instruments in the cool, clear morning. Occasionally, I hear a few seductive notes from Annoywoy on a newly constructed paldong (mouth flute), or the bright pizzicato of a kolitong (six string tube zither). The musical fragments mingle with the other sounds of Lucnab in the morning: roosters calling, dogs barking and heavily loaded jeepneys struggling up the road.

This changes as visitors from the neighbourhood drop by. Instead of hearing only two notes of Ginallupak played on an ensemble instrument by Beni alone, now and then the complete ensemble can be heard. Members of Simit arrive near the end of the day, and after greeting Beni, find an instrument which requires sanding. The sound of bamboo being sanded is occasionally overpowered by an entertaining anecdote from an individual, followed by laughter from the group. As a set of instruments is completed, Beni, and whoever has joined him, try out the tuning and timbre in an ensemble to determine if further adjustments are required. (Lucnab, Baguio City, 14 July, 2007)

\footnotetext{
${ }^{56}$ Betel nut with lime and tobacco
} 


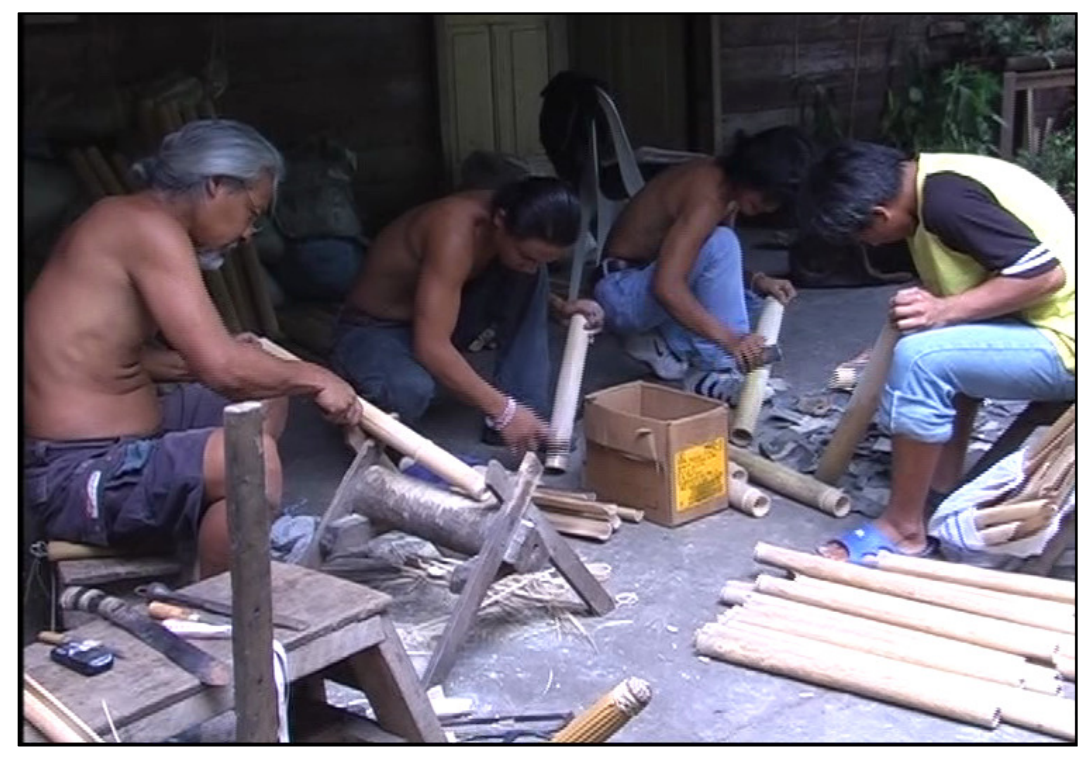

Figure 26: Beni constructing ballingbing, while members of Simit sand bamboo tubes in preparation of instruments. (Photo by author, June 2007)

Although family and friends participate and assist in making the bamboo musical instruments, it is Beni who defines every step in the process from bamboo selection to tuning a finished instrument. Beni's role as master instrument maker within the group was apparent in my observations, and he had complete control of the sonic and aesthetic quality of the instruments. Beni never actively demonstrated or taught any of the skills required for instrument making, but relied on the fact that the knowledge can be shared through observation. None of the members of Simit considered themselves to have the skill to make the instruments, although they had observed Beni for years $^{57}$ (Simit, 14 July 2007, interview).

The social setting during instrument making was incredibly relaxed; no fierce concentration from Beni or any of his assistants. For Simit, it was something they would do while standing by and

\footnotetext{
${ }^{57}$ Beni told me that he hoped to find an apprentice who he could pass on his knowledge to (Sokkong, correspondence July 2007)
} 
hanging out. Those members of Simit that were not studying, and had no continuing job, would often be found helping Beni out during the day. Although Beni worked to deadlines when the instruments were required by schools, for example, many of the orders for instruments were completed when time allowed. This meant that no haste or urgency, and the stress this creates, was apparent during the activity. The process of making the instruments seemed collectively meditative - each individual finishing the bamboo into an instrument, which, when complete, would form part of the set; the community of instruments.

\section{Instrument making at the Granary in Sukiap, Kalinga}

Two days after arriving in Sukiap, Beni had organized a group of men from the village to spend a day making instruments, as described below. This activity was to serve multiple purposes: as a demonstration for me of the traditional instrument making techniques; research for Beni, as he is always collecting knowledge of the instruments and the music they make; and a venue where Beni could encourage his family, his itangyeg (tribe), not to forget the traditions of the instruments, and to recognise their unique value, as described below.

The first task of the day is to source dried bamboo culms - both bvulo (thin walled bamboo) and bvuyog (thick walled bamboo) are required. Throughout the village of Sukiap, poles of bvulo can be found propped up against the side of houses drying in the sun. This bamboo is often used for drying racks for bundles of cut rice stalks, as well as balancing poles to carry heavy loads by the men on one shoulder. After inquiring around the village and explaining the situation to residents, Beni manages to source the required bamboo. Beni has gathered nine poles of bulo (thin walled bamboo) between five and eight nodes in length, each approximately three meters long; and a single pole of bvuyog (thick walled bamboo) with eight shorter nodes, nearly two meters long. A bunch of 
rattan cane split in centimetre strips is also brought to the granary, where the instruments are to be constructed.

The bamboo is laid out in the shade of the granary, and Beni makes decisions on which piece of bamboo will be made into what instrument. Lumayog begins cutting the bvuyog to lengths for the tambi (two string tube zither), and Bagtang sets up the kolitong (six string tube zither) on his stool which he had begun yesterday. Ben works on ballingbing and, within five minutes, he has completed the first of the set, cutting it from the bvulo pole and shaping with his pachil ${ }^{58}$ (machete). Although everyone seems adept at making any instrument, some are obviously more confident at particular instruments than others. Beni assists occasionally with any queries from the group; they are aware of his experience, and value and respect his expertise in instrument making.

After midday we are accompanied by some young boys from the community, sons and nephews of the men that have gathered. The boys, between five and ten years of age, are lost in admiration for what the men were doing, fascinated by the skill of their fathers and uncles. They help where they are able; when a bamboo pole needs to be held still while being cut, or a tool needsto be retrieved. The children pick up the instruments as they are being completed and play them, testing out the sound and the action required. They form groups with the instruments in imitation of their fathers and uncles and play with an uncanny ease.

\footnotetext{
${ }^{58}$ See Chapter 2: The Musical Instruments, ballingbing for a detailed description of Ben's method.
} 


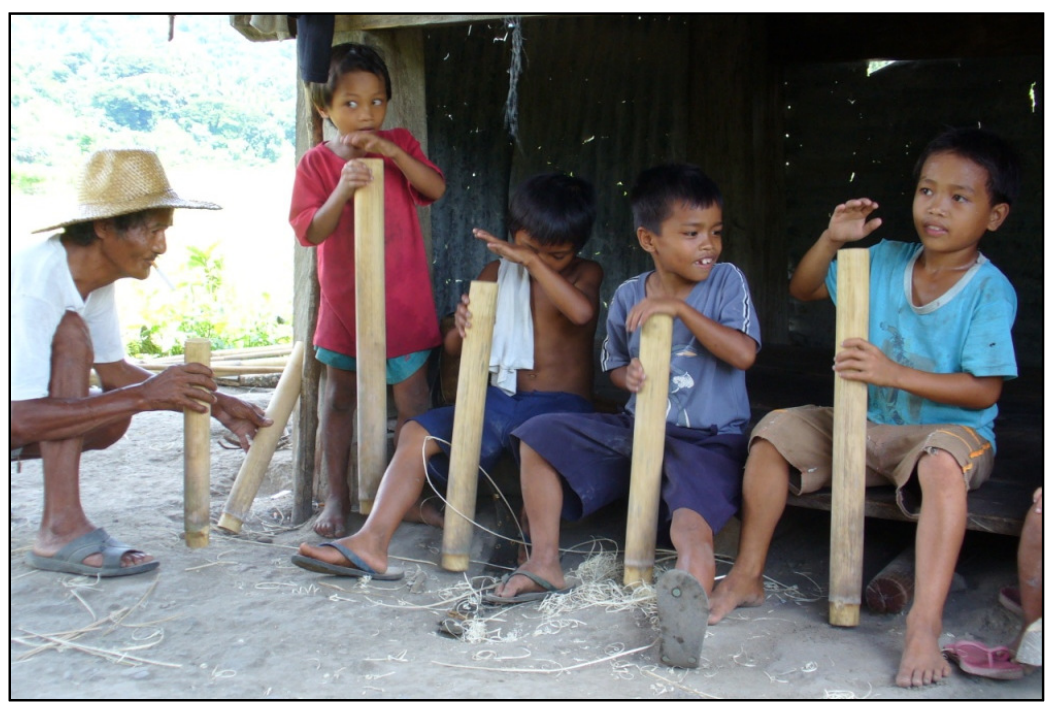

Figure 27: Ben and the boys trying out the newly made tongatong. (Photo by author, June 2007)

When the sets of instruments are finished, the men gather together to try out the ensemble. They swap tools for instruments, and Beni leads the group in Ginallupak (alternating pattern). The skill, confidence and familiarity of each individual seems to vary in the group. While Bagtang is confident of his part in the music ensemble, others seem a little unsure. To correct the sound of the ensemble, Beni takes the instrument from the unsure player, demonstrates the technique, then returns the instrument. This is accepted by the individuals and no offence seems to be taken by the player.

Towards the end of the day, after all the instruments are completed, a bamboo instrument jam session breaks out. It begins with the saggeypo set being played, but grows to include the majority of the instruments that had been made during the day. Everyone present grabs an instrument and plays along with the saggeypo, creating a pulsing Ginallupak containing all the sonic elements of the bamboo instruments: buzzing from the ballingbing, clacking of the Pattanggok, and gentle boom of the tongatong. The group 
breaks into song, singing Salidummay, a song popular throughout the Cordillera, with lyrics from the local region of Kalinga. The atmosphere is of camaraderie and nostalgia. The singing seems to be an expression of brotherhood community. (Sukiap, Kalinga, 13 June, 2007)

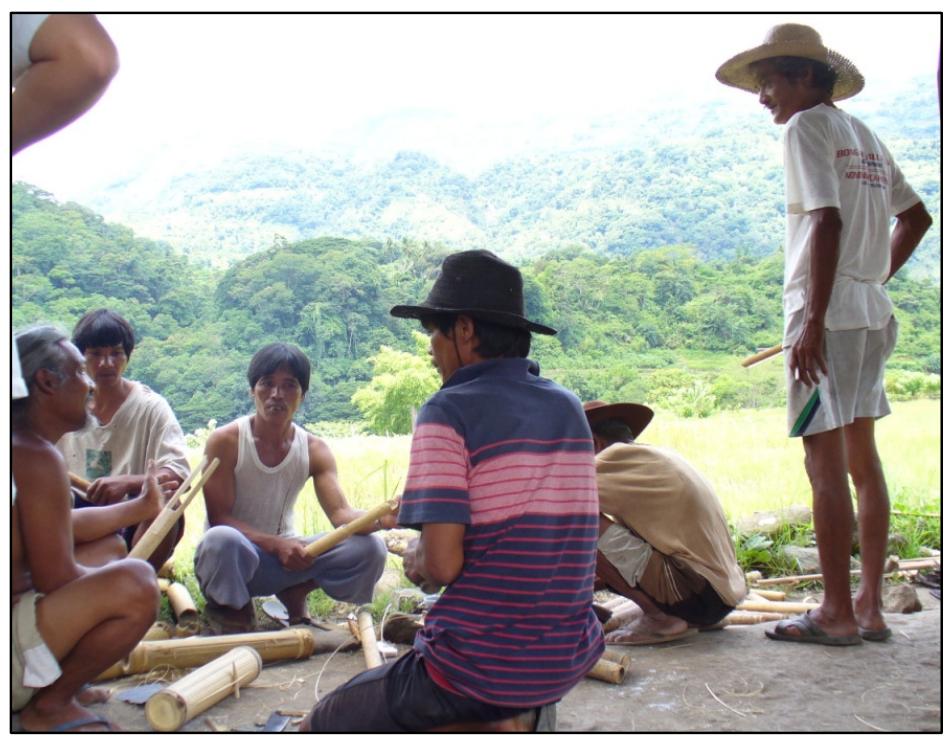

Figure 28: The group trying out Ben's ballingbing. (Photo by author, June 2007)

This mixed ensemble of bamboo instruments illustrates their contemporary use in their original homeland: the instruments are now seen as musical instruments which can be played in any ensemble. In the past, the different sets of instruments, such as the ballingbing and the pattanggok would not have been played together as they each performed different functions with connections to ritual (Benicio Sokkong, 20 February 2007, interview). Today, through Beni's influence, they are freely used together to create a new musical result, which, although is not thought of as authentic by the group, is based on the traditional musical patterns. In this way, the 
music of the instruments, combined with the song, creates a modern ethnic identifier which encapsulates Kalinga traditions and the solidarity they represent.

In contrast to the activity of making instrument in Lucnab, where only Beni would have control of the musical and aesthetic qualities of the instruments, at the granary in Sukiap all of the members gathered were involved. As Beni had explained to me, everyone could make instruments and this was not restricted to specialists. This is true with the men of Sukiap, however, it became apparent to me during this session, that there were those in the group that had a higher degree of knowledge and skill in the manufacture of certain instruments. These individuals fall into two groups: those that have invested time re-learning the skills of instrument making with Beni's guidance, such as Bagtang; and those considered elders such as Ben and Argbow who have accumulated knowledge through life experience. Bagtang's method of making the kolitong (six string tube zither) seemed similar to Beni's, and produced a similar instrument: more care was taken in peeling the surface of the bamboo away and extracting the fibrous strings from the body of the bamboo. In contrast, Ben had a unique technique for making ballingbing which required little time and effort, and produced a less refined and sustained tone than Beni's instruments. Likewise, Argbow's pattanggok were also simpler than Beni’s design but did require a significant amount of re-tuning by Beni to create a usable set.

The group activity of making bamboo instruments in the rural location of Sukiap highlights two aspects of Beni's role as an agent of music traditions and a revivalist: (1) his own research, and (2) encouraging the practise of the tradition. In observing and discussing Argbow's and Ben's methods of making the bamboo instruments, Beni is collecting information from the elders in this community which he will feed back to other instrument makers and researchers he works with at the CMTRC (Cordillera Music Research Centre) and elsewhere. Although the instrument 
making techniques demonstrated by Argbow and Ben are not refined to the same degree as Beni's instruments, understanding the method adds to the body of knowledge about the instruments, highlighting aspects of the aesthetic requirements, such as tuning and timbre. The designs of the instruments Beni now makes for schools and musicians locally and around the world are the product of years of research, such as this experience in Sukiap.

Beni's presence in Sukiap was the impetus for the activity of making bamboo musical instruments which would not have occurred otherwise. The instruments would rarely be made in Sukiap today, and only if they were required for a festival or performance. When Beni returns to Sukiap he stimulates interest in the music traditions which the community perceive as their own. Beni actively promotes discussion amongst the group and is forthcoming in sharing his knowledge with the group.

\section{Lewliwa: an impromptu performance in Sukiap, Kalinga}

The Lewliwa (fiesta) was an impromptu festival of various bamboo instrument ensembles and dance performances, which occurred in the evening of the day the bamboo instruments were made. What originally was to be a short performance of the boys playing the newly constructed instruments for my benefit, turned in to a musical gathering involving the entire village and continued late into the evening. The notes below are a short episode from a continuous musical performance, where each of the bamboo instruments were played in their respective ensembles by adult men and young boys, and were joined by women and girls dancing.

In the centre of the village, on the basketball court, which also serves as a community area, a gas lamp is set up to provide light for the boys playing the tongatong. The boys 
perform confidently having spent the day at the granary watching the instruments being made and also playing them. An audience appears from the houses surrounding the basketball court, and people now line the perimeter, all watching and listening to the group. I set up my video camera towards the back of the court hoping that the lack of light will hide me. The group of boys performing stand in a half circle, keenly watching one another to ensure the musical result is correct. Occasionally, a member of the ensemble loses his beat, disrupting the rhythm and collapsing the tune into nothing. Ben Wacdag, joins them on the makeshift stage, briefly gives the boys a demonstration to correct their mistake, and guides the piece into life again. The boys now pick up the set of six tambi (two string tube zither) which they carry while playing. A member of the group takes charge and begins rocking side to side on each foot, and is eventually followed by the other players. As they begin to dance in line making large circles around the gas lamp, a group of girls runs to join them, with much laughter; their arms out stretched horizontally and hands flicking up to the sky.

The children's performance collapses in to chasing and giggling, and the group of men who have spent the day in the granary, including Beni, take the stage. They begin with the saggeypo (individual panpipes). Gallang plays the balbal (the lowest pitch or number 1) with confidence. Beni joins in playing kadwa (second pitch, approximately a minor third above). As the participants begin their parts, the musical piece takes form and the melody can be heard, articulated by Bagtang playing lalat (sixth and highest pitch). (Sukiap, Kalinga, the evening of 13 June, 2007)

This was a gathering where the music and dance traditions of Sukiap, and the children of the community, were celebrated. Parents were delighted to see their children play the instruments 
and dance, and the atmosphere was one of communal fun. Like the instrument making, the performance was motivated by Beni's presence within the community; he was clearly the director of the events; halting the performances, rearranging the players and commentating on their playing. Like any good MC, he had the audience captivated, with his larger than life dances and encouraging heckles. Beni also spoke to the entire group at the end of the evening, explaining the importance of the music traditions and cultural heritage. This was returned by a pledge from Gallming and others that they would make a specific effort to practise the bamboo instruments and provide regular opportunities for events similar to the performance that night.

Beni created a performance environment for the bamboo instruments which was fun and relevant to all members of the community including elders and children. The lewliwa was a venue where Beni could share his knowledge of the bamboo musical instruments with his own community. By presenting the music in a context which was fun and participatory, Beni also illustrated the way past traditions can find new life in today's communities, outside of the historical ceremonial role, thus maintaining musical practises. Like the performance group Simit in Baguio City, Beni aims to highlight the positive values that are associated with knowledge of one's cultural heritage, promoting individual pride and a sense of community and solidarity.

\section{Summary}

The social contexts of the bamboo musical instruments in both Lucnab and Sukiap place emphasis on the value of cultural knowledge to individuals and communities; to use Beni's phrase 'knowing your own culture' (Benicio Sokkong, June 2007, correspondence). Beni guides both communities in this approach by creating environments for the music, which previously had not existed, and ensuring that the music is relevant and accessible to participants. In doing this, 
Beni seeks to revive the use of the bamboo musical instruments and develop a 'living tradition' (Benicio Sokkong, July 2007, correspondence).

In both locations, urban Baguio City and rural Sukiap, the ensemble instruments are social activities where individuals express their belonging to community and culture. The Simit members in Baguio City consciously use knowledge of the music traditions to construct both their individual ethnic identities, and a collective solidarity. In Sukiap, the music is not actively used to articulate identity, but to reinforce a sense of community.

In comparison, the use of solo instruments can be highlighted by examining the evening gatherings on the verandas in Sukiap. Similar to the past contexts, the kolitong (six string tube zither), tongali (nose flute) and paldong (mouth flute) continue to be played in male gatherings during downtime. Within these musical gatherings, individual players can display their skill, although it is common for many participants to play a solo instrument to some degree. Those with significant musical skill are thought of as 'experts' and are often elders with historical knowledge.

In both urban and rural locations, knowledge of the construction of the bamboo musical instruments was shared, but in different ways. In Sukiap, the members of the gathering participated in all aspects of the construction of the instrument such as design. Like the playing of the solo instruments, individuals displayed expertise in some areas, therefore showing knowledge and status. In contrast, the environment of Beni's workshop in Baguio, Simit members only assist in the sanding and finishing of the instruments, and Beni's status as master instrument maker is apparent. 
Elements of the traditional methods of learning can also be seen in both locations during instrument making and other musical gatherings. The primary means of learning both instrument construction and musical skills is observation and imitation. Children are free to play music with their peers and become involved in activities, and although encouraged, are not taught directly by adults. 


\section{CHAPTER FIVE}

\section{Conclusions}

This thesis explored the contexts the bamboo musical instruments of the Kalinga by focusing on the musical experience of an individual, Beni Sokkong, and the musical communities connected to him. I have presented a case study of two communities, one urban and one rural, and investigated the features of a grassroots revival where the influence of a single person can instigate and shape the process of revitalisation from within. The two central themes presented throughout the thesis focus on (1) the musical experiences and influence of individuals, and (2) the dynamic and fluid contexts of a reviving musical tradition within grassroots communities. Throughout this thesis I have attemtped to present my experiences and reflections of fieldwork, and identify my postion as both a researcher and a person within the community creating relationships.

\section{The influence of an individual in a revival}

The revival of music traditions do not happen without the participation, passion and energy of certain individuals. In following the approaches of recent successful musical ethnographies, the present thesis draws heavily on the musical experiences and connections of one individual (Rice 1994, Stock 1996, Vander 1988). This approach has enabled me to explore the musical life of Beni Sokkong and emphasize his influence in shaping the process of a revival (Livingston 1999).

Beni Sokkong's first musical experiences were as a boy in his own community in Kalinga during traditional ceremonies with his father. From these experiences a deep musical and cultural 
knowledge was imbibed which manifested in a lifelong passion and commitment to the transmission and maintenance of the music and culture. This led him to teach at the University of the Philippines and travel the world as an expert teacher and performer sharing his knowledge and presenting his culture. Since leaving the University of the Philippines and creating the School of Living Tradition in Baguio, the focus of his teaching has returned to his own communities, providing the musical experiences he had as boy to the younger generations, and ensure the knowledge continues and the music remains alive. This circular path of his musical life - beginning within his own community, arcing out to academic and international audiences, and then returning once more to his own communities - has provided him with a unique set of social, musical and teaching skills which are utilised in the process of reviving the musical traditions of the bamboo musical instrument. It is these skills which provide Beni the ability to negotiate a wide range of audiences: academic students, Filipino school children, local communities, and his own peers. Today, Beni teaches the concept of 'living traditions' where the bamboo musical of the Kalinga instruments have been re-contextualised into contemporary environments where the music has new relevance.

Beni's case presents a bridging of the gap between the academic world of ethnomusicology, where much of the cultural production has been dislocated from those communities whose musical tradition it is, and the communities themselves ${ }^{59}$. Sensing the need for community grounded research, in 1979 José Maceda the Filipino ethnomusicologist, composer and performer called for:

\footnotetext{
${ }^{59}$ This is also a form of applied ethnomusicology (Sheehy 1992)
} 
... no institutional break between research on the one hand and teaching or performance on the other hand. The two would not be divided into separate "systems" for they are meant to reinforce each other. Researchers, teachers, and performers in the village would become a part of the whole life of the community.

The Cordillera Musical Tutorial Research Centre embodies Beni's idea of a 'living tradition', where Beni and his colleagues are active within their own communities as teachers, and are also researchers involved in academic projects, such as international conferences, and in guiding the present thesis. This study provides evidence of this approach's value in maintaining a tradition in grassroots communities.

From my experiences of Cordilleran communities, it became apparent to me that the region has an extremely diverse and rich musical culture, which, as well as the bamboo instruments, includes a variety of solo and group song forms (Ullalim, Dango and Ading), and instrumental music using the flat gongs (gangsa), drums (sulibaw) and chimes (takik). In this study I have highlighted one particular set of musical practises and hope that other individuals from within Cordilleran communities take inspiration from Beni and continue to learn, document and maintain the other music traditions. Beni provides a model for future ethnomusicological research that is grounded within the community, where knowledge and relationships, the materials of research, already exist.

\section{Urban and rural contexts}

Throughout this thesis I discussed two communities in two different environments where the bamboo musical instruments are practised today: Lucnab, in the densely populated urban Baguio City, and in the remote rural village of Sukiap, Kalinga. Although the differences between these two locations would have been more pronounced in the past, today, due to the migration for work, education, and the influence of technology and globalization, these distinctions have 
become less defined. My investigations of the bamboo instruments of the Kalinga in both an urban and rural context show that both environments share common features: a fading of historical, ceremonial contexts, together with a willingness and enthusiasm to re-learn and maintain the musical traditions. Musical gatherings, both formal and informal, are found in both locations and function as an expression of community and pagkapwa (awareness of others), and are crucial in the forming of individual ethnic identity (Trimillos 2004, Stokes 1994, Rice 2007). No matter the location of the musical experiences, to those with an ancestral connection, the music creates an environment of belonging, pride, and solidarity. In both these locations, urban and rural, I have shown that music is fluid in context and meaning, and by consciously creating new contexts, music traditions can be maintained.

Recent studies in ethnomusicology have focused on musics within specific locations, often in either rural or urban environments (Wallach 2007, Seeger 1989). In focusing on two specific communities, one urban, one rural, this thesis shows that music cultures reach across these boundaries and are carried along with individuals and communities as they travel between locations. In this study I have shown that Beni forms a link between these two locations, and applies similar means of transferring knowledge in both. His recognition of the historical relevance of the music and the positive social effect from practising these music traditions has ensured that the knowledge is not restricted or reserved to a few, but is accessible and active within his own grassroots communities.

My fieldwork for this thesis began in my home city of Wellington, New Zealand, where I first met Beni when he was teaching and performing at Victoria University More in-depth research then took me to his current home in Baguio City and later to his ancestral home of Sukiap in rural Kalinga. This study draws from research in all of these locations and illustrates a flexibility 
of movement between musical locations in space, and also a crossing of social boundaries between universities and grassroots communities. This is a contemporary feature of many music cultures. Studies that emphasize and investigate the mobility of music traditions can reveal how musical practices are meaningful for communities across diverse cultural and national boundaries (Turino 1993).

\section{The bamboo instruments}

This thesis also investigates the instruments themselves and presents information on the processes and materials required in the manufacture the instruments. The design and manufacture of the instruments is an important aspect of Beni's role in the revival of the bamboo musical instruments of the Kalinga, and the cultural knowledge he imparts. This again illustrates the influence that one individual can have on the re-shaping and reviving of a tradition. Like the musical traditions themselves, the instruments have undergone a redesign to function in new contexts, such as classrooms and concert halls, thus creating and maintaining relevance to today's Kalinga communities, students and a wider global audience.

Inquiry into the material of bamboo and bamboo music intimates deeper connections with the ecology and the spirit world of the Kalinga. Although Beni's approach to the selection of bamboo and physical means of manufacture is predominantly pragmatic, his vast cultural knowledge and experience suggests a deeper understanding of the relationship between bamboo, instrument maker and music. Further research into language, myths, and Kalinga beliefs may extend our understanding of the music to reveal the historical, underlying connections.

\section{The Fieldwork Experience}


To participate in the lives of others, in another society, is to discover the crossing-points where one's own experience connects with theirs - the points at which sameness subsumes difference. (Jackson 2006:149)

The success of an ethnography lies in the relationships we form with our subjects. As researchers in the field, whether in our home town or a distant location, the process of research - of both passively and actively absorbing knowledge - is rooted in the relationships we create. The skills required to establish and maintain these relationships are not necessarily founded in academic training, but are the basic human tools we develop as individuals in the world. We build relationships not through abstract roles of researcher and informant but through finding common human experiences, and taking part in daily life a member of the community.

The challenge of this thesis was to take the experiences of these relationships and to translate and articulate them in writing within the bounds of academia. In writing this thesis I have placed the individuals and communities at the forefront, and have not excluded myself from the environments and events described. In this way I hope to sincerely represent the music, the individuals themselves, and my experiences, and provide a study which is relevant and honest.

Beni uses the term na suklit to describe music when all the individual elements are correct, creating a cohesive whole. This captures the essence of the bamboo music of the Kalinga. The music is a meaningful way for an individual to express himself as an integral part of the community, and is a sign of the community's close social and cultural bonds. When the instruments are played together, a complex web of sound is produced, where each individual instrument is tonally represented, but embedded in the warp and weft of the musical sum. I imagine my research experience as being woven in to the fabric of Beni's community, from where I not only experienced the music but also founded relationships which would last a lifetime. 


\title{
APPENDIX
}

\section{List of Participants}

\author{
Lucnab, Baguio City
}

The Sokkong Family:

Jhoone, Humby, Xena, Yaira and BJ

Simit:

Ariel Delim, Edward Pangod, Dexter Clemente, Rowell Martin, Jayson Barcelo and Shane Lindaoa

Cordillera Music and Research Center - School of Living Tradition:

Delfin Sallidao, Arvin Arvin Manuel Villalon, Manny Gayao

\section{Sukiap, Kalinga}

Adults:

Francisco Damagon (Gallang), Martin Linggayo (Lumayog), Lorenzo Damagon (Bagtang), Jesus Otal (Etos), Benjamin Wacdag (Ben), Ermenio Donga-as (Gallming), José Curtaran, Ramos Domalsin, Fransico Arrgabao, Edmund Cutaran.

\section{Children:}

Boys in the Fiesta: Bonie Curtaran, Marlo Campilis, Freddy Wacdag, Rasen Sumongbat, Ralphel Beneto, Jefferson Donga-as, Jerome Berry. Girls in the Fiesta: Kara Donga-as Laris Wacdag, Kaysi Sumongbat, Percy Damagon, Hayvie Baggay, Lanie Baggay, Layan Wacdag. 


\section{Compact Disc Contents}

Note:

The format for the CD track entries is as follows:

CD Track X: [Name of Instrument]: [Name of Musical Piece], [Performer]. [Location of recording], [Date recorded].

CD Track 1: Tongatong: Tinglayan, Ethnomusicology Students NZSM451, New Zealand School of Music Wellington, New Zealand, 28 February 2007.

CD Track 2: Pattatag: Ginallupak, The house of Fidel Tayawa, Gobgob, New Tanglag, Kalinga, 21 June 2007.

CD Track 3: Ballingbing: Ginallupak, The house of Fidel Tayawa, Gob gob, New Tanglag, Kalinga, 21 June 2007.

CD Track 4: Saggeypo: Ginallupak, Ethnomusicology Students NZSM451, New Zealand School of Music Wellington, New Zealand, 28 February 2007.

CD Track 5: Tambi: Binutbut, Ethnomusicology Students NZSM451, New Zealand School of Music Wellington, New Zealand, 28 February 2007.

CD Track 6: Pattatag: Binutbut, The house of Fidel Tayawa, Gobgob, New Tanglag, Kalinga, 21 June 2007.

CD Track 7: Paldong: Annoywoy, Beni Sokkong. Wellington, New Zealand, February 2007.

CD Track 8: Paldong: Uggayyum/Salidummay The house of Fidel Tayawa, Gobgob, New Tanglag, 26 June 2007.

CD Track 9: Tongali: Oynasi, Beni Sokkong. Wellington, New Zealand, February 2007.

CD Track 10: Tongali: Nan ani, Beni Sokkong. Wellington, New Zealand February 2007.

CD Track 11: Kulibaw: Tuppayya, Fidel Tayawa. Gob gob, Kalinga, 26 June 2007.

CD Track 12: Kolitong: Tuppayya, Henry Linggayo. Liglig, Kalinga, 18 June 2007.

CD Track 13: Kolitong: Tuppayya, Ben Wacdag. Sukiap, Kalinga, 18 June 2007.

CD Track 14: Kolitong: Tuppayya, Ben Wacdag and Beni Sokkong. Sukiap, Kalinga, 18 June 2007.

CD Track 15: Ullalim, Delfin Sallidao, Lucnab, Baguio, 15 July 2007.

CD Track 16: Uggayyum, Delfin Sallidao, Lucnab, Baguio, 15 July 2007. 


\section{GLOSSARY}

\section{Location of use Definition}

anito

Kalinga and throughout the Philippines

ballingbing Kalinga

basi

Kalinga

bodong

bvulo

bvunyeg

bvuyog Kalinga

Chico River

chumchumog Sukiup

dongadong Paracelis

gangsa Cordilleran

Ginallupak Kalinga

Gobgob

gomugong Paracelis Kalinga. bamboo.
An anito is a type of spirit. They can be spirits of the forest, guardian angels, and good or bad.

A buzzer made from a tube of bamboo.

Sugar cane wine, also called bayjus.

Peace pact agreements which are held between tribes in

A hard and thin walled species of bamboo.

The ceremony when a child is given a name

A hard, thick walled species of bamboo. Bvuyog is sometime referred to as kawayan, the Tagalog word for

The largest river in Luzon running south to north through the Cordillera.

House blessing ceremony

Stamping tubes (tongatong in Kalinga)

Flat gongs found throughout the Cordillera.

The name given to a form of musical piece where the basic pattern is formed through alternating beats.

The area of Kalinga where the community of Tanglag resettled. Also referred to as New Tanglag.

House blessing ceremony 
ijo Kalinga

Ilocano

Kankan-ey

kasey

Sukiap

kawayan

kolitong

(kolibit)

Paracelis

Pattanggok

pattatag

(gallupak)

pinikpikan Cordillera

piyanos

pangudan

Liglig

saggeypo

Kalinga

Sukiap

tambi

Kalinga

Tanglag

Tanglag,

New
A certain bird which is avoided during travelling due to it's being perceived as a bad omen.

The common language used throughout the Cordillera. Originally from the lowlands.

An ethno-linguistic group within the province of Benguet

Post-wedding celebrations

The Tagalog word for bvuyog. Sometimes also a generic term for bamboo.

A 6 stringed zither made from a bamboo tube

Paracelis is a municipality in Mountain Province, bordering the province of Kalinga

Quill shape bamboo tubes struck with a hard wood block.

Individual bamboo xylophone blades. Also called gallupak.

The most popular chicken soup dish found throughout the Cordillera.

Pre-wedding celebrations

The ceremony when a child is given a name

Liglig is one of the two villages that form Old Tanglag. Liglig is situated on the eastern bank of the Chico, about $3 \mathrm{~km}$ from Sukiap over a foot bridge across the Chico.

A set of six individual bamboo pan pipes.

Sukiap is one of the two villages that form the community of Tanglag in Kalinga

A two string struck zither made from a bamboo tube.

Tanglag is the community formed by the two villages Liglig and Sukiup. These Two villages are about 20 minutes walk apart either side of the Chico River in Lubuagan, Kalinga.

New Tanglag is located in Gobgob, Tabuk in the plains of Kalinga. Some members of the Tanglag community were relocated there during a proposed Chico river dam project 
in the 1980's.

$\begin{array}{lll}\begin{array}{l}\text { tongali } \\ \text { tongatong }\end{array} & \text { Kalinga } & \text { Bamboo nose flute. } \\ \text { Tuppayya } & \text { Kalinga } & \begin{array}{l}\text { Bamboo stamping tubes. } \\ \text { The name given to a piece of music where the gangsa (flat } \\ \text { gongs) are played with the palms of the hands. }\end{array} \\ \text { Uggayyum } & \text { Kalinga } & \begin{array}{l}\text { The sung melody which can carry any lyrics such as a } \\ \text { greeting, prayer or political discussion. }\end{array} \\ \text { Ullalim } & \text { Kalinga } & \begin{array}{l}\text { The sung vocal epics of the Kalinga } \\ \text { A certain snake which is avoided during travelling due to it } \\ \text { uyog }\end{array} \\ \text { being perceived as a bad omen. }\end{array}$




\section{BIBLIOGRAPHY}

\section{List of Interviews}

\section{Mrs Bar-inay Alit Marawis}

20071 July Batigue, Paracelis, Mt. Province. Translated by Delfin Sallidao.

\section{Benicio Sokkong}

200720 February Wellington, New Zealand Recorded Interview.

200728 February Wellington, New Zealand Recorded Interview.

200710 March Wellington, New Zealand Recorded Interview.

2007 February-March Wellington, New Zealand. Personal correspondence.

2007 June The Philippines. Personal correspondence.

2007 July The Philippines. Personal correspondence.

2010 May The Philippines. Personal correspondence.

\section{Constancina Sokkong}

2011 July New Zealand. Personal correspondence.

\section{Cresencio Ngaya-an}

200718 June Liglig, Kalinga, the Philippines. Recorded Interview.

\section{Fidel Tayawa}

200720 June Gobgob, Tabuk, Kalinga. Recorded Interview.

\section{Imelda Sokkong}

2009-2011 Wellington, New Zealand. Personal communication.

\section{Jimenez, Carolina Gozon}

2010 October Email correspondence.

\section{Lorenzo (Bagtang) Damagon}

200712 June Sukiap, Kalinga, the Philippines. Recorded interview. 
Members of Simit:

Ariel Delim

Jayson Barcelo

Rowell Martin

Dexter Clemente

200714 July Lucnab, Baguio City. Recorded Group Interview.

2007 June, July, August Lucnab, Baguio City. Personal correspondence. 


\section{Literature}

Appadurai, Arjun

1996 Modernity at Large: Cultural Dimensions of Globalization. Minneapolis: University of Minnesota Press.

Bacdayan, Albert S.

1969 Peace Pact Celebrations: The Revitalization of Kalinga Intervillage Law. Law \& Society Review 4(1):61-78.

Baes, Jonas

2004 To the Memory of an Angel: Philippine Indigenous Music and the Politics of Cultural Appropriation. Graduate Journal of Asia-Pacific Studies 2(1):44-58.

2004 Modes of Appropriation in Philippine Indigenous Music: The Politics of the Production of Cultural Difference. PhD Dissertation, University of the Philippines.

2007 Program notes: Daluy I-V in the concert Transformations, St Andrews on the Terrace, Wellington, NZ.

2008 Bamboo and Music Composition in the Philippines: Disquietudes on the Ascendancy of a "Cultural Object". Humanities Diliman 5:1-2, 127-136.

Bansa.org.

2011 Online Philippine Dictionary. www.bansa.org. Accessed 2011

Barton, R. F

1949 The Kalingas. Their Institution and Custom Law. Chicago: The University of Chicago Press.

Benitez, Kristina

1983 Toward an Understanding of Gong Ensembles in South East Asia: A study of Resultant Melodies in the Music of Two Gong Ensembles from the Philippines. MA Thesis, University of the Michigan.

Berliner, Paul

1994 Thinking in jazz: the infinite art of improvisation. Chicago, University of Chicago Press

Billiet, Francisco

1930 Kalingga Riddles. Primitive Man 3(3): 71-74.

1970 The Kalinga Ullalim. Studies on Kalinga Ullalim and Ifugaw Orthography. Baguio: Publications of the Catholic School Press.

Cadar, Usopay

1975 The role of Kulintang in Maranao Society. Asian Music 27(2):80-103.

Castro, Christi-Anne

2011 Musical Rendering of the Philippine Nation. New York: Oxford University Press.

Chernoff, John Miller

1979 African Rhythm and African Sensibility: Aesthetics and Social Action in African Musical Idioms. Chicago: University of Chicago Press.

Cordillera Music Tutorial and Research Centre (CMTRC)

2003 Promotional pamphlet. Photocopy. Baguio City. 
Copland, David

1991 "Ethnomusicology and the Meaning of Tradition". In Ethnomusicology and Modern Music History, edited by Stephen Blum, Philip Bohlman, and David Neuman, 35-48. Urbana and Chicago: University of Illinois Press.

Corazon, C. Dioquino

1982 Musicology in the Philippines, Acta Musicologica, 54(1):124-147.

2008 Philippine Bamboo Instruments. Humanities Diliman 5:1-2, 101-113.

De Raedt, Jules.

1989 Kalinga Sacrifice. Baguio: Cordillera Studies Center, University of the Philippines.

1993 Buaya Society. Baguio: Cordillera Studies Center, University of the Philippines.

Dozier, Edward. P

1967 The Kalinga of Northern Luzon, Philippines. First Irvington Edition. New York: Holt, Rinehart and Wilson, Inc.

Feld, Steven

1990 Sound and Sentiment: Birds, Weeping, Poetics, and Song in Kaluli Expression.

Second Edition. Philadelphia: University of Pennsylvania Press.

2004 Doing anthropology in sound. American Ethnologist 31(4):461-474.

Francisco Demetrio

1968 Creation Myths among the Early Filipinos. Asian Folklore Studies 27(1):41-79.

Giddens, Anthony

1991 Modernity and self-identity. Cambridge: Polity.

GoBaguio!

2011 Gobaguio.com Your Complete Guide to Baguio City, Philippines.

Hood, Mantle

www.gobaguio.com. Accessed December 2010.

1980 The Evolution of Javanese Gamelan. Wilhelmshaven, Germany: Heinfichshofen's Press.

Hutter, Karl L.

1998 "Southeast Asia in Prehistory". In The Garland Encyclopaedia of World Music Volume 4, edited by Terry E. Miller and Sean Williams, 32-46. New York and London: Garland Publishing.

Jackson, Michael

1995 At Home in the World. Durham: Duke University Press.

2006 The Accidental Anthropologist: a Memoir. Dunedin: Longacre Press.

Jimenez, Carolina Gozon

2010 Carolina Bamboo Garden. carolinabamboogarden.com. Accessed August 2010

Junker, Laura Lee

1999 Raiding Trading and Feasting: the Political Economy of Philippine Chiefdoms. United States of America: University of Hawai'i Press.

Karnow, Stanley

1990 In Our Image: America's Empire in the Philippines. New York: Ballantine Books.

Kartomi, Margaret J.

1990 On concepts and classifications of musical instruments. Chicago: University of Chicago Press. 
Keesing, Felix M.

1962 The Ethnohistory of Northern Luzon. Stanford Anthropological Series (4). Stanford: Stanford University Press.

Keyes Cheryl L.

1996 At the Crossroads: Rap Music and Its African Nexus. Ethnomusicology 40(2):223248

Kisliuk, Michelle

1997 "(Un) doing Fieldwork: Sharing Songs, Sharing Lives". In Shadow in the Field: New Perspectives for Fieldwork in Ethnomusicology, edited by Greroy F.Barz and Timothy J. Cooley, 23-44. New York: Oxford University Press.

1998 Seize the Dance: BaAka Musical Life and the Ethnography of Performance. New York: Oxford University Press.

Livingstone, Tamara $\mathrm{E}$

1999 Music Revivals: Towards a General Theory. Ethnomusicology 43(1):66-85.

Lockard, Craig A.

1996 Popular Musics and Politics in Modern Southeast Asia: A Comparative Analysis. Asian Music, 27(2):149-199.

Maceda, José

1963 The Music of the Magindanao in the Philippines. Ph.D. Dissertation. Los Angeles University of California.

1986 A concept of Time in Music of Southeast Asia (a preliminary account). Society for Ethnomusicology 30(1):11-53.

1990 In Search of a Source of Pentatonic Hemitonic and Anhemitonic Scales in South East Asia. Acta Musicologica 2(2):192-223.

1995 A Logic in Court Music of the Tang Dynasty. Acta Musicologica 67(2):109-141.

1998 Gongs and Bamboo. A panorama of Philippines Music Instruments. Diliman, Quezon City: University of the Philippines Press.

1998 "Upland Peoples of the Philippines". The Garland Encyclopaedia of World Music, Southeast Asia, pp. 913-938. New York: Garland.

2001 The Structure of Principal Court Musics of East and Southeast Asia. Asian Music 32(2): 143-178.

Malinowski, Bronislaw

1961 Argonauts of the Western Pacific: an account of native enterprise and adventure in the archipelagoes of Melanesian New Guinea. Preface by Sir James George Frazer. London: Dutton.

Merriam-Webster

2011 Merriam-Webster Online. http://www.merriam-webster.com/dictionary/barangay. Accessed August 2011.

Mora, Manolete

2008 The Sounding Pantheon of Nature. T'boli Instrumental Music in the Making of an Ancestral Symbol. Acta Musicologica 59(2):187-212.

1997 Ut om: Summoning the Spirit, Music in T'boli Heartland. CD Liner notes. Rykodisc, U.S.A: The WORLD series, $360^{\circ}$ Productions.

Myers, Helen, editor

1993 Ethnomusicology: Historical and Regional Studies, edited by Helen Myers. London: Macmillan. 
National Mapping and Resource Information Authority

1997 Administrative Map: Cordillera Administrative Region. Fort A. Bonifacio, Makati City: Department of the Environment and Natural Resources.

National Statistics Office, Republic of the Philippines

2007 Total Population by Province, City, Municipality and Barangay: as of August 1, 2007. www.census.gov.ph/data/census2007. Accessed 2010.

2003 Number: 2003-23. Date Released: February 18, 2003.

www.census.gov.ph/data/pressrelease/2003/pr0323tx.html. Accessed January 2010.

Nunns, Richard and Allan Thomas

2005 The Search for the Sound of the Pūtōrino: "Me te wai e utuutu ana". Yearbook for Traditional Music 37:69-79

Otto, Steven, Walter

1976 The Muranao Kakolintang: An approach to the Repertoire. PhD Dissertation, University of Washington.

pinoymountaineer.com

2008 Mt. Pulag/Akiki Trail. www. pinoymountaineer.com. Accessed 2011.

Prudente, Felicidad A.

1984 Musical Process in the Gasumbi Epic of the Buwaya Kalingga People of the Northern Philippines. PhD Dissertation, University of the Philippines.

Porterfield, William M.

1933 Bamboo, the Universal Provider. The Scientific Monthly, 36(2):176-183

Rice, Timothy

1994 May it fill your Soul: experiencing Bulgarian music Chicago: University of Chicago Press.

2003 Time, Place, and Metaphor in Musical Experience and Ethnography. Ethnomusicology 47(2):151-179.

2003 The Ethnomusicology of Music Learning and Teaching. College Music Symposium 43:65-85

2007 Reflections on music and identity in Ethnomusicology. Muzikologija 2007(7):1738

Russell, Susan D.

1989 The Grand Cañao: Ethnic and Ritual Dilemmas in an Upland Philippine Tourist Festival. Asian Folklore Studies 48(2):247-263

Santos, Ramón P.

1998 "Popular Music in the Philippines". In The Garland Encyclopaedia of World Music, Southeast Asia: 883-888. With Arnold Cabalza. New York: Garland.

Scott, William Henry

1974 The Discovery of the Igorots: Spanish contact with the Pagans of Northern Luzon. Revised Edition. Quezon City, Republic of the Philippines: New Day Publishers.

Seeger, Anthony

1987 Why Suya Sing: a musical anthropology of an Amazonian people. New York: Cambridge University Press.

Sheehy, Daniel

1992 A Few Notions about Philosophy and Strategy in Applied Ethnomusicology. Ethnomusicology 36(3):323-336Published by: University 
Stallsmith, Glenn Ress

2007 The Music of a Kalinga Peace-pact Celebration: Making Place through the Soundscape. MA Thesis, Bethel University

Stock, Jonathan

1996 Musical creativity in Twentieth-Century China: Abing, his music, and its changing meanings. Rochester, N.Y. University of Rochester Press.

Stokes, Martin,

1994 Introduction: Ethnicity, Identity and Music. In Ethnicity, Identity and Music: The Musical Construction of Place, XX-XX. Oxford, U.K.: Berg,

Such, David G

2000 The Bamboo Musical Instruments of the Kalinga. Video Recording. Quezon City, The Philippines: University of the Philippines Department of Music.

Sugguiyao, Miguel

1990 The Kalinga Hilltribe of the Philippines. Manila: ONCC

Thomas, Allan,

2004 Music is Where You Find It : Music in the Town of Hawera, 1946 : An Historical Ethnography. Wellington, N.Z.: Music Books New Zealand.

Trimillos, Ricardo, D

1972 Tradition and Repertoire in the Cultivated Music of the Tausug of Sulu, Philippines. PhD Dissertation, University of California, Los Angeles.

2004 "Subject, Object and the Ethnomusicology Ensemble." In Performing Ethnomusicology, edited by Ted Solis, 23-52.California: University of California Press.

2008 Histories, Resistances, and Reconciliations in a Decolonizable Space: The Philippine Delegation to the 1998 Smithsonian Folklife Festival. Journal of American Folklore 121(479):60-79

Turino, Thomas

1993 Moving away from silence: music of the Peruvian Altiplano and the experience of urban migration. Chicago: University of Chicago Press.

2000 Nationalists, cosmopolitans, and popular music in Zimbabwe. Chicago: University of Chicago Press.

2008 Music as Social Life: the Politics of Participation. Chicago: University of Chicago Press

University of the Philippines

2011 University of the Philippines Centre for Ethnomusicology. www.upethnom.com. Accessed July 2011

Vander, Judith

1988 Songprints: the musical experience of five Shoshone women . Urbana: University of Illinois Press.

Wallach, Jeremy

2008 Modern Noise, Fluid Genres. Popular Music in Indonesia, 1997-2001. Wisconsin: University of Wisconsin Press.

Woods, Damon L.

2006 The Philippines: a global studies handbook. Santa Barbara California: ABCCLIO. Accessed: http://books.google.co.nz/books 
Yoneno-Reyes, Michiyo

2010 Salidummay's Hybridity and Congregational Singing. Humanities Diliman 7:1:24-57: University of the Philippines

Yoshida, Shuji and Yukio Toyoda

1998 "Sound of Bamboo as Talk of Spirit: Social Meaning of Sound among the Waxei People in the Sepik Hills". In Fringe Area of Highlands in Papua New Guinea. Osaka, Japan: National Museum of Ethnology.

Zemp, Hugo

1978 'Are'Are Classification of Musical Types and Instruments. Ethnomusicology 22(1):37-67. 